University of New Hampshire

University of New Hampshire Scholars' Repository

Spring 2015

\title{
Seeing and Believing: The Emergent Nature of Extreme Weather Perceptions
}

Matthew John Cutler

University of New Hampshire, Durham

Follow this and additional works at: https://scholars.unh.edu/dissertation

\section{Recommended Citation}

Cutler, Matthew John, "Seeing and Believing: The Emergent Nature of Extreme Weather Perceptions" (2015). Doctoral Dissertations. 2178.

https://scholars.unh.edu/dissertation/2178

This Dissertation is brought to you for free and open access by the Student Scholarship at University of New Hampshire Scholars' Repository. It has been accepted for inclusion in Doctoral Dissertations by an authorized administrator of University of New Hampshire Scholars' Repository. For more information, please contact Scholarly.Communication@unh.edu. 


\title{
SEEING AND BELIEVING: THE EMERGENT NATURE OF EXTREME WEATHER PERCEPTIONS
}

\section{BY}

\section{MATTHEW JOHN CUTLER}

BA, Political Science and Justice Studies, University of New Hampshire, 2007

MA, Justice Studies, University of New Hampshire, 2009

\section{DISSERTATION}

\author{
Submitted to the University of New Hampshire \\ in Partial Fulfillment of \\ the Requirements for the Degree of
}

Doctor of Philosophy

in

Sociology

May, 2015 


\section{ALL RIGHTS RESERVED}

(C) 2015

Matthew John Cutler 
This dissertation has been examined and approved in partial fulfillment of the requirements for the degree of PhD in Sociology by:

Dissertation Director, Dr. Lawrence Hamilton, Professor of Sociology, University of New Hampshire

Dr. Thomas Safford, Associate Professor of Sociology, University of New Hampshire

Dr. Cliff Brown, Associate Professor of Sociology, University of New Hampshire

Dr. Mary Stampone, Assistant Professor of Geography, University of New Hampshire

Dr. Cameron Wake, Research Associate Professor of Glaciology/Environmental Chemistry, University of New Hampshire

On March 5, 2015

Original approval signatures are on file with the University of New Hampshire Graduate School. 


\section{DEDICATION}

For my mother, Maryann Cutler. 


\section{ACKNOWLEDGEMENTS}

I owe an enormous debt of gratitude to the director of my dissertation, Dr. Lawrence Hamilton, for his invaluable support and guidance. I could not have come this far without Dr. Hamilton's insights and direction. I also wish to thank my dissertation committee members, Dr. Thomas Safford, Dr. Cliff Brown, Dr. Mary Stampone, and Dr. Cameron Wake, for providing crucial suggestions in the early phases of my project, as well as their indispensable feedback and assistance throughout it. Not only was my dissertation greatly improved, but I also became a much better sociologist and researcher generally speaking as a result of their involvement.

I would also like to thank my peers, Andrew Schaefer, Nicholas Adams, Michael Staunton, Alex Parkhouse, Luke Rogers, Michael Staley, and Justin Young for their continuous support, encouragement, and camaraderie throughout our journey together as doctoral students in sociology at the University of New Hampshire. The stress of graduate school was eased because I was able to share the experience with such exceptional people.

Finally, and most importantly, I would like to thank my parents, Lawrence and Deborah Cutler, my brothers, Michael and Daniel Columbare, and my fiancée, Kelly Drugan, for their unconditional love and encouragement. I could not have persevered without their unwavering support. 


\section{TABLE OF CONTENTS}

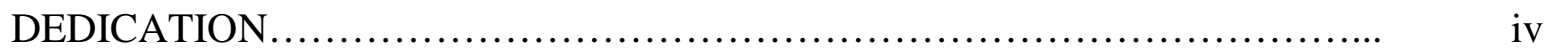

ACKNOWLEDGEMENTS .............................................. $\quad \mathrm{v}$

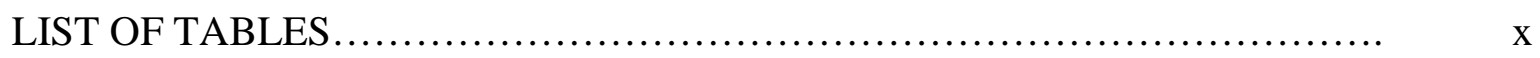

LIST OF FIGURES........................................................

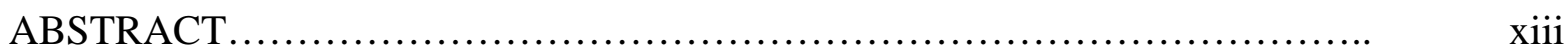

$\begin{array}{ll}\text { CHAPTER } & \text { PAGE }\end{array}$

I. INTRODUCTION.................................................... 1

1.1 Research Questions............................................. 1

1.2 Hypotheses.................................................. 5

1.2.1 Hypothesis H1...................................... 5

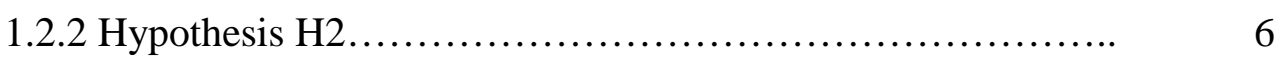

1.2.3 Hypothesis H3.......................................... 7

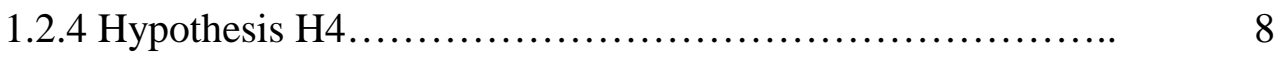

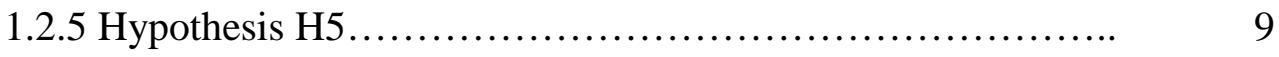

1.3 Practical Significance........................................... 10

II. PREVIOUS RESEARCH AND THEORETICAL DISCUSSION.............. 12

2.1 The Social Bases of Environmental Concern........................ 13

2.1.1 Early investigation of the social bases of environmental Concern................................................. 13

2.1.2 "Values-Beliefs-Norms" Theory.......................... 15

2.1.3 Education, Knowledge, and Political Identity............... 17 
2.2 Socioeconomic Characteristics and Environmental Justice.

2.3 Place and Environmental Concern................................ 22

2.4 Integrating Multiple Indicators and the Realist-Constructivist Divide 28

2.5 Shared Perceptions and the Concept of "Emergence"................. 34

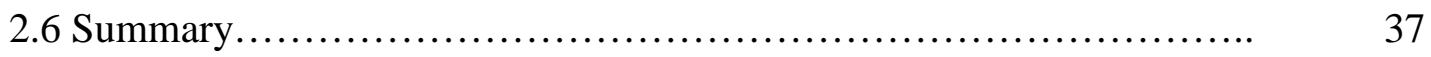

III. DATA AND METHODS ........................................... 39

3.1 The CERA Coastal Surveys...................................... 41

3.1.1 Background $. . \ldots \ldots \ldots \ldots \ldots \ldots \ldots \ldots \ldots \ldots \ldots \ldots \ldots \ldots \ldots \ldots, \quad 41$

3.1.2 Dependent variable: weather perceptions.................. 44

3.1.3 Independent variables: individual characteristics........... 46

3.2 Extreme weather indicators................................. 53

3.2.1 Severe thunderstorms................................. 53

3.2.2 Property damage from all storm events.................. 58

3.3 County characteristics........................................ $\quad 60$

3.4 Analytical Methods......................................... 63

3.4.1 Regional differences in weather perceptions................ 63

3.4.2 Mixed-effects modeling............................... 65

3.4.3 Multiple imputation of missing values................... 67

IV. RESEARCH FINDINGS........................................ 71

4.1 Bivariate Analysis.......................................... 71

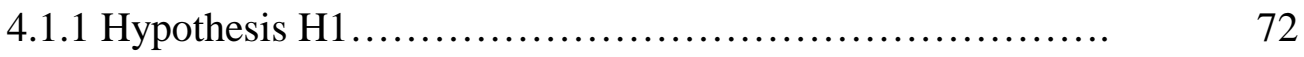

4.1.2 Hypothesis H2.................................. 75 
4.1.3 Hypothesis H3..................................... 78

4.2 Multivariate Analysis.......................................... 81

4.2.1 Effects of Objective Weather Events..................... 86

4.2.2 Effects of Individual values or beliefs..................... 88

4.2.3 Effects of Social Position and Socioeconomic Context........ 90

4.2.4 Interaction Effects................................... 91

4.2.5 Place-to-place variation................................. 100

4.3 Summary ................................................ 102

V. DISCUSSION ....................................................... 106

5.1 Summary of findings...................................... 106

5.1.1 Impact and frequency of weather events................... 106

5.1.2 Political and Environmental Values....................... 108

5.1.3 Social Position and Socioeconomic Context............... 112

5.1.4 Interaction Effects.................................... 114

5.1.5 Place-to-Place Variation.............................. 117

5.2 Theoretical Implications..................................... 121

5.2.1 Moving beyond the social-interactional level............... 121

5.2.2 Perceptions of extreme weather as emergent properties....... 123

5.3 Limitations and Future Research.............................. 130

5.3.1 Limitations of the present study....................... 130

5.3.2 Future Research..................................... 133

5.4 Concluding Remarks......................................... 134 
REFERENCES .........................................................

APPENDIX A - SPC EVENT SELECTION GUIDELINES .....................

APPENDIX B - ALTERNATIVE MODELS AND EXTREME WEATHER

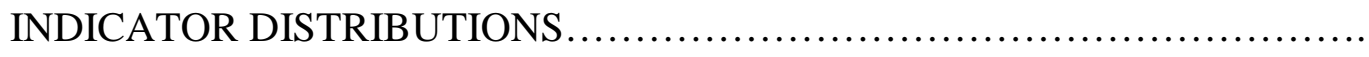

155

APPENDIX C - MAJOR VS. MINOR EFFECTS MODEL......................

166 


\section{LIST OF TABLES}

Table 3.1: Coastal Surveys........................................... 42

Table 3.2: Individual-level Independent Variables.............................. 47

Table 3.3: Descriptive Statistics for Independent Variables.................... 47

Table 3.4: Extreme Weather Indicators................................. 56

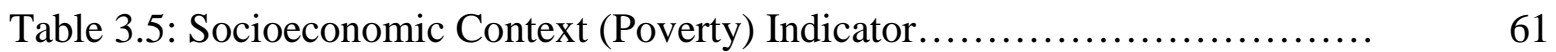

Table 4.1: Imputed and Non-imputed Mixed Effects Logistic Regression of Perceiving Effects of Extreme/Unusual Weather on Individual- and County-level Characteristics............................................ 93

Table 4.2: Mixed Effects Logistic Regression of Perceiving of Extreme/Unusual Weather on Individual- and County-level Characteristics, with and without Downeast Maine......................................................... 


\section{LIST OF FIGURES}

Figure 3.1: Weighted percent of respondents' beliefs about conservation rules,

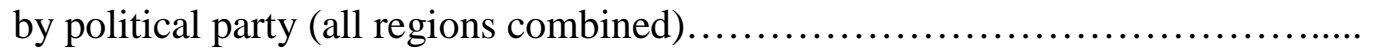

Figure 3.2: Weighted percent of respondents' beliefs about climate change, by political party (all regions combined).................................

Figure 3.3: Weighted percent of respondents reporting "no effect," "minor effects," or "major effects" of extreme or unusual weather

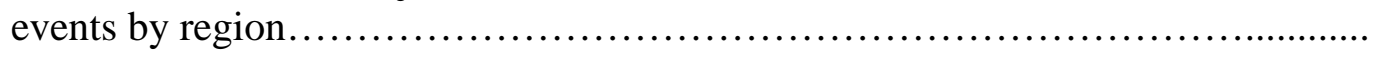

Figure 4.1: Weighted percent of respondents reporting "minor/major effects" of extreme/unusual weather vs 5-year property damage estimates from severe weather events (log scaled)....

Figure 4.2: Weighted percent of respondents reporting "major/minor effects" from extreme/unusual weather events vs total number of severe thunderstorm

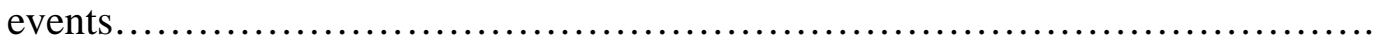

Figure 4.3: Weighted percent of survey respondents' 'extreme or unusual weather effects perceptions,' by political party affiliation (all regions combined)

Figure 4.4: Weighted percent of respondents' 'extreme/unusual weather effects perceptions,' by beliefs about climate change (all regions combined)...............

Figure 4.5: Weighted percent of survey respondents' 'extreme/unusual weather effects' perceptions by household income (all regions included)............

Figure 4.6: Weighted percent of survey respondents reporting effects of 'extreme or unusual weather events' vs the percent of people in poverty at the county level.

Figure 4.7: Adjusted marginal plot showing effect on perceived weather impacts, from the interaction of objective, 5-year total thunderstorm events and respondent political party. Based on weighted logit model analogous to Model 3 of Table 4.1, adjusting for other predictors. 
Figure 4.8: Adjusted marginal plot showing effect on perceived weather impacts, from the interaction of objective property damage of severe weather and respondent household income. Based on weighted logit model analogous to Model 3 of Table 4.1, adjusting for other predictors........................... 96

Figure 4.9: Causal/Theoretical Model...................................... 100

Figure 4.10: Mean of Random Intercepts by County, from Model 3 in Table 4.1.. 101

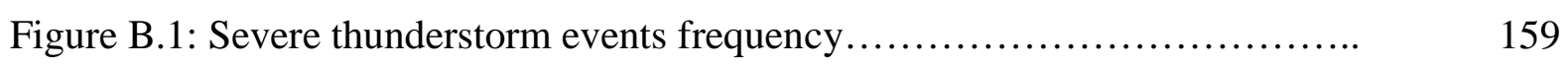

Figure B.2: Log-transformed severe thunderstorm events frequency.............. 159

Figure B.3: Property Damage (in dollars) from all severe weather event types..... 160

Figure B.4: Log-transformed property damage (in dollars) from all severe weather

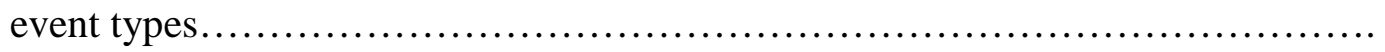




\begin{abstract}
SEEING AND BELIEVING: THE EMERGENT NATURE OF EXTREME WEATHER PERCEPTIONS

By

Matthew John Cutler

University of New Hampshire, May, 2015
\end{abstract}

Perceptions of environmental issues are influenced by a variety of factors. Sociological research on this topic has largely taken a social-psychological approach and as a result the effects of community and biophysical contexts on individual perceptions are given less attention than individual-level predictors, such as political party affiliation or measures of educational attainment. Using data from the Communities and Environment in Rural America (CERA) surveys, I employ a mixed-effects modeling technique to investigate the influence of individualand county-level characteristics on public perceptions of unusual or extreme weather.

In addition to the survey data, I also utilize county-level weather events data from the National Oceanic and Atmospheric Administration’s (NOAA) Storm Events Database (SED) and the Storm Prediction Center's (SPC) Severe Thunderstorm Events Archive (STEA) in order to test whether the incidence and impact of severe weather influences public perceptions of unusual or extreme weather. This study adds to a growing body of literature on public perceptions of 
environmental issues by illuminating the socio-demographic and -contextual nature of individual-level perception formation through the use of integrated social and biophysical data. 


\section{CHAPTER I}

\section{INTRODUCTION}

\section{$\underline{1.1 \text { Research Questions }}$}

In the last three decades, the field of environmental sociology has charted the social bases of individual knowledge, beliefs, and concern related to various environmental issues at the local, national, and global levels. These areas of inquiry spawned from Riley Dunlap's "New Environmental Paradigm (NEP)," an eco-centric challenge to the dominant Western worldview embraced by sociological thinkers throughout the discipline's history ${ }^{1}$ (Dunlap and Van Liere 1978; Dunlap 2002). With the force of a shifting paradigm, environmental sociologists have made good use of many different methods to examine a variety of research questions related to societal-environmental interactions. Among the most well-known topical areas to emerge from the NEP shift has been "the social bases of environmental concern," (Van Liere and Dunlap 1980). This perspective focuses on the ways that people’s attitudes about the environment are affected by other features of their social identity, like a level of education, socioeconomic status, religious background, gender, age, and so on. Since the introduction of the phrase, many researchers have attempted to map out these "social bases" and provided a great deal of evidence for them. For example, political orientation has emerged in several studies as a robust moderator

\footnotetext{
${ }^{1}$ The dominant Western worldview refers to the predominant paradigm of Western academic discourse which has traditionally emphasized the point of view that humans are fundamentally different from the rest of the natural world and have unlimited opportunities to flourish given the assumption of boundless resources.
} 
of the relationship between education and concern for environmental issues (McCright and Dunlap 2011; Hamilton 2008; Hamilton 2011; Hamilton and Keim 2009; Malka et al 2009; Hamilton et al 2010).

Beliefs and norms have also been given ample consideration in the new age of environmentally-sensitive social science research. The connection between values, beliefs and normative behaviors has been elucidated by Thomas Dietz and colleagues over the course of multiple studies on the topic (Dietz et al 2007; Dietz et al 2005; Shwom and Dietz 2006; Shwom et al 2008). Their body of work has demonstrated an indirect link between altruistic values and support for greenhouse gas emissions policies through the vehicle of environmentally-conscious beliefs and worldviews (Dietz et al 2007; Dietz et al 2005). Prior to the development of Dietz's theory of values-beliefs-norms $(\mathrm{VBN})^{2}$ through structural equation modeling (SEM) ${ }^{3}$, values had been treated in the literature as direct predictors of environmental "attitudes ${ }^{4}$, " (Schultz and Zelezny 1999; Stern and Dietz 1994; Stern 2000). Both "attitudes" and "beliefs" about the environment were measured in part using a revised form of the NEP scale, thus demonstrating the lasting influence of this construct.

Socio-demographic and social-psychological approaches have been fruitful in the study of environmental views, but many questions regarding social processes at the level of the community and linked to geography have been left unanswered in the wake of such research.

\footnotetext{
${ }^{2}$ VBN theory "suggests that values influence our worldview about the environment (general beliefs), which in turn influences our beliefs about the consequences of environmental change on things we value, which in turn influence our perceptions of our ability to reduce threats to things we value," (Dietz et al 2005).

${ }^{3}$ The statistical technique of SEM tests "direct and indirect effects of model variables on multiple outcomes," thus illuminating the role of intervening variables and indirect effects for use in path diagrams and causal models (Dietz et al 2007).

${ }^{4}$ Attitudes were measured using a revised NEP scale and an eco-centrism-anthropocentrism scale (Schultz and Zelezny 1999).
} 
Where people live may influence their thinking about environmental issues because regional differences in climate and weather, as well as proximity to mountains, oceans, forests, or urban landscapes, all may shape people's experience of the environment, and consequently, influence their beliefs about it. While it is has been a coherent focus of various research efforts to demonstrate VBN in action, the literature on place-based differences in individual beliefs has been more conceptually and theoretically disjointed. Place effects on environmental views have been examined using such frameworks as NEP, VBN, and social/environmental attachment theories, but have not reached consensus on any single paradigmatic approach to place and environmental views (Hamilton and Keim 2009; Hamilton et al 2010; Shwom and Dietz 2006; Guagnano and Markee 1995; Vorkinn and Riese 2001; Brehm et al 2012). Moreover, "the social bases of environmental concern” is implicitly constructivist, as opposed to realist, ${ }^{5}$ and consequentially ignores societal-environmental interactions in the formation of environmental views. Our understanding of environmental views is in need of a unified place-based conceptual focus and a thorough consideration of actual social-environmental interactions.

My research addresses these gaps in the literature by drawing on insights from recent developments in the field of community sociology and recent use of integrated biophysical and social-structural datasets (Sampson 2012; Hamilton and Keim 2009; Hamilton and Stampone 2013; Hamilton et al 2010). Robert Sampson, in studying place effects in urban areas and neighborhoods, has stressed the importance of social-interactional and institutional processes in the formation of moral cynicism or altruism, trust and collective efficacy, perceptions of neighborhood disorder, and other emergent dynamics related to geography. Sampson's research

\footnotetext{
${ }^{5}$ This distinction refers to an ongoing debate regarding the role of "core environmental sociology," (Dunlap 2010).
} 
integrates social-structural data, such as observational data on neighborhood disorder, with survey data in order to develop an approach he coins, "ecometrics," or the systematic method for measuring neighborhood-level phenomena. Like Sampson, researchers in environmental sociology have integrated biophysical data, or data on the material conditions of the environments of particular geographic locations, with survey data in order to understand the social and physical bases of environmental attitudes (Hamilton et al 2010; Hamilton and Keim 2009; Hamilton and Stampone 2013). While not as interested in emergence, per se, these studies have highlighted the possibility that environmental attitudes are "emplaced” in the particular social and environmental contexts of geographic locations (Hamilton et al 2010).

Using a mixed-effects statistical approach, I investigate two interrelated questions about the place-based nature of perceptions of extreme or unusual weather events: (1) How do coastal counties across America compare in their residents' perceptions of the effects of extreme or unusual weather events? (2) How are perceptions of the effects of extreme or unusual weather events shaped by inter-subjective context and/or direct observations of the phenomena? I utilize coastal region data from the Communities and Environment in Rural America (CERA) surveys, weather events data from the National Oceanic and Atmospheric Administration's (NOAA) Storm Events Database, and economic and demographic data from other sources to conduct a mixed-effects statistical regression of individual- and county-level variables on environmental and social issue perception variables. The research methods are discussed in greater detail in Chapter 3. In the following section, I propose five hypotheses of expected results as they relate to the prior research and relevant concepts and theories, such as values-beliefs-norms, emergence, embedded place effects, and environmental justice. 


\subsection{Hypotheses}

\subsubsection{Hypothesis H1}

Impact and frequency of severe weather events, objectively measured by the 5-year, county-level total of severe weather events and property damage in dollars, will influence subjective individual perceptions of extreme or unusual weather events.

The first of my five hypotheses predicts that the impact and frequency of severe weather events will influence residents' subjective perceptions of extreme or unusual weather events. "Impact" will be assessed by the objectively measured, county-level, 5-year total of property damage in dollars from all severe weather event types. These data will come from NOAA's Storm Events Database. Many studies of extreme weather include measures of both frequency and magnitude, but some efforts to study the societal impacts of extreme weather have considered “social vulnerability,” or objective measures of infrastructural damage from environmental hazards such as severe weather events (Cutter et al 2003). This trend in the broader literature on environmental hazards provides the rationale to include property damage from severe weather events. I expect that respondents who have more frequent experience with severe weather will be more sensitized to the natural environment as well as variation in environmental conditions as a function of their exposure to weather extremes 


\subsubsection{Hypothesis H2}

Values, as measured by political identity, beliefs about the effects of conservation rules, and beliefs about climate change, also influence perceptions of extreme or unusual weather events.

My second hypothesis predicts that individual-level values, measured by political identity, beliefs about conservation rules, and beliefs about climate change, will influence perceptions of extreme weather events. These data come from the CERA coastal surveys. The specific survey items utilized for these measures are described in detail in Chapter 3. Political and environmental values have stood out over three decades of research as important predictors of environmental beliefs or attitudes towards environmental policies (Van Liere and Dunlap 1980; Guagnano and Markee 1995; Dietz et al 2005; Dietz et al 2007; Hamilton 2008; Hamilton et al 2010; Hamilton and Stampone 2013). I will extend this area of inquiry into perceptions of extreme or unusual weather events. While values and ideological predispositions have been predictive of policy support (Dietz et al 2005), risk assessment (Kahan et al 2011), and concern about the effects of climate change (Hamilton 2008; Hamilton et al 2012), I will examine the ideological influence on perceptions of the effects of major weather hazards on individuals and their communities and/or families. Although experience with severe weather is important, those experiences are interpreted against a backdrop of beliefs and values that are linked to political identity and other factors. How individuals think about environmental issues, therefore, is not just a function of their direct experience with the natural world. Rather, it is conditioned by social forces. 


\subsubsection{Hypothesis H3}

Social privilege or position indicators (such as household income) and socioeconomic context (such as county poverty rates) affect perceptions about extreme or unusual weather events.

A significant area of inquiry in environmental sociology has focused on the socioeconomic and racial disparities in exposure to environmental hazards. This field has become colloquially known as the "environmental justice movement” (Bullard and Johnson 2000; Brulle and Pellow 2006). I will investigate whether and the extent to which individuallevel income and county-level poverty rates influence individual perceptions of extreme or unusual weather events. As demonstrated by extensive research on the exposure of communities to toxic sites (Brulle and Pellow 2006), the unequal impacts from Hurricane Katrina (Finch and Emrich 2010; Levy 2012; Eisenman et al 2007; Bullard and Wright 2009), the placement of pipelines in the developing world and the emergence of collective action against other energy site proposals (McAdam et al 2010; McAdam and Boudet 2012), and the community action in response to the Three Mile Island disaster (Walsh 1981; Cable et al 1988), there are salient differences in impacts from environmental hazards by socioeconomic position. I anticipate that social position, measured by household incomes and county poverty, will influence individual perceptions of extreme or unusual weather. Those who are privileged in terms of their socioeconomic status may be able to insulate themselves from environmental risks some degree, and income and race may also be linked to value differences as described in hypothesis two. 


\subsubsection{Hypothesis H4}

Individual values and social position indicators will exhibit interaction effects, such that they moderate the relationship between objectively-measured weather events, and individual perceptions about the impacts of weather events.

Prior studies of environmental attitudes and beliefs have found significant interactions between climate knowledge, educational attainment, and political identities on individual beliefs and concern about the effects of environmental issues, notably climate change and economy/environment trade-offs (Hamilton 2008; Hamilton and Keim 2009; Hamilton et al 2010; Hamilton 2011; Hamilton et al 2012; McCright and Dunlap 2011). I will examine whether and the extent to which values and social position indicators interact with objectively-measured weather events and impacts in the analysis of individual weather perceptions. Specifically, I anticipate that values and social position will moderate the relationship between objectivelymeasured weather events/property damage and individual perceptions about the impacts of weather events. While prior research has shown that values moderate the relationship between knowledge/education and concern (McCright 2011), my research will add to this growing body of literature on interaction effects by expanding the inquiry into interactions between personal values, social position, and objective impacts of environmental hazards. Social and material factors do not influence individuals in a vacuum. Rather, these factors likely interact in people's lives, thus producing nuanced and complex individual attitudes and beliefs about the environment based on the intersection of multiple social and material factors related to placespecific contexts. 


\subsubsection{Hypothesis H5}

There will be significant, systematic place-to-place variations in perceptions about weather impacts, even after controlling for objective weather indicators, values and other individual- or county-level socioeconomic characteristics.

Recent studies have identified place-to-place variation in environmental beliefs and perceptions even when controlling for a multitude of factors, including individual-level and contextual indicators (Hamilton and Keim 2009; Hamilton et al 2010; Hamilton and Safford 2014). These studies have varied widely in their foci and as such are difficult to compare in their conclusions, but the commonality, namely that regional variation matters, is what is important to my research questions and goals. As it relates to the sociological concept of emergence (Sawyer 2002; Sampson 2012; Hannigan 2006), significant regional variation can signal the possibility that perceptions of extreme or unusual weather are as Hamilton and colleagues suggest --embedded in place-specific contexts.

\subsection{Practical Significance}

My research provides three valuable contributions to our understanding of societalenvironmental interactions. First, I bring context to the relationship between place and environmental views. I combine survey data and objective weather data in order to tease out the nuance of place effects and environmental views. Second, I provide a case for the unification of realist and constructivist perspectives in environmental sociology. There is room in research 
pursuits for the integration of data outside the social-psychological realm without having to abandon the investigation of the social construction of environmental problems. Neglecting either the integration of objective conditions or the use of social indicators to expose sociallyconstructed meanings are equally perilous propositions for the future of research on societalenvironmental interactions. Finally, I provide useful knowledge about the formation of perceptions of social and environmental problems to policy-makers and institutional leaders who often make crucial decisions that can alter (and perhaps lessen) the extent of the effects of social and environmental problems in the future. A better understanding of community members' perceptions of environmental hazards can help scientists, policy researchers and policy makers communicate hazards to the public. 


\section{CHAPTER II}

\section{PREVIOUS RESEARCH AND THEORETICAL DISCUSSION}

In this chapter, I review findings from previous research and discuss a theoretical framework to explain individuals' perceptions of extreme or unusual weather events. Specifically, I discuss three most relevant substantive areas in prior research on environmental concern and then introduce the proposed theoretical framework. First, the social bases of environmental concern is outlined, beginning with early hypotheses and independent variables of interest, moving to a discussion of a process theory of environmental attitudes and norms, and concluding with a discussion of the education/knowledge and political identity interaction. My hypotheses, especially those dealing with social position and values or beliefs, were heavily influenced by these prior studies on the social bases of environmental concern.

Second, research on place and environmental concern will be addressed. Various studies on the influence of place of residence on environmental beliefs and attitudes will be covered. I focused on place in this study because prior research on the effect of place on environmental concern seemed to be lacking a coherent theoretical or conceptual framework for explaining the significance of place. Third, the integration of multiple indicators and objective measures with survey data is discussed. In this portion, I also comment on the relevance of the realistconstructivist cleavage in environmental sociology to this research. This split in the broader environmental sociology literature inspired me to include measures of both objective material conditions to and social or social-psychological phenomena. In doing so, I aim to demonstrate the necessity of both the realist and constructivist theoretical frames in sociological research on 
environmental issues. Finally, I discuss the theoretical framework of emergence and how it can explain individuals' perceptions of environmental issues. This particular theoretical framework has been applied in community sociology, as well as other scientific fields focusing on unrelated phenomena, but has not gained much traction in this particular field of environmental sociology. Given the context of the realist-constructivist divide and the emphasis on place in the literature of environmental sociology, emergence fits well as a construct for explaining the simultaneous importance of social, material, and geographical influences on environmental concern found across a wide variety of studies on environmental-societal interactions.

\subsection{The Social Bases of Environmental Concern}

\subsubsection{Early investigation of the social bases of environmental concern}

Widespread public concern about environmental problems ("environmental concern") is a relatively new phenomenon, arising over the course of the last quarter of the 20th century. This public concern responds to increasing calls from the scientific community, warning about the consequences of industrial activities for the environment (Hannigan 2006). Public awareness of society's impact on the environment has grown since the 1970s (Dunlap and Marshall 2007), but different segments of the public vary in their concern and certain issues tend to be more divisive. Among the most controversial issues in the current public discourse is climate change, and climate-related issues have been heavily investigated by sociological research, including public belief in the reality of climate change and opinions about the appropriate public policy responses to the phenomenon. Particular social influences on public beliefs and opinions have been at the 
center of such research efforts. For example, political liberals express greater concern than conservatives (Van Liere and Dunlap 1980; Guagnano and Markee 1995; Hamilton 2008). College-educated respondents tend to express higher concern than those without college educations (Van Liere and Dunlap 1980; Dietz et al 2007; Hamilton 2008). But some effects are not additive: concern about climate change tends to increase with education among liberals and moderates, but not so among conservatives (see McCright 2011).

Sociological research on environmental concern began with an influential study by Kent Van Liere and Riley Dunlap, who coined the phrase, "the social bases of environmental concern," (Van Liere and Dunlap 1980). Van Liere and Dunlap reviewed five hypotheses relating to social and demographic predictors of levels of environmental concern. The hypotheses covered age, class, residence, political, and sex effects. The five hypotheses proceed as such; 1 ) "the age hypothesis" predicts that "(y)ounger people tend to be more concerned about environmental quality than older people;" 2) "the social class hypothesis" predicts that "environmental concern is positively associated with social class as indicated by education, income, and occupational prestige;" 3) "the residence hypothesis" predicts that urban residents will be more likely to express concern about the environment than rural residents; 4) "the political hypothesis" predicts that liberal Democrats will be more likely to express concern about the environment than conservative Republicans; and 5) no agreement has been reached about the "direction of the relationship between sex and environmental concern," (Van Liere and Dunlap 1980).

In their summary, Van Liere and Dunlap conclude that only three of the hypotheses (age, education, and political ideology) should be considered to have empirical generality with respect 
to predicting levels of environmental concern among the population (Van Liere and Dunlap 1980). Generally, "younger, well-educated, and politically liberal persons tend to be more concerned about environmental quality than their older, less educated, and politically conservative counterparts," (Van Liere and Dunlap 1980). There have been mixed results from these "sociodemographic predictors" in the years following this study (see Guagnano and Markee 1995). Therefore, the social bases of environmental concern became the focal point for future research on public views of the environment. Dunlap's more recent work has shifted towards political polarization and climate change beliefs, specifically the systematic and organized denial of anthropogenic climate change and its effect on public views (McCright and Dunlap 2011; McCright, Dunlap, and Xiao 2013, Dunlap and McCright 2008).

\section{$\underline{\text { 2.1.2 "Values-Beliefs-Norms" Theory }}$}

Given the variety of "social bases" that could emerge as theoretically-interesting predictors of environmental concern, a sizeable body of research has followed in Van Liere and Dunlap's wake. Some of the most notable contributions have come from Thomas Dietz and colleagues in their work on the connection between values, beliefs, and norms of behavior relating to the environment. Their major theoretical contribution came in the form of a valuesbeliefs-norms theory (VBN) of environmental concern, which proposes that our values influence our beliefs, which in turn influence our normative orientations and subsequent actions in response to environmental issues (Dietz, Fitzgerald, and Shwom 2005). Specifically, measures of self-interest are negatively related to environmentalism (or pro-environmental behaviors such as 
recycling or environmental activism), while measures of humanistic ${ }^{6}$ and biospheric $^{7}$ altruism are positively related to environmentalism (Dietz, Fitzgerald, and Shwom 2005).

VBN theory advanced the "social bases" literature by asserting a useful place for NEP within a broader theoretical schematic. This development in the literature on the social bases of environmental concern emerged from prior inquiries into the presence and effect of such values systems on environmental views. A number of studies found a positive relationship between altruism (biospheric and humanistic) and self-reported pro-environmental behaviors, such as recycling, contributing money to environmental organizations, reducing personal vehicle use, and purchasing environmentally-friendly products (Karp 1996; Schultz and Zelezny 1999; Nordlund and Garvill 2002). Additionally, altruists have been found to more often follow vegetarian diets, though not as explicitly an environmentally-minded endeavor in all cases (Dietz, Frisch, Kalof, and Guagnano 1995; Kalof, Dietz, Stern, and Guagnano 1999). Using structural equation modeling to test the paths hypothesized by VBN theory, Dietz, Dan, and Shwom (2007) found multiple significant direct and indirect relationships between values, beliefs, and support for climate change policies, thus building evidence for the claims of VBN. For example, greater altruism indirectly increased policy support through its influence on respondents' awareness of consequences of environmental problems, trust in environmental groups, and tendency towards an NEP worldview (Dietz, Dan, and Shwom 2007). VBN theory

\footnotetext{
${ }^{6}$ Schwartz's "norm activation" model of altruism defines humanistic altruism as "behavior intended to help other humans beyond what self-interest would dictate," (Dietz, Fitzgerald, and Shwom 2005).

${ }^{7}$ Dietz, Fitzgerald, and Shwom (2005) define biospheric altruism as behaviors that arise from concern for "other species or the state of ecosystems themselves, beyond the benefits to humans of those species or ecosystems." Also, biospheric altruism acknowledges an "inherent value" in other species and ecosystems, whereas humanistic altruism or self-interest do not (Dietz, Fitzgerald, and Shwom 2005).
} 
has also been influential in the development of theories on the emergence of environmentally conscientious behavior among individuals (Stern 2000).

As important as VBN theory has been to research on the social bases of environmental concern, it crosses the social-psychological boundary in most instances and is often utilized by researchers publishing in psychology-related journals. Therefore, the emphasis in the research has tended towards individual-cognitive processes and away from social processes underlying the development of environmental concern. Recently, however, social scientists interested in the public perception and knowledge of climate change have adapted the "social bases" logic to the study of these phenomena.

\section{$\underline{\text { 2.1.3 Education, Knowledge, and Political Identity }}$}

Perhaps the most robust finding from this line of research has been the moderating effect of ideology or political identity on the relationship between education/climate change understanding/overall science literacy and beliefs/concern about the effects of climate change. For instance, conservatives and liberals increasingly diverge in their concern for sea level rise as their education levels increase. Lawrence Hamilton's groundbreaking research revealed that extremely liberal individuals with graduate degrees are the most likely to be concerned whereas extremely conservative individuals with the same level of education are the least likely to be concerned about sea level rise (Hamilton 2008). Echoing this education and party interaction effect, Hamilton again found an interaction effect between self-assessed knowledge about global warming and probability of seeing global warming as a threat. Specifically, the probability of 
seeing global warming as a threat increases among self-described "strong Democrats" as their self-assessed knowledge increases, whereas the probability of seeing global warming as threat decreases among "strong Republicans" as their self-assessed knowledge of the issue increases (Hamilton 2011). This effect has emerged in much the same way over the course of several studies on the topics of climate change beliefs and concern (McCright and Dunlap 2011; Hamilton, Cutler, and Schaefer 2012; Hamilton and Keim 2009; Malka, Krosnick, and Langer 2009).

\section{$\underline{\text { 2.2 Socioeconomic Characteristics and Environmental Justice }}$}

Socioeconomic characteristics of individuals and places have been given much attention in the literature on environmental-societal interactions, especially in the vein of environmental justice. Environmental justice has been defined as "the principle that 'all people and communities are entitled to equal protection of environmental and public health laws and regulations,"' (Brulle and Pellow 2006). Many studies emerged throughout the last quarter of the 20th century on the disproportionate impacts of environmental hazards on racial/ethnic minority groups and lowerincome groups. A landmark contribution to this field of research came from Robert Bullard's, Dumping in Dixie, in which Bullard demonstrated that hazardous waste sites had been deliberately placed near spatially segregated minority communities. Dumping in Dixie was one of the earliest major studies to document the phenomenon of "environmental racism," or "any policy, practice, or directive that differentially affects or disadvantages (whether intended or 
unintended) individuals, groups, or communities based on race or color," (Brulle and Pellow 2006). A majority of the literature following Bullard's study has found race to be the "major driving factor" (Brulle and Pellow 2006) in environmental inequalities, but substantial consideration has still been afforded to class-related indicators, such as personal or household incomes.

Class-based patterns of environmental injustice have been encapsulated in Ulrich Beck's theoretical construct of a "risk society." In the context of corporations maximizing profits and increasing growth, modern industrial societies have lost the ability to ensure the safety of all citizens from environmental hazards (Brulle and Pellow 2006). This resulted in the formation of what Beck termed "risk positions," which relate to the differential exposures to environmental hazards of different socioeconomic classes (Beck 1992). The distribution of risks, according to Beck, is the inverse of the distribution of wealth in society, such that wealth is concentrated at the top and risks are concentrated at the bottom of the socioeconomic hierarchy (Beck 1992).

Beck's "risk society" provides a useful construct to predict and explain perceptions of extreme or unusual weather events due to differential vulnerabilities to weather impacts and capabilities to recover in the aftermath of destructive weather events. For example, lower-income households may be more likely to live in low-lying areas, increasing their vulnerabilities to floods resulting from torrential rain. Lower-income coastal residents, in particular, may live in homes ill-equipped to deal with destructive thunderstorm winds and rain, thus increasing the likelihood that they will encounter structural damage to their homes. In addition to vulnerabilities related to the locations and structural integrities of their homes, lower-income households may not be sufficiently insured against the most unusual or extreme weather events, increasing the 
likelihood that they will endure long-term financial burdens or forced relocations, temporary or permanent, in the aftermath of severe storm events. If environmental risks are indeed disproportionately concentrated at the bottom of the socioeconomic ladder, I expect lowerincome households will be more likely to report effects from extreme or unusual weather events than their higher-income counterparts.

Prior research has addressed the issue of vulnerability to environmental hazards, and with specific attention to place-based variation in vulnerabilities. Susan Cutter and colleagues utilized county-level socioeconomic and demographic data from 1990 to construct a "Social Vulnerability Index,” (2003). Their index included measures of personal wealth, age, the density of the built environment, single-sector economic dependence, housing stock and tenancy, race, ethnicity, occupation, and infrastructure dependence (Cutter et al 2003). Cutter and colleagues found modest correlations of their social vulnerability index with the number of presidential disaster declarations at the county-level, but their research signals an important component well worth considering: social vulnerability to extreme or unusual weather events.

Cutter’s findings utilizing the "Social Vulnerability Index," as well as the findings from other hazard vulnerability studies (Chakraborty et al 2014; Cutter 2012; Cutter 2001; Zahran et al 2008), correspond well with Beck’s differential “risk positions,” but Beck’s broader theory of reflexive modernization ${ }^{8}$ can extend the discussion of hazard vulnerability to the transformation of modern society through what Beck termed, "second-order side effects," or the "side-effects of social institutions” which "result in new conditions which call them into question,” (Beck et al

\footnotetext{
${ }^{8}$ Reflexive modernization refers to "the modernization of modern society," or the stage in which modernization "radicalizes" and begins to "transform, for a second time, not only the key institutions but also the very principles of society" due to the accumulation of side-effects of modern Western society which "eventually put its touchstone ideas into question," (Beck et al 2003).
} 
2003). The hazards produced by modern industrial society, particularly the effects of extreme or unusual weather events linked to anthropogenic climate change, could spur the public discourse into questioning the abilities of policy-makers, industries, and sciences to both anticipate and deal with the potential environmental impacts of their practices. Extreme weather, as a hazard that is linked to modern industrial practices, may play a role in the formation of reflexive modernization as a phenomenon marking the next stage of modern industrial society. By investigating individual perceptions of extreme weather, and their potential social, material, and geographic correlates, my research teases out this link between social vulnerability and reflexive modernization.

\section{$\underline{2.3 \text { Place and Environmental Concern }}$}

Early inquiries into the role of place in the formation of individual environmental views yielded theoretically interesting results. Van Liere and Dunlap found evidence for the "Residence Hypothesis," namely that urban residents are more likely to be environmentally concerned than rural residents (Van Liere and Dunlap 1980). They provided a two-part explanation: 1) urban residents are more concerned because they are exposed to higher levels of pollution and 2) rural residents have "utilitarian" orientations towards the environment, meaning their involvement in occupations such as farming, logging, and mining dampens their levels of concern by increasing dependence upon natural resources to provide for their livelihoods (Van Liere and Dunlap 1980). Though this provided the potential for plenty of follow-up research, few studies over the subsequent two decades attempted to investigate the relationship between place and environmental concern. 
Perhaps the most prominent article to follow prior to the new millennium was Guagnano and Markee's 1995 study of regional differences in environmental concern. They made an important argument for studying regional differences by stating, "...attitudes, values, and beliefs have historical and cultural roots, and these roots may be specific to different regions of the United States, each of which has its own unique cultural heritage and tradition," (Guagnano and Markee 1995). This rationale has in part inspired my own research agenda as I also see place as an indispensible determinant of values, beliefs, and the reinforcing inter-subjective experiences of residents to any given area. To ignore place as a predictor of any attitudinal or perceptual outcome variable would be to overlook a great deal of potential linkages between personal identity and the social world and the resultant effects on attitudes and perceptions

After the turn of the new millennium, however, research on place effects began to gain steam. Several studies have been published highlighting the significance of place on the public perception of a host of environment issues. These studies range from the level of the state and region (Shwom, Dan, and Dietz 2008; Hamilton and Keim 2009; Hamilton, Colocousis, and Duncan 2010; Safford and Hamilton 2012) to the national level in a cross-national comparative context (Brechin 2003; Lorenzoni and Pidgeon 2006). Using a survey of Michigan and Virginia state residents, Shwom, Dan, and Dietz (2008) found that Michigan residents were less likely to support climate change mitigation policies than Virginians. Given their limited ability to elaborate on this place-based difference, the authors speculate that the pervasiveness of the auto industry in Michigan influenced the quality and quantity of information disseminated regarding climate change (Showm, Dan, and Dietz 2008). In-depth research is needed to tease out the 
contextual factors which might illuminate such place-based differences in environmental concern.

Hamilton and Keim (2009) tested perceptions of climate change effects among residents in rural regions of different states through the use of mixed effects modeling. They found that people living in regions with snowy winters expressed the most concern, suggesting that recent warmer-than-usual winters could be responsible for increased awareness of climate change effects. Additionally, the mixed effects model showed significant regional variation net of the individual-level predictors tested, including sex, race, age, income, education, party, religious attendance, and length of residence. The authors point to "objective local conditions" as important factors in influencing residents' perceptions of the effects of climate change (Hamilton and Keim 2009). In the next section I will return to the topic of integrating of biophysical indicators with individual-level survey data.

Place-based variation in environmental attitudes was explored in depth again after the BP Deepwater Horizon oil spill disaster of 2010. Hamilton, Safford, and Ulrich (2012) investigated the extent to which spill-related and other environmental views varied in the aftermath of the spill by individual characteristics of survey respondents, personal experience with the spill, or characteristics of place. They found that Gulf Coast Louisianans reported significantly higher effects from the spill, extreme weather, and threats from climate change than the Gulf Coast Floridians in the sample, but the Louisianans expressed significantly lower support for a moratorium on deep water oil drilling, alternative energy, or resource conservation. One possible explanation the authors provide is that the difference is related to the socioeconomic development around the oil and gas industry in Louisiana versus the tourism-related 
development in Florida. Perhaps as importantly, however, the authors point out that their research "adds another example where community relationships to the natural world affect views on environmental issues," (Hamilton et al 2012).

I will contribute to research on the link between community and environment by taking a new approach that integrates extreme weather event data with survey data. This approach is equipped to deal with the social-psychological components associated with process theories such as VBN, but it also broadens the scope of this perspective in order to transcend the realistconstructivist and micro-macro divisions in environmental attitude research of the past. Additionally, while the BP oil spill provided an opportunity to study attitudes in the wake of a single anthropogenic environmental disaster event, there has been less attention to the cumulative effect of multiple natural disaster events over time on public attitudes about the environment. My research will address that gap.

Safford and Hamilton utilized the coastal surveys associated with the project, Communities and Environment in Rural America (CERA), by exploring the place-based differences between the environmental views of residents in the two counties of Downeast Maine. According to their research, Hancock county residents expressed significantly higher levels of concern about pollution, seafood contamination, aquaculture, climate change, and development or sprawl (Safford and Hamilton 2012). The strongest predictor of sprawl was Hancock county residence, net of a host of individual-level background characteristics. These findings were logical given that Hancock County is more affluent and is amenity-rich, whereas Washington County is relatively poor and dependent on resource extractive industries (Safford and Hamilton 2012). Safford and Hamilton repeatedly emphasize the usefulness of sociological 
research like this to policy makers because it explores the link between community characteristics and residents' opinions. Such information is valuable when considering new development projects or investments in particular industries. I aim to accomplish a similar task by informing policy makers, climatologists, and other interested parties in business, government, or the sciences about the factors influencing perceptions of extreme weather events within the context of overall environmental concern.

Hamilton and colleagues explored the link between characteristics of place and views on environmental issues across 38 counties in 12 regional CERA surveys. They found that there was significant place-to-place variation on three issues of environmental concern, namely climate change, conservation rules, and whether to conserve resources or promote economic growth, due to the "countless unmeasured differences between those places," (Hamilton et al 2013). In order to provide some possible explanations for the significant place-based variation, the authors introduced a hybridized approach to this type of research by "embedding regional case studies" into the survey results from multiple regions (Hamilton et al 2013). Specifically, they contextualized their initial analysis of a survey of Oregonians by examining interviews of individuals living in many other regions of the country. In doing so, the authors were able to step-back from their findings about Oregon to see how the same issues were perceived and understood in dissimilar social, economic, and environmental contexts.

Other studies have emerged that demonstrate the importance of "sense of place" and the difference between coastal residence and other places of residence on attitudes and beliefs about the environment. Larson and colleagues (2013) tested the relationship between several "sense of place" indicators and some salient "wellbeing factors" related to environmental issues. 
Interestingly, the authors found that respondents who lived in coastal areas and had spent less time in their place of residence were more likely to place emphasis on the importance of environmental wellbeing (Larson et al 2013). Part of the explanation, the authors suggest, is related to the shift from environmental to social connections over time as respondents remain in their places of residence for longer periods. According to Larson and colleagues (2013), people develop stronger social connections and tend to place higher emphasis on the importance of local social or economic issues than on environmental wellbeing. These findings are particularly informative to my research because of the evidence of an association between coastal residence and environmental values.

The development of social connections to place can lead to conflict over policies and institutional practices which might transform or present significant changes to areas in which residents have a strong “sense of place.” The Three Mile Island nuclear accident of 1979 presented a unique, albeit unfortunate, circumstance for social science researchers to study the factors associated with community-level organizing in response to environmental hazards. Ed Walsh and colleagues published a series of studies (1981- 1988) utilizing survey data and field research to illuminate the social-interactional and -structural factors underlying grassroots activism in response to the disaster at Three Mile Island. In one study, they identified and studied four communities with active citizen protests: Middleton, Newbury, Harrisburg, and Lancaster (Cable et al 1988). Walsh and colleagues found that local impacts from the Three Mile Island disaster were more important to those living in communities closer to the incident, whereas those in communities further away were more likely motivated by the ideologically-based positions 
against nuclear power and its potential risks on a broader scale than just the local communities affected by Three Mile Island itself (Cable et al 1988).

Walsh's research highlights an important component to the place-based nature of perceptions of environmental issues. Geographical distance corresponds to social distance such that one's proximity to an environmental disaster could influence the degree to which one connects either to the localized impacts of the disaster or the broader issues related to the occurrence of such disasters. In the case of extreme or unusual weather, those who are concerned about extreme events but have not been directly impacted by such events might be more likely to connect the events to broader issues such as climate change than to consider the actual impacts of such events on local communities. Similarly, those who experience extreme events directly may be less concerned with broader climatic issues and more inclined to be concerned with localized impacts. Also, those who have direct experiences with extreme events over a prolonged period of time may become desensitized to the impacts and may view attempts to connect them with larger global climatic issues as unwarranted or ideologically motivated and thus unreliable.

\subsection{Integrating Multiple Indicators and the Realist-Constructivist Divide}

Dunlap, in his influential essay "The maturation and diversification of environmental sociology: from constructivism and realism to agnosticism and pragmatism," argued that the realist-constructivist cleavage persists despite recent concessions by those on the constructivist side regarding the factual reality of climate change (Dunlap 2010). The cleavage, he argued, relates to the continued separation of "environmental sociologists who confine their analyses to the symbolic/ideational/cultural level and those who examine material conditions," (Dunlap 
2010). Social constructivists who have focused on symbolic or cultural factors have been primarily concerned with "contextualizing, problematizing, and deconstructing the claims about ecological conditions issued by scientists, activists, and policy-makers,” (Dunlap 2010). Examples include efforts to expose the expert-layperson divide on knowledge of risk (Wynne 1996; Beck 1992; Lash et al 1996), as well as the social dimensions of controversies over environmental conservation versus economic development (Eder 1996; Greider and Garkovich 1994; Macnaghten and Urry 1998). Realists, on the other hand, have employed indicators of ecological conditions to understand societal-environmental interactions (Dunlap 2010). Perhaps most prominent among the realists have been the environmental justice pursuits of sociologists studying socioeconomic and racial disparities in environmental hazard exposures (Bullard and Johnson 2000; Bullard and Wright 2009; Brulle and Pellow 2006).

There are indeed few studies which have successfully transcended the realistconstructivist divide and integrated both conceptual frames into their methodologies and analyses. Without alluding to persistent conceptual divisions amongst the broader literature, recent studies have integrated multiple indicators of various biophysical, demographic, and social-structural phenomena with social-psychological indicators. Hamilton and Keim (2009) adapted temperature trend data from the United States Historical Climate Network (USHCN) to correlate local temperature trends with residents' perceptions of climate change effects on their communities. Climate change effects perceptions were higher in regions that experienced the most warming during winter months. Interestingly, Kansas stands out as an anomalous case and the authors suggest that the predominant conservative ideologies of the region to be at the core of this inconsistency (Hamilton and Keim 2009). Warm weather and perceptions of a changing 
climate seem as though they would be intuitively linked, but social science research can provide evidence regarding this otherwise anecdotal or assumed correlation.

Even more recently, Hamilton and Stampone (2013) demonstrated a striking effect of the temperature on political independents' belief in anthropogenic climate change, which is the scientific consensus. Using USHCN daily temperature data and a survey of New Hampshire residents, the authors found that politically independent respondents were more likely to believe that climate change is happening now, caused mainly by humans, if the interview day and the previous day were unseasonably warm (Hamilton and Stampone 2013). Another striking aspect of this research is the sizable and consistent gap between beliefs of Republicans and Democrats regardless of the temperature on the previous day. This speaks to the rhetorical connection, by some scientists, science writers, and other prominent voices in media and politics, between climate change and weather events (Wallace 2012). Public perceptions of extreme or unusual weather events may be shaped in part by this construal of such events as early warning signs of climate change by trusted sources of information.

Effective integration of multiple indicators has also been achieved in studies analyzing perceptions of urban sprawl, beliefs about resource conservation/consumption, and beliefs about the impact of environmental regulations restricting development. Hamilton, Colocousis, and Duncan (2010) integrated U.S. Census estimates of population growth and employment in agriculture, forestry, hunting, fishing, or mining with data from the Communities and Environment in Rural America (CERA) surveys. Their findings showed strong correlations between these Census data and respondents' perceptions of urban sprawl and beliefs about conservation and restricting development. Percent population change was positively associated 
with the percent of respondents perceiving effects of urban sprawl and percent believing environmental rules restricting development have been good for the local community. On the other hand, percent employed in agriculture, forestry, hunting, fishing, or mining was negatively associated with the percent of respondents favoring the conservation of resources for the future.

Integration of multiple indicators has not proved as fruitful in the investigation of factors influencing the formation of environmental risk perceptions. Carlton and Jacobson (2013) utilized survey data of Floridian residents to examine the factors that influence perceptions of several types of risks, including both social and environmental risks. One major indicator included was the respondents' self-reported assessment of the extent of effects on their personal lives from the 2004 hurricane season. This variable is similar to the dependent variable utilized my research, namely individual extreme weather perception, but it was utilized by Carlton and Jacobson as an independent predictor of risk assessments. As an independent predictor, the selfreported assessment of hurricane effects was not found to signficantly influence risk perceptions among Floridian respondents (Carlton and Jacobson 2013). In their discussion of findings, Carlton and Jacobson speculate that too much time may have elapsed from the 2004 hurricane cycle and the implementation of the surveys for their study. They also claim that hurricanes "might not cause an availability heuristic effect beyond hurricane-related risks," (Carlton and Jacobson 2013). This underscores the important point that severe weather exposure is not necessarily a determinant of broader climate-related risk perceptions, such as climate change. Moreover, researchers utilizing multiple indicators in social science should be careful to consider how the use of biophysical or socio-contextual predictors could be misinterpreted to mean things that might not reflect reality. 
In contrast to Carlton and Jacobson's research, Prati and Zani (2013) investigated the change in environmental attitudes after learning of a major environmental catastrophe. By using a longitudinal design, their study was able to test the values-beliefs-norms (VBN) model of environmental commiment (Prati and Zani 2013). The authors were afforded a unique, though very unfortunate, opportunity to measure the change in attitudes towards nuclear power, trust in science, and environmental beliefs immediately following the Fukushima nuclear power plant accident in 2011. They administered a survey questionnaire to 32 Italian citizens one month prior to the Fukushima incident and then again one month after. All 32 respondents were retained in the second phase of data collection and the same exact questionnaire was used for both iterations. Participants were asked a series of questions that Prati and Zani adopted from Dunlap and Van Liere's New Ecological Paradigm (NEP). They were also asked to rate their trust in scientists and the level risk associated with nuclear power. The study found that pro-environmental and antinuclear attitudes emerged among participants after the Fukushima accident (Prat and Zani 2013). Given the large effect size associated with these findings, Prati and Zani conclude that "people may be influenced by even a single dramatic event," (Prati and Zani 2013). I expect severe weather events to produce the same emergence of heightened weather effects perceptions among individuals experiencing the severe weather, but Prati and Zani's findings suggest that such heightened perceptions may emerge among individuals who were simply exposed to news of the events.

Environmental views are clearly connected to place in some meaningful ways and the integration of "contextual" data with individual-level survey data can help to illuminate such relationships. Hamilton, Colocousis, and Duncan (2010) conclude their investigation of place 
and environmental views by stating that, "Individual perspectives, as social phenomena, are emplaced (Gieryn 2000) in geographic locations and related physical, practical, and symbolic structures." Now that the "emplaced" perspective of environmental views has been established, it is important that research not simply follow from this logic but also dig deeper to find placespecific contexts and meanings underlying statistical relationships between aggregate social, biophysical, or individual-level data. I hope to break down the analytical barrier between studies that investigate the social, cultural, and symbolic levels (constructivists) and studies that examine the material conditions (realists) of societal-environmental interactions. Also, I aim to transcend the micro-macro division between studies that specifically focus on structural or material influences on environmental attitudes and studies of social-psychological processes underlying environmental attitudes, such Dietz’s VBN framework. My goal is to apply insights from the social-psychological processes established by Dietz and colleagues while incorporating multilevel analyses and multiple indicators of social, structural, and environmental conditions. This approach is intended to provide another link to bridge the realist-constructivist divide in the literature while at the same time transcending the micro-macro distinctions between socialpsychological and geographical/biophysical studies of the past.

\subsection{Shared Perceptions and the Concept of "Emergence"}

In his text, Environmental Sociology, Hannigan proposes "an approach to environment and society that pivots on the concept of emergence," (2006). Hannigan outlined several areas of the sociological literature which have entertained the concept of emergence in the explanations 
of various social processes. Emergence appears in the studies of norms, collective behavior, disasters, social movements, and social learning (Hannigan 2006). Although it is difficult to pin down, the most relevant conceptual definition of emergence for my purposes is, "...that social organization and the production of knowledge are fundamentally fluid, dynamic, and adaptive," and "...that they percolate from the grassroots rather than pass from the top downwards," (Hannigan 2006). Properly understood, emergence is a social process that occurs through interaction rather than a social-psychological process that relates to the influence of social experiences on individuals. Cast in this light, emergence can be a useful tool for the study of place-based differences in perceptions of environmental and social issues. As I noted previously, Guagano and Markee (1995) proposed the useful notion that "...attitudes, values, and beliefs have historical and cultural roots, and these roots may be specific to different regions of the United States, each of which has its own unique cultural heritage and tradition." Given this noteworthy and empirically sound assertion, Hannigan's call for emergence in the study of societal-environmental interactions seems appropriate. Current "place-effects" studies in environmental sociology have lacked this type of paradigmatic theoretical framework. I am proposing to take up Hannigan's call and pursue emergence in the study of shared perceptions of social and environmental issues. Some of the sociology of community literature, as I will outline briefly below, has already made some progress in applying this framework to the study of "neighborhood effects," (Sampson 2012).

Though it has not reached paradigmatic status, emergence is not a new idea in sociology. The earliest theories of emergent properties reach all the way back to the founding of the discipline. Sawyer (2002) argued that “emergence processes are central to Durkheim's empirical 
and theoretical projects, and that sociologists have neglected this aspect of Durkheim's work.” According to Sawyer, emergence can be found in Durkheim's ideas about social facts, collective representations, and sui generis. Indeed, social facts and collective representations are "emergent social phenomena. Both are sui generis properties of a social system, emerging from the association of individuals," (Sawyer 2002). Sawyer is also keen to point out that theories of emergence are present in several other scientific and academic disciplines, such as philosophy, economics, and the biological and physical sciences ${ }^{9}$.

The emergence framework recently gained significant traction in the sociology of community. In his groundbreaking study of Chicago neighborhoods, Sampson (2012) set out to study "neighborhood effects," or the range of outcomes predicted or explained by differences in neighborhood-level correlates. For instance, crime and health problems "tend to come bundled together" at the level of the neighborhood and "are predicted by neighborhood characteristics such as the concentration of poverty, racial isolation, single-parent families, and to a lesser extent rates of residential and housing instability," (Sampson 2012). Even though a long history of research has charted the demographic correlates of community well-being, Sampson argues "the social mechanisms and dynamic processes accounting for neighborhood effects have remained largely a black box," (Sampson 2012). These processes and mechanisms within the black box are also "not merely the reflection of individual characteristics," but "stem from social-interactional and institutional processes that involve collective aspects of community--emergent properties,"

\footnotetext{
${ }^{9}$ According to Sawyer, emergence appears in philosophy in the form of hypothetical arguments about the nature of traffic jams and the "flying V" of a bird flock, which each suggest that higher level regularities emerge from lower level rules and interactions. Similarly, Sawyer points out that the study of "complex adaptive systems" is present in economics, biological, social, and physical sciences, such as the study of global macroeconomic networks, stock markets, social insect and ant colonies, the biosphere and ecosystem, the brain and immune system, the cell and developing embryo, ideologies, communities, and the internet and cyberspace.
} 
(Sampson 2012). The "black box" is a useful metaphor for the processes underlying public perceptions of environmental problems because researchers have yet to understand the details comprising place differences in such perceptions.

In his research, Sampson attempted to unpack this "black box" through a variety of methods and analytical strategies. Among those strategies was his approach to studying perceptions of neighborhood disorder. Sampson employed a survey of Chicago neighborhood residents, U.S. Census data, Chicago police records of violent offenses, and systematic social observation in order to understand the bases of perceived disorder. His main finding was that the concentration of racial/ethnic minorities led to implicit bias, stigmatized places, and shared meanings, which in turn led to perceived or felt disorder (Sampson 2012).

Sampson's study of shared perceptions of disorder provides a useful framework for the investigation of perceptions of environmental problems. Moreover, shared perceptions as emergent properties could serve as a useful conceptual configuration for explaining how individuals come to understand the environment in a world otherwise disconnected from ecological processes of the environment. In other words, perceptions of the environment are likely emergent properties of localities, communities, and regions stemming from socialinteractional processes rather than simply individual judgments based on observations or actual experiences with the environment. My research will be an attempt to unpack this "black box" of place effects on perceptions of the environment. 


\section{$\underline{\text { 2.6 Summary }}$}

The social bases of perceptions of unusual or extreme weather are perhaps the most theoretically and empirically interesting factors to investigate because one might expect perceptions of the weather to be based mostly upon direct individual experiences with the weather. We take for granted the amount we learn about weather events through social/institutional interactions versus the amount we actually experience in our day-to-day routines. It seems logically coherent to expect that the formation of our weather perceptions relies heavily upon social factors influencing our lives, chief among them being the social and ideological context of where we live. Some recent research has demonstrated linkages between objectively measured weather, or climate anomalies, and public concern or beliefs about climate change (Goebbert et al 2012; Howe and Leiserowitz 2013; Egan and Mullin 2014; Zaval et al 2014; McCright et al 2014; Lang 2014; Marquart-Pyatt et al 2014; Hamilton and LemckeStampone 2014; Shao et al 2014; Shao 2015). Therefore, the extreme/unusual weather outcome presents a compelling but previously under-explored instance where environmental perceptions may have both a social and physical basis.

As stated throughout my literature review, prior studies have, perhaps unintentionally at times, compartmentalized the influences on environmental perceptions and attitudes into either the social or material realms, but a broad view of all of these studies reveals that social and material conditions may converge and could be inextricable in influencing individual perceptions of environmental issues. My research will advance the study of environmental perceptions in the field of environmental sociology by synthesizing the effects social-psychological, geographical, and objective material conditions on individual perceptions of extreme weather. In the next 
chapter I detail the specific methods I utilized in order to achieve this synthesis, namely the integration of multiple indicators of social contextual, individual social-psychological, and objective weather events. 


\section{CHAPTER III}

\section{DATA AND METHODS}

In the preceding chapters I explained the research questions and hypotheses of my study based on a comprehensive review of the relevant literature and theoretical perspectives in the fields of community and environmental sociology. In this chapter, I introduce the data sets employed in my research, describe the dependent and independent variables, and explain the analytical approach of my study. To begin, I introduce the Communities and Environment in Rural America surveys and describe the individual-level dependent and independent variables. These data were chosen because they offered the under-examined phenomenon of individual extreme weather perceptions. Additionally, these data come from a variety of coastal communities across the United States thus allowing for cross-regional comparisons, an advantage that is particularly useful in the investigation of the social and geographic dimensions of individual extreme weather perceptions.

Next, I introduce and describe data on extreme weather events. Specifically, I describe the Severe Thunderstorm Events Archive and Storm Events Database and the particular countylevel weather indicators from those data sets. These data represent the biophysical or objective material indicators to be combined with the social dimensions from the survey data. Since it is my approach to integrate both realist and constructivist perspectives in order to transcend old divisions among prior studies, these objective weather data are crucial to the investigation of the material, or "environmentally real," influences on individual perceptions of extreme weather. Finally, I explain and justify the analytical strategies of my study. 
I describe mixed-effects modeling and multiple imputation techniques in general terms and then describe their application in my research in detail. Missing data on personal and household incomes often present complications in social science research because individuals tend to be reluctant to offer answers to survey questions related to this sensitive information. However, income, as an indicator of social position, is critical to understanding the impact of socioeconomic standing on individual perceptions of extreme weather. It is also important for comparison to previous research in the field of environmental sociology, particularly the environmental justice sub-field. Multiple imputation was chosen as a strategy for dealing with missing values on income and the reasons, as well as the technical details of the method, will be discussed in depth in this chapter.

Finally, mixed effects statistical modeling was chosen because of the ability to test for the presence of significant unexplained variation by geographical location net of other individuallevel and objective material indicators. The "place” component of environmental attitudes and perceptions has emerged in recent literature as a conceptually and empirically important factor in explaining the formation of these attitudes and perceptions. Characteristics of place may be relevant to the discussion of individual-level extreme weather perceptions and mixed effects modeling can at least identify specific geographic locations which vary significantly from others net of all other characteristics, social and biophysical. 


\subsection{The CERA Coastal Surveys}

\section{$\underline{\text { 3.1.1 Background }}$}

The main source of data for my project comes from the Communities and Environment in Rural America (CERA) surveys. CERA is an ongoing effort, carried out by the Carsey Institute at the University of New Hampshire, to "better understand the changing social, economic, and environmental factors in different rural parts of the country and the implications for sustainable community development policies and practices," (http://carseyinstitute.unh.edu/cera). The first phase of CERA included surveys of almost 8,000 residents in 19 rural counties aimed at determining their "opinions, experiences, and attitudes about the changes occurring in their lives, the lives of their families, and in their communities," (Hamilton et al 2008). Researchers at the Carsey Institute initially focused their analyses of CERA data on five issue areas important to rural Americans today; 1) economic changes, challenges, and realities; 2) migration and demographic changes; 3) religion, trust, and civil institutions; 4) environment, natural resources, and energy; and 5) infrastructure and changing populations (Hamilton et al 2008).

Starting in 2009, the CERA project focused in on coastal regions. The first of these coastal surveys interviewed residents of two Maine counties, Hancock and Washington. Researchers on the project have analyzed Maine residents' opinions on marine resource use, coastal development, and marine environmental concerns (Safford and Hamilton 2013). The coastal survey initiative extended to the Gulf Coast following the BP Horizon oil spill in 2010 (Hamilton et al 2012; Safford et al 2012) and eventually the regions of Southeast Alaska, the Columbia River, and the Olympic Peninsula in a collaborative effort alongside the Communities and Forests in Oregon (CAFOR) project (Hamilton et al 2013). I utilized all of the coastal survey 
data from this larger CERA project. The regions surveyed in this sample are Down East Maine, the Pacific Northwest, Gulf Coast Florida, Gulf Coast Louisiana, the Olympic Peninsula, and Southeast Alaska. The total sample sizes for each region surveyed are presented in Table 3.1.

\section{Table 3.1. Coastal Surveys}

\section{Atlantic}

Downeast Maine: Hancock and Washington Counties ( $n=1,518$; August-September 2009)

Gulf Coast

Gulf Coast Florida: Bay, Franklin, and Gulf Counties ( $n=1,005$; August-September 2010)

Gulf Coast Louisiana: Plaquemines and Terrebonne Parishes ( $n=1,017$; late July-September 2010)

\section{Pacific Northwest}

Columbia River: Clatsop County, Oregon and Pacific County, Washington $(n=1,023$; JanuaryFebruary 2011)

Olympic Peninsula: Clallam and Grays Harbor Counties ( $n=1,013$; October-November 2010)

\section{Alaska}

Ketchikan, Alaska: Ketchikan Gateway Borough and Prince of Wales Census Area $(n=509$; June-August 2010)

Southeast Alaska: Haines, Juneau, Sitka, Skagway, Wrangell and Yakutat Boroughs; HoonahAngoon and Petersburg Census areas ( $n=1,033$; November-December 2010, with a small number of interviews in February 2011)

Note: Table adapted from Hamilton and Safford 2014.

The CERA surveys provide a unique platform to study both individual and regional factors affecting individuals' environmental perceptions. This is valuable because studies of environmental perceptions, beliefs, and attitudes are typically either confined to a single region, limiting their scope, or sampled broadly across many regions with too few individuals in each to make comparisons. CERA coastal data support individual-level comparisons across widely different social and physical contexts. This will be especially useful given my focus on perceptions about extreme/unusual weather events because the events themselves tend to be 
region-specific. Socio- and infrastructural- contextual factors also differ by region. For instance, coastal Louisiana experiences a very different cycle of weather compared with Downeast Maine. They also have very different social milieus, perhaps including different predominant views on environmental issues. Add to these differences the recent major hurricanes to hit the Gulf Coast and there are a host of good reasons to consider cross-regional differences in environmental perceptions, most especially weather perceptions.

Although a number of cross-regional studies have been done using CERA data, these have not systematically examined people's perceptions about extreme weather effects. Nor have most other environmental-concern studies focused on this topic. Previous research has given more attention to attitudes and beliefs about major environmental issues, such as climate change or environmental degradation, with less about social factors influencing perceptions about the impacts of environmental phenomena on communities. Moreover, very few studies (Hamilton et al 2012; Nerlich and Jaspal 2014; Carlton and Jacobson 2013) consider the social aspects of the increasingly important issue of extreme or unusual weather events. My research makes a unique and timely new contribution to the extant literature on environmental perceptions by examining coastal residents' perceptions about extreme weather events in relation to their individual characteristics, social context, and the objectively-measured weather events themselves.

These data are limited to a specific set of U.S. coastal regions, so my results invite broader replication based on other data. Coastal residents may experience different social, economic, and biophysical contexts than inland residents. The weather affecting coastal communities is much different than inland communities, although it differs very substantially among the coastal regions in my study, too. However, drought or tornadoes tend to be less 
common in coastal areas than inland, especially compared with "Tornado Alley" in the west/midwestern and southern U.S. These caveats will be kept in mind for drawing broader generalizations. However, the wide geographical and social variation already present in the coastal CERA surveys gives a strong basis for exploring this new line of research on communities and extreme weather effects.

\subsubsection{Dependent variable: weather perceptions}

The CERA coastal surveys included a series of items that asked respondents to report the effects of a host of environmental issues on the area in which they lived. Among these items was a question about the effect of extreme or unusual weather. Unlike the variety of other "issue" variables, the extreme weather item had not been investigated to any significant extent, either by CERA project researchers or other social science researchers in the field. This question stands out as ripe for analysis given the volume of literature on the other environmental questions in CERA, such as effects of climate change or urban sprawl and development.

Prior to the list of environmental issues, respondents are primed with an interlude to the following section of questions they will be asked. The introduction to this series reads as such:

Let's change the subject for a moment ... I'm going to read a list of environmental issues that might be problems in some places. With regard to the place where YOU live, for each issue I'd like to know whether you think this has had no effect, had minor effects, or had major effects ON YOUR FAMILY OR COMMUNITY OVER THE PAST 5 YEARS?

Following this primer, respondents are then asked about the host of environmental issues that may or may not be affecting the place where they reside. The item about extreme weather reads as such: 
Unusual or extreme weather-related events

Do you think this has had no effect...had minor effects ...or had major effects

ON YOUR FAMILY OR COMMUNITY OVER THE PAST 5 YEARS?

This item has three response categories, namely "no effect," minor effects," and "major effects." Respondents also have the option of declining to answer or responding with "don't know/not sure." Of the 7,118 in the sample, only 9 respondents gave no answer and 82 responded by saying they did not know or weren't sure. About forty-four percent $(3,065)$ of respondents in the sample reported no effects, thirty-three percent $(2,314)$ reported minor effects, and twenty-three percent $(1,648)$ reported major effects of extreme or unusual weather. Missing values on this particular item were not significantly related to any independent variables of interest in this research. On the other hand, some independent variables of interest did have missing values totals which theoretically could have affected results. A discussion of how these missing values were accounted for is provided in the following methods of analysis sub-section.

Since there is a distinction between "minor effects" and "major effects" of extreme or unusual weather events, I also tested for significant differences in the likelihood of respondents reporting major versus minor effects and arrived at some interesting results. Better educated individuals, individuals believing climate change is happening now due mainly to human activities, and individuals living in counties with higher property damage are significantly less likely to express minor versus major effects of extreme weather (Appendix C). On the other hand, those favoring conservation rules, higher income, and self-identified Republicans are more likely to report minor versus major effects (Appendix C). Finally, I found there to be significant county-to-county variation net of all individual- and county-level fixed effects in the model (Appendix C). I return to these findings later in my concluding section. For the major portions of 
analyses, I focused on differences between those who either reported major or minor effects and those who reported no effects at all because this dichotomy corresponds more directly to my research questions.

\subsubsection{Independent variables: individual characteristics}

The CERA coastal surveys feature a host of useful and analytically important individuallevel background questions. All of those variables used as independent, moderating, or control factors in the analysis of the present study are outlined in Table 3.2. Descriptive statistics for independent variables are given in Table 3.3.

\section{Table 3.2. Individual-level Independent Variables}

\begin{tabular}{|c|c|}
\hline Variable & Treatment \\
\hline Age & Continuous \\
\hline Sex & 0 - male, 1 - female \\
\hline Race & 0 - non-Hispanic white, 1 - Non-white \\
\hline Income & $\begin{array}{l}-2 \text { - }<\$ 20 \mathrm{k},-1-\$ 20-40 \mathrm{k}, 0 \text { - \$40-60k, } 1 \text { - \$60-90k, } 2 \text { - \$90- } \\
160 \mathrm{k}, 3 \text { - > } \$ 160 \mathrm{k}\end{array}$ \\
\hline Education & $\begin{array}{l}-1 \text { - high school/less, } 0 \text { - some college, } 1 \text { - college graduate, } \\
2 \text { - post-graduate }\end{array}$ \\
\hline Newcomer & 0 - lived here as a child, 1 - newcomer as an adult \\
\hline Own & 0 - renter, 1 - own home \\
\hline Political Party & 1 - democrat, 2 - independent, 3 -republican \\
\hline Conservation Rules & 1 - bad here, 2 - no effect, 3 - good here \\
\hline $\begin{array}{r}\text { Climate Change Beliefs } \\
4\end{array}$ & $\begin{array}{l}\text { is } 1 \text { - don't know/not applicable, } 2 \text { - not now, } 3 \text { - now/natural, } \\
4 \text { - now/human }\end{array}$ \\
\hline
\end{tabular}


Table 3.3. Descriptive Statistics for Independent Variables

\begin{tabular}{|c|c|c|c|c|}
\hline Variable & Obs. & Range & Mean & SD \\
\hline Age & 7,018 & $0-96+$ & 57.14 & 15.72 \\
\hline Sex & 7,118 & 0,1(female) & 00.60 & 00.49 \\
\hline Race & 6,980 & 0,1 (non-white) & 00.11 & 00.32 \\
\hline Income & 5,844 & $\begin{array}{l}1-6(\$<20 \mathrm{k}- \\
\$ 160 \mathrm{k}+)\end{array}$ & 03.23 & 01.48 \\
\hline Education & 7,031 & $\begin{array}{l}\text { 1-4(high school or } \\
\text { less - post-grad) }\end{array}$ & 02.28 & 01.06 \\
\hline Newcomer & 6,934 & 0,1 (yes) & 00.67 & 00.47 \\
\hline Own & 6,921 & 0,1 (own) & 00.84 & 00.37 \\
\hline Political Party & 6,405 & $\begin{array}{l}\text { 1-3(Democrat- } \\
\text { Republican) }\end{array}$ & 01.93 & 00.90 \\
\hline $\begin{array}{l}\text { Conservation Rules } \\
\text { Climate Change }\end{array}$ & 7,118 & 1-3(bad-good) & 02.10 & 00.76 \\
\hline Beliefs & 5,600 & $\begin{array}{l}\text { 1-4(don't know- } \\
\text { now/human) }\end{array}$ & 03.20 & 00.89 \\
\hline
\end{tabular}

The major individual-level background characteristics of interest in my research are respondents' income, education, whether or not respondents' were newcomers to their areas as adults, whether respondents' rent or own their home, their political party affiliation, their perceptions of the effects of conservation rules on their communities, and their beliefs about climate change (viewed in part as proxies for broader "environmentalist" values). Including income in statistical models reduces the number of observations significantly, but its incorporation was necessary for two reasons. First, it could be a salient predictor of extreme or unusual weather effects perceptions because higher incomes could be associated with increased ability to guard against some of the more damaging effects of extreme weather, if not completely buffer oneself due to the careful placement of high priced homes. Individuals who can afford to "weather the storm," so-to-speak, might have different views of extreme or unusual weather events which might be affecting nearby (and perhaps lower income) residents in very different ways. A second important reason to include income, despite its high frequency of missing 
values, is that it is useful for comparisons with previous research ${ }^{10}$. Given these circumstances, I dealt with missing values through multiple imputation, described in the following section.

Respondents' educational attainment is important as a potential predictor of extreme/unusual weather effects perceptions, but it has also been shown to interact with political party affiliation in affecting climate change and other environmental views across numerous studies (McCright and Dunlap 2011; Hamilton 2008; Hamilton, Cutler, and Schaefer 2012; Hamilton and Keim 2009; Hamilton, Colocousis, and Duncan 2010; Malka, Krosnick, and Langer 2009). I will test this interaction effect along with the main effects and other interactions of possible interest.

Prior research established the importance of education as an independent factor in environmental attitude research. Education also has salience in my research because higher education could be associated with the type of higher socioeconomic position that could insulate individuals from the most severe consequences of extreme/unusual weather events. On the other hand, higher education has been associated with higher levels of support for conserving resources and restricting development, suggesting that more education precipitates a heightened sensitivity to the environmental issues (Hamilton et al 2010). Education is a complex variable and has been demonstrated to operate through the prism of ideology in its influence on individual perceptions of environmental issues, so it seems undoubtedly important to include here as well. Owners versus renters and newcomers to the region versus lifetime residents could hold quite different views on the effects of extreme or unusual weather events. Homeowners may

\footnotetext{
${ }^{10}$ Hamilton et al (2010) addressed the issue of income and missing values by testing models with and without it included and determined that its inclusion did not "bias the conclusions either way," so they left it in the model for "comparability with previous studies."
} 
have more at stake in the case of extreme or unusual weather, especially lower income homeowners living in areas of relative deprivation. On the other hand, renters may experience fewer obligations to deal with or rebuild in the aftermath of extreme or unusual weather events. Conversely, renters may experience stress and frustration from the resultant disruption to their lives if they are forced to move in the aftermath of extreme weather events completely decimating their residences. These represent just a few good reasons for why owning versus renting is an analytically important variable to the explanation of extreme weather effects perceptions.

Similarly, length of residence, expressed in terms of whether or not respondents' migrated to their areas of residence as adults, could influence their relative perceptions of the kind of weather that is, or should be, considered "usual" or typical in their respective regions. Long-time and lifelong residents may be less sensitive to the impact of extreme weather because of their identification with predominant local attitudes about the abnormality or unpredictability of perennial weather patterns. For instance, lifelong residents may internalize the locally-based belief that their region has high variability in year-to-year and season-to-season weather, so an extreme or unusual weather event might conform to this dominant belief of the local social milieu. By contrast, newcomers to the region (people who migrated in as adults) may not be socialized into the local culture and as a result could view a severe weather event as actually unusual or particularly extreme given what they may be used to.

Perhaps the most analytically important individual-level variables in my research are those that represent "personal values:" political party identification, beliefs about the effects of conservation rules on local communities, and beliefs about climate change. While political party 
identification is more salient as a proxy for personal values, the connection of perceptions of conservation rules to personal values is not so easy to convey. One way to demonstrate this connection is through bivariate analyses. Figures 3.1 and 3.2 graph the relationship between political party identification and individuals' beliefs about conservation rules and climate change, respectively.

A majority of Democrats in the sample report conservation rules have been good where they live, whereas Republicans more often report conservation rules have been bad where they live as opposed to good. There is nearly an equal number reporting conservation rules have had no effect. This relationship between party and beliefs about conservation rules is significant and in the expected direction, namely that Democrats are more likely to support environmental conservation efforts than Republicans. These two variables, however, are certainly not measuring the same thing nor are they mapped on to each other perfectly. Fourteen percent of Democrats view conservation rules as bad where they live and twenty-four percent of Republicans view them as good.

Additionally, conservation rules could matter in different ways to residents of each of the regions in the sample, whereas party affiliation likely has a more consistent meaning across regional boundaries. Therefore, both were tested for their independent direct relationships with the dependent variable, as well as their interactions with other variables of interest. As we might expect, there's an even greater partisan divide on the issue of climate change (Figure 3.2). Sixtyseven percent of Democrats believe climate change is happening due mainly to human activities, whereas sixty percent of Republicans believe climate change is happening due to natural 
phenomena. There is hardly a more divisive issue politically than climate change and this sample only reinforces that truism.

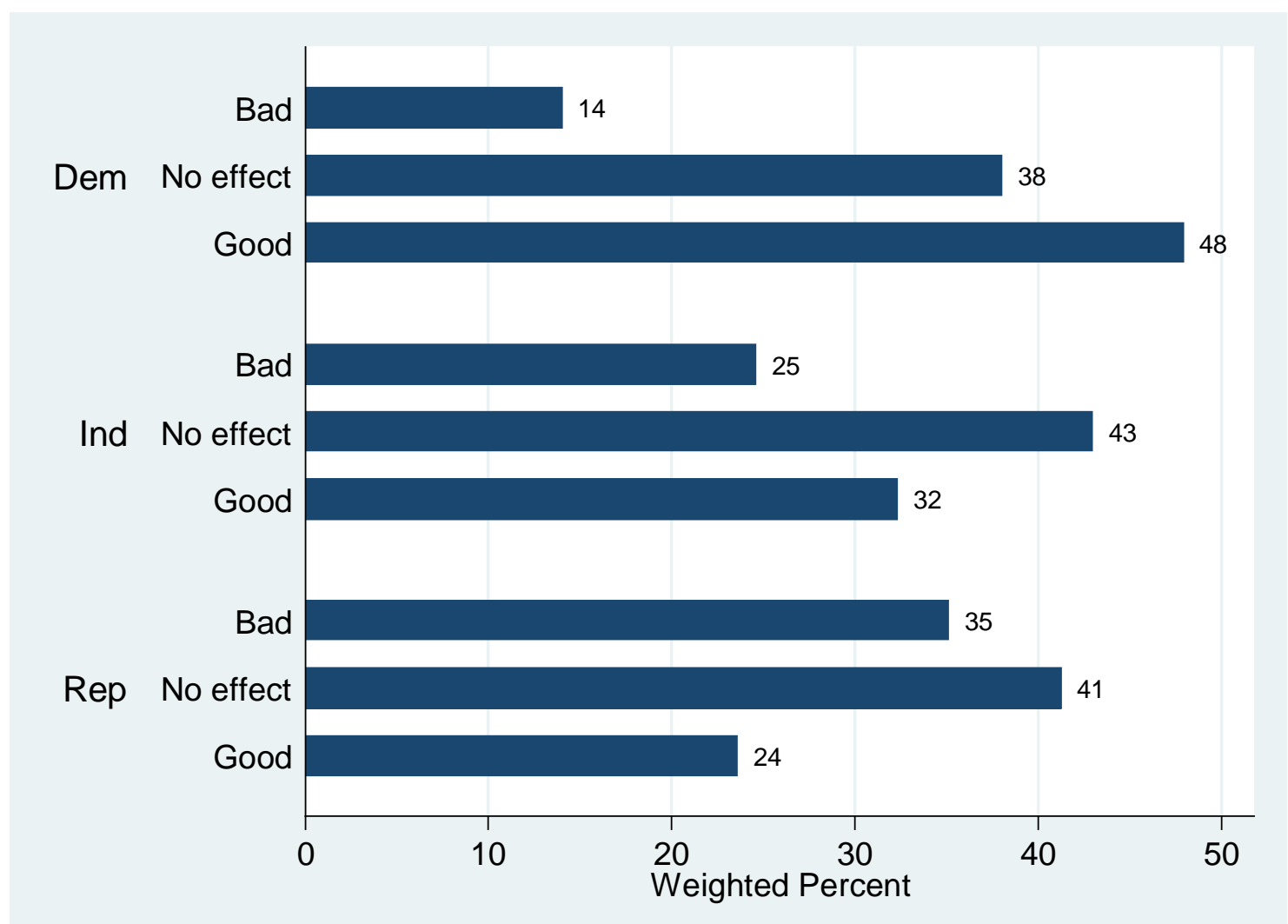

Figure 3.1: Weighted percent of respondents' beliefs about conservation rules, by political party (all regions combined) 


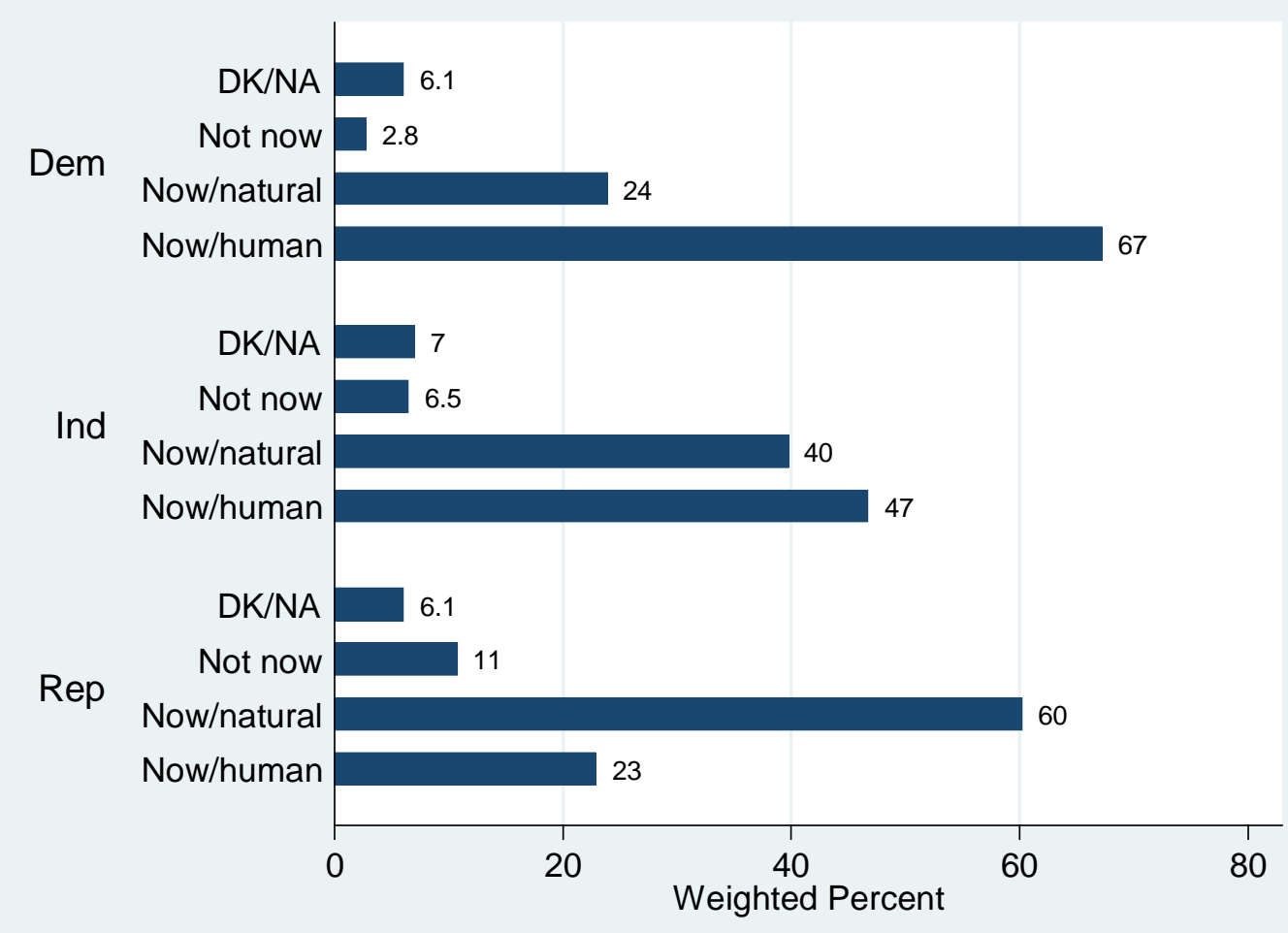

Figure 3.2: Weighted percent of respondents' beliefs about climate change, by political party (all regions combined)

\subsection{Extreme weather indicators}

\section{$\underline{\text { 3.2.1 Severe thunderstorms }}$}

In addition to the CERA coastal surveys, I will incorporate data on actual weather events from two archival sources. The first of these sources is the Storm Prediction Center's (SPC) Severe Thunderstorm Events Archive (STEA). According to its web page, the SPC's mission is 
to "provide timely and accurate forecasts and watches for severe thunderstorms and tornadoes over the contiguous United States," (http://www.spc.noaa.gov/faq/\#1.1). The SPC has archived significant severe weather events since January 3, 2000. The archive is accessed via a simple search engine at http://www.spc.noaa.gov/exper/archive/events/.

I selected severe thunderstorm events because the data can be compared cross-regionally. Some severe weather events are not amenable to this type of analysis, such as major snowstorms, because of their extremely low probability of happening in the Gulf Coast or similar southern and particularly warmer year-round climates. Droughts were also passed over for the similar reason that they were not prevalent in any of the areas under study over the course of the time period selected (droughts and other weather event types, however, are included in the property damage estimates described in the next section).

The SPC website's introduction to the STEA is keen to point out that; "Organized severe thunderstorm episodes can occur anywhere in the United States in any month of the year. The synoptic environments in which these storms develop can vary in many ways depending on region of the country and time of the year,"

(http://www.spc.noaa.gov/exper/archive/events/introduction.html). Clearly severe thunderstorm data is useful for my research, but it still presents some limitations worth pointing out. Although severe thunderstorms can occur anywhere and at any time, they are nonetheless quite variable depending upon the environment of the region in which they occur. As the SPC makes clear:

Climatologically most of the severe thunderstorm episodes in the United States occur in an area bound by the continental divide on the west side and a line approximately $1000-1200$ miles east of the continental divide on the east side. The part of the United States east of this high frequency area has a large number of severe thunderstorm episodes but not near the number in the high frequency area. The part of the United States west of the continental divide has an extremely low frequency of severe thunderstorms when compared to the high frequency area and the eastern area, (http://www.spc.noaa.gov/exper/archive/events/introduction.html). 
Event selection by the SPC is highly structured. The SPC uses guidelines ${ }^{11}$ for event day selection and they differ depending on whether the storms occurred either east or west of the Rocky Mountains. Selection of events for inclusion may vary a little from the "strict definition" of severe thunderstorms: "A severe thunderstorm is a thunderstorm which produces hail 3/4 inch, and/or damaging winds or wind 50 knots, and or a tornado," (http://www.spc.noaa.gov/exper/archive/events/introduction.html). From these data, I constructed a variable for the frequency of severe thunderstorm events at the county-level over the 5 years preceding the date of the survey interview. This variable's construction and usage will be detailed more in the following section.

The STEA archives thunderstorm events which include severe winds, hail, and tornados. Event frequencies for each county were tabulated from the archived data on events that occurred over the course of the 5 years preceding the date of the survey. These county-level tabulations were then aggregated into regional-level totals and log-transformed to deal with skew prior to analyses. The pre-logged and log base 10 totals at the regional-level are presented in Table 3.4. While potentially useful for predicting perceptions of individuals in regions that experience many thunderstorms, these data are likely less useful in regions where relatively few thunderstorms occur, such as Southeast Alaska (Table 3.4). Therefore, this measure of weather conditions is hindered by its inability to take into account the actual event types which most frequently affect certain regions in the sample. Moreover, this measure does not take into account the magnitude of these thunderstorms as it is only a frequency of events. The severity of

\footnotetext{
${ }^{11}$ Event day selection guidelines are given in Appendix A.
} 
thunderstorms in Louisiana, for example, could be markedly different than those occurring in other regions represented in the sample. This thunderstorm event total has some serious limitations worth keeping in mind during the discussion of findings from analyses.

Table 3.4. Extreme Weather Indicators

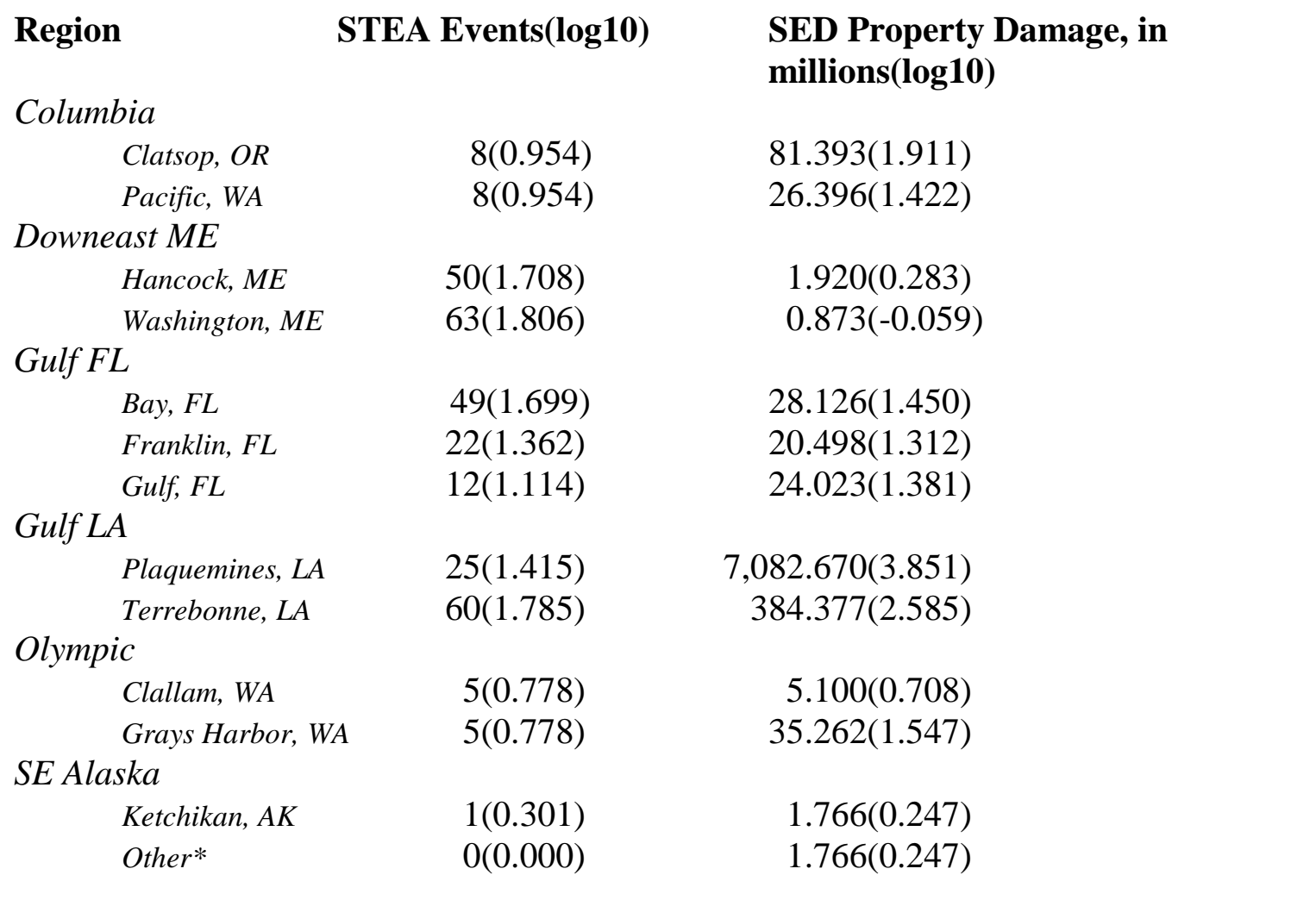

*Haines Borough, AK; Hoonah-Angoon CA, AK; Juneau Borough, AK; Petersburg CA, AK; Prince of Wales, AK; Sitka Borough, AK; Skagway Borough, AK; Wrangell Borough, AK; Yakutat Borough, AK

Given the flaws inherent in the thunderstorm event measure, I complimented it through the use of property damage data from another national severe storm events reporting archive described in depth below. Property damage estimates are useful for two reasons: (1) It adds another measure of severe weather event impact which can add to the overall validity of the 
county-level weather dataset used in this study, especially since this damage measure includes impacts from virtually all event types, and (2) property damage adds an element that gets at the actual impact of severe weather events on communities and their members' built environments. Much of the prior research on coastal storms has focused on frequency and intensity (or magnitude) of storms (Vose et al 2014), but there is no scale for intensity of severe thunderstorms in the same manner scales are used to measure the intensity of tornadoes and winter or tropical storms.

Prior research has demonstrated the usefulness of direct property damage as a measure of the human impact of natural hazards. Kevin Ash and colleagues (2014) recently studied regional impacts of natural hazards utilizing data on property losses due to severe thunderstorm hazards, tropical cyclones, and coastal and freshwater flooding. They included a place-based statistical comparison of hazard losses by creating "relative loss ratios" based on an estimate of countylevel gross domestic product as a proxy for county wealth (Ash et al 2014). According to Ash and colleagues, impacts from hazards are well construed in terms of property losses because state and federal disaster relief funds are increasingly prioritized for communities experiencing the greatest financial burdens from natural disasters (2014).

\subsubsection{Property damage from all storm events}

The Storm Events Database (SED) is maintained by the National Oceanic and Atmospheric Administration's (NOAA) National Climatic Data Center (NCDC). The NCDC receives its data on storms from the National Weather Service (NWS) on a continuing and regular basis and the NWS receives its storm reports from "a variety of sources, which include 
but are not limited to: county, state, and federal emergency management officials, local law enforcement officials, skywarn spotters, NWS damage surveys, newspaper clipping services, the insurance industry and the general public," (https://www.ncdc.noaa.gov/stormevents/faq.jsp).

The accuracy of this data is addressed in this disclaimer provided on the NCDC's website:

\begin{abstract}
Storm Data is an official publication of the National Oceanic and Atmospheric Administration (NOAA) which documents the occurrence of storms and other significant weather phenomena having sufficient intensity to cause loss of life, injuries, significant property damage, and/or disruption to commerce. In addition, it is a partial record of other significant meteorological events, such as record maximum or minimum temperatures or precipitation that occurs in connection with another event. Some information appearing in Storm Data may be provided by or gathered from sources outside the National Weather Service (NWS), such as the media, law enforcement and/or other government agencies, private companies, individuals, etc. An effort is made to use the best available information but because of time and resource constraints, information from these sources may be unverified by the NWS. Therefore, when using information from Storm Data, customers should be cautious as the NWS does not guarantee the accuracy or validity of the information. Further, when it is apparent information appearing in Storm Data originated from a source outside the NWS (frequently credit is provided), Storm Data customers requiring additional information should contact that source directly. In most cases, NWS employees will not have the knowledge to respond to such requests. In cases of legal proceedings, Federal regulations generally prohibit NWS employees from appearing as witnesses in litigation not involving the United States, (https://www.ncdc.noaa.gov/stormevents/faq.jsp).
\end{abstract}

Although the accuracy or validity of data is not guaranteed by the NWS, the variety of sources tapped to derive this information lends it a degree of credibility. Nevertheless, I utilized a second weather events database in order to try to maximize the reliability and validity of the weather data used in this study. Keeping validity and reliability concerns in view, these data are extremely useful as a source to construct a basic measure of property damage from severe weather events at the level of the county. The data are searchable via the online search tool at https://www.ncdc.noaa.gov/stormevents/. Users can filter by date down to the day, beginning in 1996 and through to the most recent update. For each storm event reported in the Storm Events Database, information is given on the location of the event, the county or zone it took place 
within, the state, the exact date, the local time and time zone, the event type, the magnitude of the event (where applicable), the number of direct human deaths resulting from the event, the number of direct human injuries resulting from the event, the estimated property damage total (in US dollars), and the estimated crop damage total (in US dollars).

The SED property damage estimates variable is a continuous indicator of property damage from all county-based (floods, hail, heavy rain, winds, and tornadoes) and zone-based storm events (astronomical low tide, avalanche, blizzard, coastal flood, cold/wind chill, dense fog, drought, excessive heat, hurricane, ice storm, lakeshore flood, storm surge/tide, tropical storm, tsunami, and volcanic ash) in U.S. dollars. This variable was also log-transformed to deal with its skew. The pre-logged values for each county are given in Table 3.3. The Gulf Coast region, including both Louisiana and Florida, was the hardest hit over this 5-year span when considering both events and damage. All of the major hurricanes, including Hurricane Katrina, are included in these variables. Even without the hurricane season of 2005, however, the Gulf Coast region would still have the highest totals in property damage from severe weather events. Downeast Maine also had a relatively high number of events, but the total property damage in the region is a small fraction of the totals in the Gulf. The Pacific Northwest had few reported events, but relatively moderate property damage totals. Southeast Alaska experienced the least damage and events according to these data. Given the high variability between events and damage totals, it seems appropriate to have both indicators in order to capture a fuller picture of the severe weather experienced in these regions over the 5-year period under study. Additionally, much of the current research on impacts from environmental disasters is utilizing measures of direct property losses in order to estimate the impacts on communities and local economies (Ash 
et al 2014). As demonstrated in the preceding sub-sections, there are multiple good reasons to justify the inclusion of both storm event frequency and property damage.

\section{$\underline{3.3 \text { County characteristics }}$}

The American Community Survey (ACS) is an ongoing yearly data collection effort conducted by the United States Census Bureau. Starting in 2010, the decennial census transitioned to the sole use of short-form surveys asking only a handful of basic demographic questions. In-depth household and individual information, such as education, income, and other

detailed socioeconomic information, has been reassigned entirely to the ACS for collection. As opposed to a full count, the ACS is a random sample survey sent to only a small percentage of households in the United States. It is nevertheless a useful tool for researchers, especially those conducting cross-regional comparisons, because it provides timely, uniform data on a host of important socioeconomic characteristics (U.S. Census Bureau, 2009).

I utilized the 2010 5-year estimates of the county poverty rate collected by the ACS. These data are particularly useful to my research because of the 5-year frame, as the dependent variable asked respondents to report weather effects in their area within a 5-year span just prior to the survey administration. Specifically, I incorporated the percent of all people in poverty at the county-level over the course of 2006 through 2010 (Table 3.5). 
Table 3.5. Socioeconomic Context (Poverty) Indicator

\begin{tabular}{|c|c|c|c|}
\hline $\begin{array}{l}\text { Region } \\
\text { Columbia }\end{array}$ & $\%$ in poverty & $\begin{array}{l}\text { Region } \\
\text { Southeast Alaska }\end{array}$ & $\%$ in poverty \\
\hline Clatsop, $O R$ & 12.8 & Juneau, $A K$ & 6.5 \\
\hline Pacific, WA & 16.8 & Ketchikan, $A K$ & 8.3 \\
\hline Downeast Maine & & Petersburg, $A K$ & 9.7 \\
\hline Hancock, $M E$ & 11.5 & Prince of Wales, $A K$ & 14.0 \\
\hline Washington, $M E$ & 19.8 & Sitka Borough, AK & 7.0 \\
\hline Gulf FL & & Skagway, $A K$ & 10.8 \\
\hline Bay, $F L$ & 12.4 & Wrangell, AK & 8.3 \\
\hline Franklin, FL & 25.6 & Yakutat, $A K$ & 4.3 \\
\hline Gulf, FL & 19.5 & & \\
\hline \multicolumn{4}{|l|}{ Gulf LA } \\
\hline Plaquemines, $L A$ & 11.6 & & \\
\hline Terrebonne, LA & 17.4 & & \\
\hline \multicolumn{4}{|l|}{ Olympic } \\
\hline Clallam, WA & 14.3 & & \\
\hline Grays Harbor, WA & 16.1 & & \\
\hline \multicolumn{4}{|l|}{ Southeast Alaska } \\
\hline Haines Borough, $A K$ & 7.2 & & \\
\hline Hoonah-Angoon, AK & 15.9 & & \\
\hline
\end{tabular}

County poverty is analytically important for a number of reasons. First, the county poverty rate is likely to be an accurate indicator of the available tax base, which is typically linked to the institutional and infrastructural development of communities. Communities with more wealthy and high income residents logically have more resources to withstand the impact or rebuild in the aftermath of major storm events than communities with higher poverty and thus fewer high earning, wealthy households to draw revenue from. County poverty may also indicate the kind of social milieu related to either economic distress or relative comfort. In counties with particularly high poverty, other indicators of economic deprivation may be present, such as high unemployment. These factors could be suggestive of the relative resilience of communities following the occurrence, and perhaps persistence, of severe weather events. 
Since the CERA coastal surveys interviewed respondents in living in metropolitan and micropolitan statistical areas, I constructed a dichotomous indicator of metropolitan and micropolitan or rural residence from the 2010 U.S. Census designations. This (sub)urban-rural distinction may prove important in analyses for a variety of reasons. Urban versus rural residents have been shown to hold varying views on environmental issues in prior research (Dunlap and Van Liere 1984; Freudenburg 1991; Mohai and Twight 1987; Lowe and Pinhey 1982). Beyond the prior literature, however, it seems logically coherent to expect differing perceptions specifically about extreme/unusual weather between urban/suburban and rural residents due to the differences in institutional and infrastructural capacities to protect against and respond to disasters. For instance, rural residents may have to wait longer than (sub)urban residents to have their power restored after severe weather events knock out electrical lines.

\subsection{Analytical Methods}

\subsubsection{Regional differences in weather perceptions}

Bivariate statistical analyses revealed interesting place-based variation in perceptions of extreme or unusual weather events (Figure 3.3). Interestingly, residents of Gulf Coast Louisiana and Florida reported very different levels of effects on their community or family over the 5 years preceding the date of the survey. Almost half of respondents in Louisiana reported "major effects," whereas only about twenty percent of Floridians reported the same experiences. Both Gulf Coast Louisiana and Florida had a high number of severe events, but Louisiana had 
markedly higher property damage as a result of weather events. That being said, Florida did sustain high property damage compared to the other regions. Similarly to the Floridian responses, Downeast Maine residents reported relatively low effects while the region had the highest number of severe thunderstorm events of all regions sampled. It seems apparent that the characteristics of these places and the respondents who live there matter to the formation of their effects perceptions over and above the actual incidence of weather events themselves (see Figures 4.1, 4.2, and 4.6).
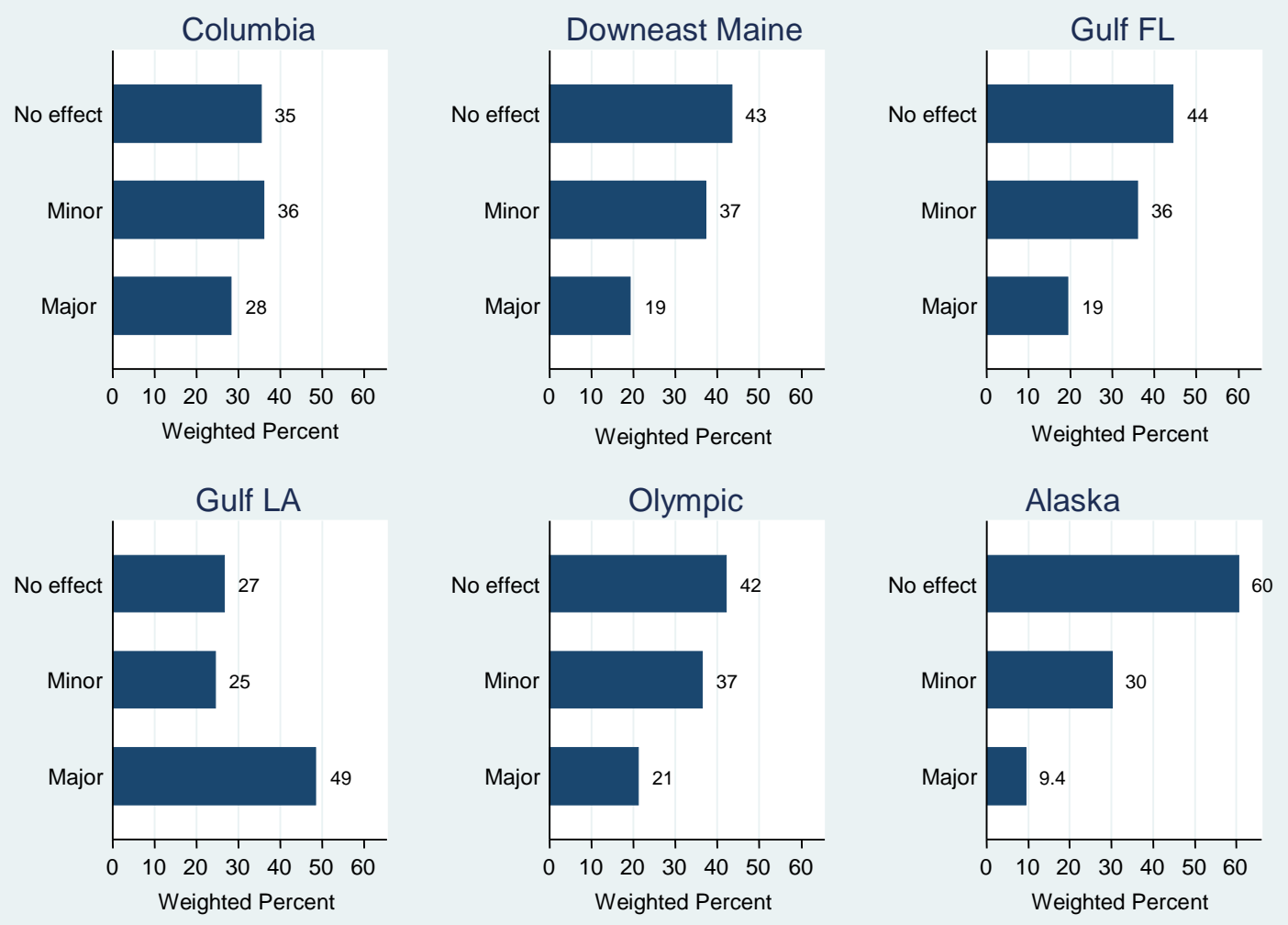

Figure 3.3: Weighted percent of respondents reporting "no effect," "minor effects," or "major effects" of extreme or unusual weather events by region. 


\section{$\underline{\text { 3.4.2 Mixed-effects modeling }}$}

Both individual and place effects can be modeled together using the advanced statistical technique of mixed effects modeling. As opposed to single-level models which assume effects remain the same across units, mixed effects models are multi-level and thus can "capture heterogeneity across units" by "allowing for random variation in intercepts or slopes," (Hamilton et al 2010). Also, as previous authors have pointed out, the errors of observations within single units are likely correlated (Hamilton et al 2010; Luke 2004). Therefore, I utilized a mixed effects model with a random intercept for county clusters in the data. Random intercepts thus allow for place-to-place differences in perceptions that are not explained by other individual characteristics, county characteristics, or weather variables explicitly in the model.

Beyond the practical advantages over single-level models, a mixed-effects modeling technique can help to address the conceptual and theoretical considerations of the present study. Significant county-level variation, net of individual- and county-level characteristics, can represent shared meanings arising from the local circumstances particular to the CERA survey regions and the counties that make them up. Perceptions of extreme weather events are likely "shared" and "emplaced" in much the same way beliefs about conservation or urban sprawl have been shown to be (Hamilton et al 2010). It is my contention that the conceptual frame of emergence can explain how extreme weather perceptions can vary so significantly from place-toplace even after controlling for a variety individually- and place-based characteristics.

Prior studies in this area have not construed environmental attitudes, beliefs, or perceptions as emergent properties, but research looking at neighborhood-level variation in collective efficacy has applied emergence in order to explain how moral cynicism, altruism, and 
perceptions of disorder are shared properties arising from social-interactional and institutional processes at the level of the neighborhood (Sampson 2012). A significant contribution of my research is that weather perceptions, much like perceptions of neighborhood disorder, likely arise from the ground up through shared local contexts. Mixed effects modeling illuminated the existence of place-specific contexts such as these.

Binary logistic regression was chosen after multiple tests were conducted using a variety of other regression techniques. The three response categories, namely "no effect," "minor effects,” and “major effects,” were determined to be best construed as a dichotomous indicator of either "no effect” or "effects” because no significant or theoretically interesting differences arose from tests between “major” and "minor" effects ${ }^{12}$. This suggests that my analyses are sufficiently robust to draw conclusions from. In addition to the aforementioned qualities, findings from binary logistic regression are easier to explain than ordered logistic output (Hamilton et al 2010).

\section{$\underline{\text { 3.4.3 Multiple imputation of missing values }}$}

The problem of missing cases is commonplace in survey research, but the manner of dealing with it can vary depending upon the analytical circumstances. In this case, the individuallevel income measure from the CERA surveys brings with it a sizeable number of missing observations. As an item on surveys, personal (or family) income is often problematic due to the sensitive nature of disclosing such information. Many survey respondents decline to answer and

\footnotetext{
${ }^{12}$ In addition to binary logistic regression, multinomial and ordered logistic models were tested to be certain that the dependent variable is best construed as a dichotomous indicator. The response categories of "major" and "minor" effects demonstrated similar relationships to the "no effect" response category and only property damage was predictive of significant variation between those who reported “major" versus "minor" effects. A unit increase in the log-transformed property damage variable corresponded to a 35\% increase in the odds of reporting major versus minor effects of extreme or unusual weather.
} 
as a result the income item is often placed towards the end of surveys to ensure that respondents remain willing to answer the more important questions to the principal investigators who design the surveys. The CERA surveys were no exception to this general rule of thumb in survey research. Information about respondents' incomes was requested near the end of every CERA coastal survey utilized in this research. As to be expected, nearly 1,400 respondents did not answer the items associated with personal and family income.

One method for dealing with missing values is to drop the unimportant variables that reduce observations, but individual-level income is important to retain for a couple reasons. First, prior studies on environmental attitudes, beliefs, and perceptions have utilized income, so I will make every effort to include it for the simple purpose of comparability. Additionally, and perhaps more importantly, individuals' income levels likely correspond to their relative abilities to avoid, withstand, or endure the most destructive effects of extreme or unusual weather events. For instance, a high-income family could afford to live in a development insulated from floods due to factors related to decisions made by contractors to position the development on elevated territory or in places not prone to damaging weather events. Even in the case of an expensive home positioned in an untenable spot, however, the high-income earning residents would be better able to afford costly repairs than low-income families living in lower cost housing. Therefore, in the case extreme weather and relative to prior research on environmental beliefs, income will be included in my final analyses and conclusions.

In order to preserve income in the models while ensuring stability of findings, I will incorporate multiple imputation (MI). MI is a statistical technique that predicts a subsample of values for missing data based on present values from other variables. Predicted values are filled 
in for missing data, or "imputed," and this process is repeated multiple times in order to reproduce the variability associated with missing values and the uncertainty involved in estimating predicted values. As Wayman pointed out, MI is not guessing or making up data, but instead is a method for delivering analyses which make use of all available information (2003). This procedure is preferred over simply deleting cases because case-deletion can lead to biased results if data are not missing entirely at random. In the example of income discussed above, there are sufficient reasons to believe self-reported income data are not completely missing at random. Using the MI technique, I compared imputed and non-imputed models in order to be certain that missing values do not bias the results of the non-imputed models. If the non-imputed and imputed models show the essentially the same results, I can be confident my results are not biased by missing data on income, which could reasonably be a concern given that my dependent variable deals with effects from damaging weather events. Appendix B contains detailed statistical analysis including the regression and MI tables.

Some critics of MI techniques have argued that even when it is properly applied, MI is “highly inefficient,” (Nielsen 2003). As the "father of MI,” Donald Rubin, points out, MI is "potentially inefficient” if the "complete-data analysis is inefficient," but little evidence has been provided to support the notion that MI is extraordinarily inefficient compared to the imperfections of most other applied statistics (Rubin 2003). Moreover, the use of MI can only be valid if the user's procedure isn’t entirely arbitrary (Rubin 2003). In other words, the implicit assumption of $\mathrm{MI}$ is that the multiple imputations are "only correcting for missing data, and not attempting the impossible task of correcting for flaws in all subsequent complete-data analyses,” (Rubin 2003). In my case, the procedure is not at all arbitrary given the nature of the income 
variable and its relevance to the dependent variable. Also, I am only interested in the possibility of missing data biasing my results, thus I am only using MI as a method for estimating this possibility, as Rubin prescribes. Put another way, I am not concerned with whether or not to impute, but rather with what the comparison of imputed and non-imputed models tells me about the robustness of my results. 
CHAPTER IV

RESEARCH FINDINGS

\subsection{Bivariate Analysis}

In this section I use descriptive statistics to characterize the variable distributions, and bivariate analyses to explore simple correlations. Some of these may turn out to be spurious correlations between two variables that are explained by some third, unincorporated factor. Therefore, I return to these hypotheses in section 4.2 with more rigorous tests using multivariate models, testing each relationship while statistically controlling for other, possibly confounding factors. 


\subsubsection{Hypothesis H1}

Impact and frequency of severe weather events, objectively measured by the 5-year, county-level total of severe weather events and property damage in dollars, will influence subjective individual perceptions of extreme or unusual weather events.

Objective material conditions were significantly related to perceptions of extreme or unusual weather events. The log-transformed, 5-year property damage estimates were positively associated with extreme weather perceptions. Respondents living in areas with higher property damage totals were more likely to report that extreme or unusual weather events had either minor or major effects on their communities than those who live in areas with fewer total dollars in property damage (Figure 4.1). The 5-year severe thunderstorm events total, however, was only weakly associated with extreme weather perceptions (Figure 4.2). This distinction between thunderstorm events and overall property damage highlights important conceptual and analytical issues related to research of this kind. First, property damage appears to be a more useful contextual variable than the sum of weather events, with the added caveat that this research only considered the number of thunderstorm events in coastal areas, not the intensity or magnitude, and the property damage estimates included a wider variety of weather event types. Second, property damage appears to be a more salient measure of human impacts from extreme or unusual weather than the basic tabulation of the number of events in a given area. That being said, property damage in dollars might be experienced differently depending upon levels of individual or county wealth and income. Therefore, it will be important to consider social position and socioeconomic context, in this case using the measures of county poverty rates and individual-level incomes. 
A few interesting takeaways arise from the comparison of Figures 4.1 and 4.2. First, respondents in Gulf Coast Florida were somewhat anomalous in their perceptions of extreme weather relative to respondents in other areas of the sample. Gulf Coast Florida sustained relatively moderate property damage and had the third most severe thunderstorm events, yet respondents to that survey were slightly less likely to report effects than those to the Columbia, Olympic and Downeast Maine surveys, and much less likely to report effects than their coastal neighbors from the Gulf Coast Louisiana survey. Also, property damage helps to explain the relatively high level of effects perceptions among respondents to the Columbia and Olympic surveys. According to Figure 4.2, it would appear that residents in the Columbia and Olympic Peninsula coastal regions perceived effects from relatively very few thunderstorm events, but an inspection of Figure 4.1 reveals that the severe weather events which did occur in those areas, including major snow and other types of events, were quite impactful on the regions' built environments. This suggests that it is not just the number of extreme or unusual weather events, but also the relative damage inflicted by the events that matter to the formation of individuals' perceptions of such events. Additionally, thunderstorms are only one kind of problem, whereas "extreme weather" encompasses other events in places like the Pacific Northwest where thunderstorms are rare compared with the Gulf Coast. 


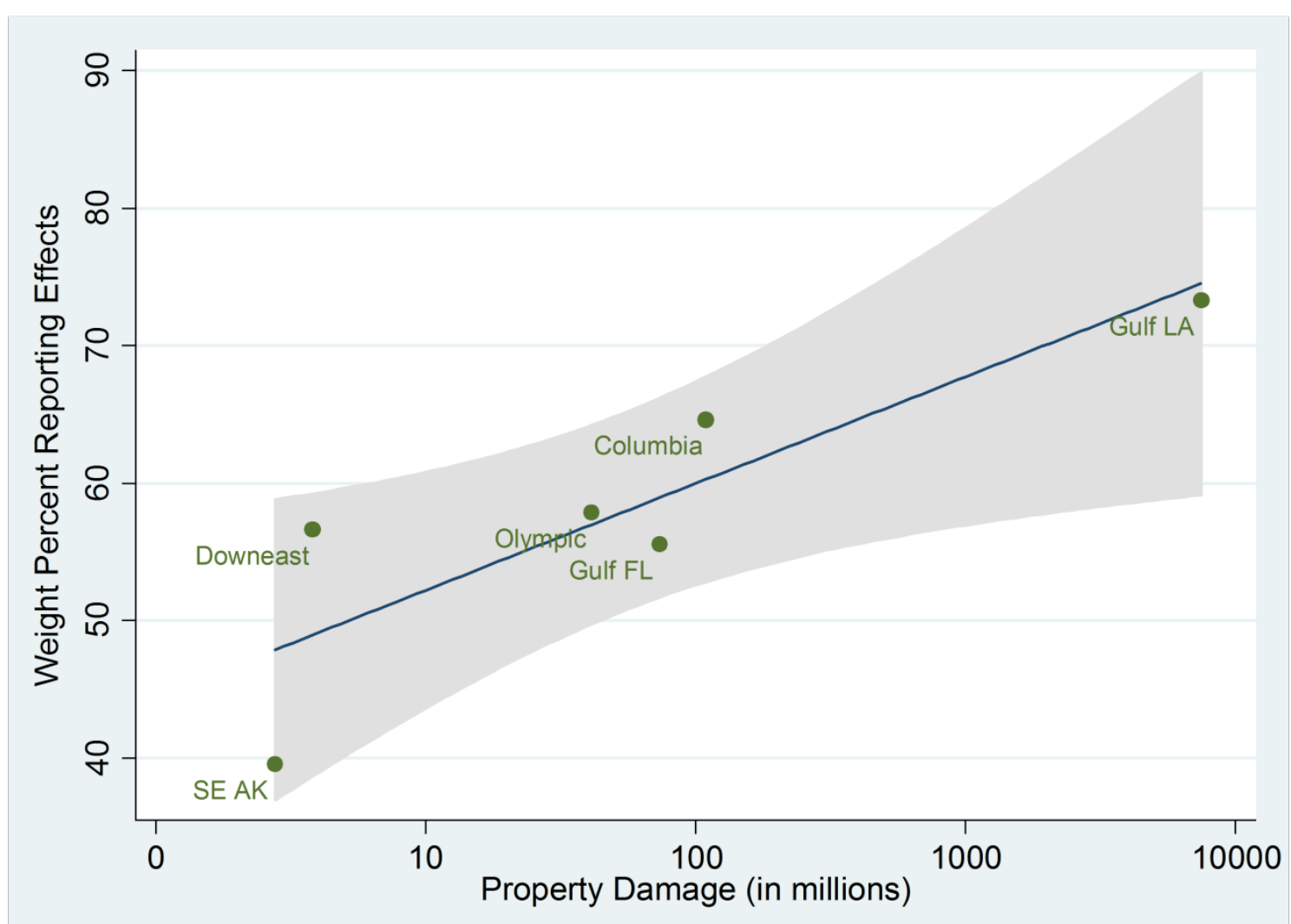

Figure 4.1: Weighted percent of respondents reporting "minor/major effects" of extreme/unusual weather vs 5-year property damage estimates from severe weather events (log scaled). ${ }^{13}$

${ }^{13}$ The property damage/weather perception relationship remained significant and in the same direction without the Gulf Coast Louisiana sub-sample, confirming that Gulf LA did not bias this result as an outlier on the property damage indicator. 


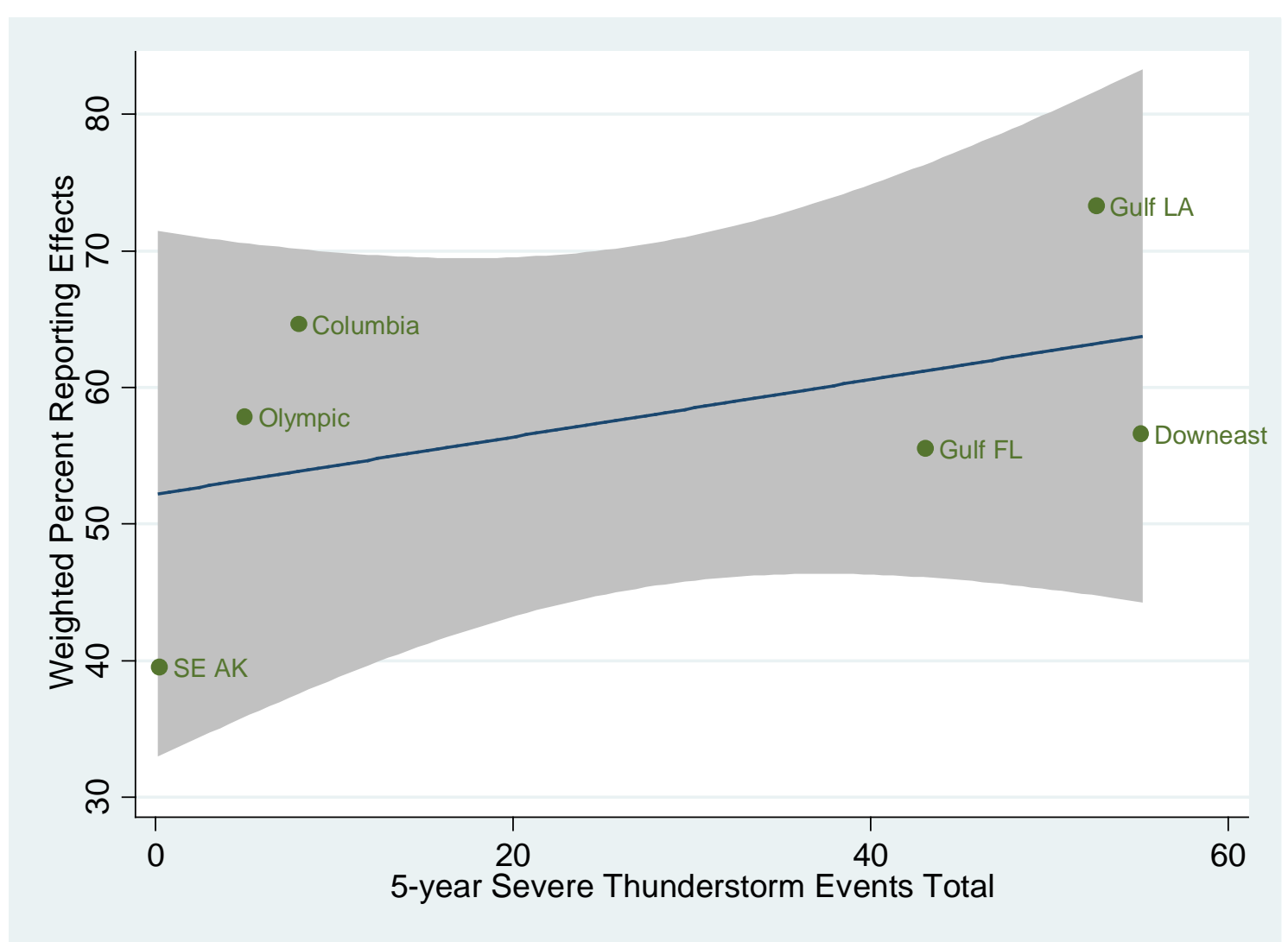

Figure 4.2: Weighted percent of respondents reporting "major/minor effects" from extreme/unusual weather events vs total number of severe thunderstorm events.

\subsubsection{Hypothesis $\mathrm{H} 2$}

Values, as measured by political identity, beliefs about the effects of conservation rules, and beliefs about climate change, also influence perceptions of extreme or unusual weather events.

Figure 4.3 charts the weighted percentages for perceptions about unusual or extreme weather, broken down by respondents’ political party. Political affiliation was significantly related to weather effects perceptions. Fifty-one percent of self-identified Republicans reported "no effects" of extreme or unusual weather events, whereas thirty-five percent of self-identified Democrats reported the same (Figure 4.3). This finding is consistent with prior research on the relationship between political party affiliation and environmental concern regarding both general 
issues (Van Liere and Dunlap 1980; McCright and Dunlap 2010) and local (Hamilton et al 2010; Hamilton and Stampone 2013; Hamilton and Safford 2014). My analysis extends earlier findings by showing evidence of ideological effects on perceptions of extreme or unusual events. It suggests that ideology powerful enough to affect how individuals perceive objective and substantial natural events.

Extreme or unusual weather perceptions were also found to be significantly related to respondents' personal beliefs about the issue of climate change. Those who believed climate change is not happening now or is happening now due to natural causes were more likely to say extreme or unusual weather events have had no effect than those who believed climate change is happening now and is due to human activity (Figure 4.4). This finding particularly interesting given the rich literature that has shown a relationship between political identity and a wide range of other climate change beliefs (Hamilton 2008; Hamilton et al 2012; McCright and Dunlap 2010; Hamilton and Keim 2009; Hamilton 2011; Malka et al 2009; Leiserowitz 2006) because it suggests that what individuals believe about the environment can substantially influence how they actually perceive major events in the environment, such as extreme or unusual weather.

One important caveat to the party measure is that it may mask the presence of ideological fringes within the sample, which may influence the divisions we are seeing along party lines. For example, the Tea Party movement often represents the ideological fringe within the Republican Party on many social, economic, and environmental issues. If a sizable number of Republicans in my sample were Tea Party Republicans, there may be significant variance among Republicans to the extent that moderate Republicans view extreme weather differently than their Tea Party contemporaries. Recent research has shown evidence that non-Tea Party Republicans are closer to Independents on science and environmental issues than their Tea Party comrades (Hamilton 
and Saito 2014). On the other hand, fringe leftist Democrats may also be masked within the broad category of Democrat in my party measure. Their weather perceptions may be more heavily influenced by their beliefs about environmental issues than more moderate Democrats, especially with respect to climate change.

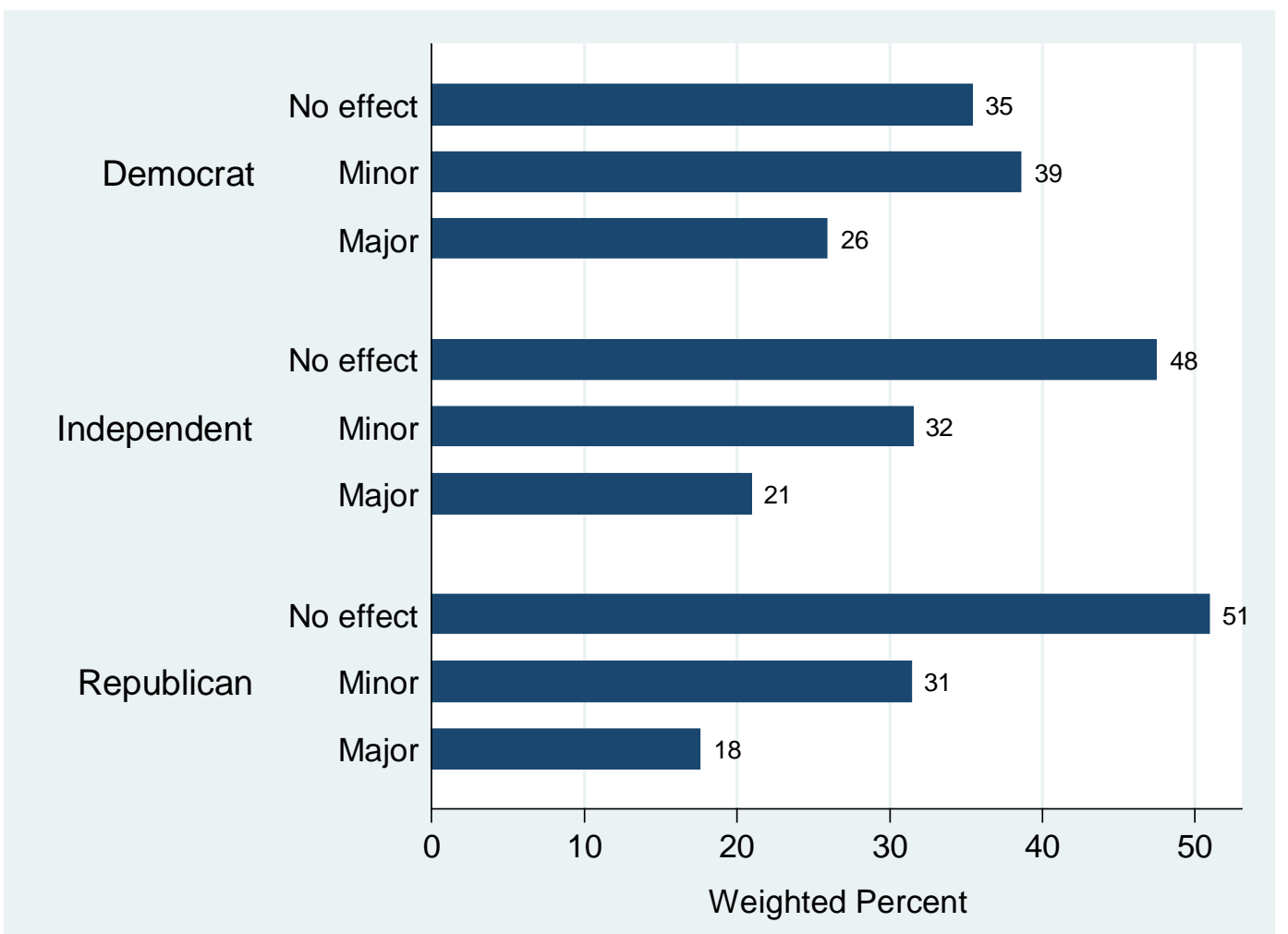

Figure 4.3: Weighted percent of survey respondents' 'extreme or unusual weather effects perceptions,' by political party affiliation (all regions combined). 


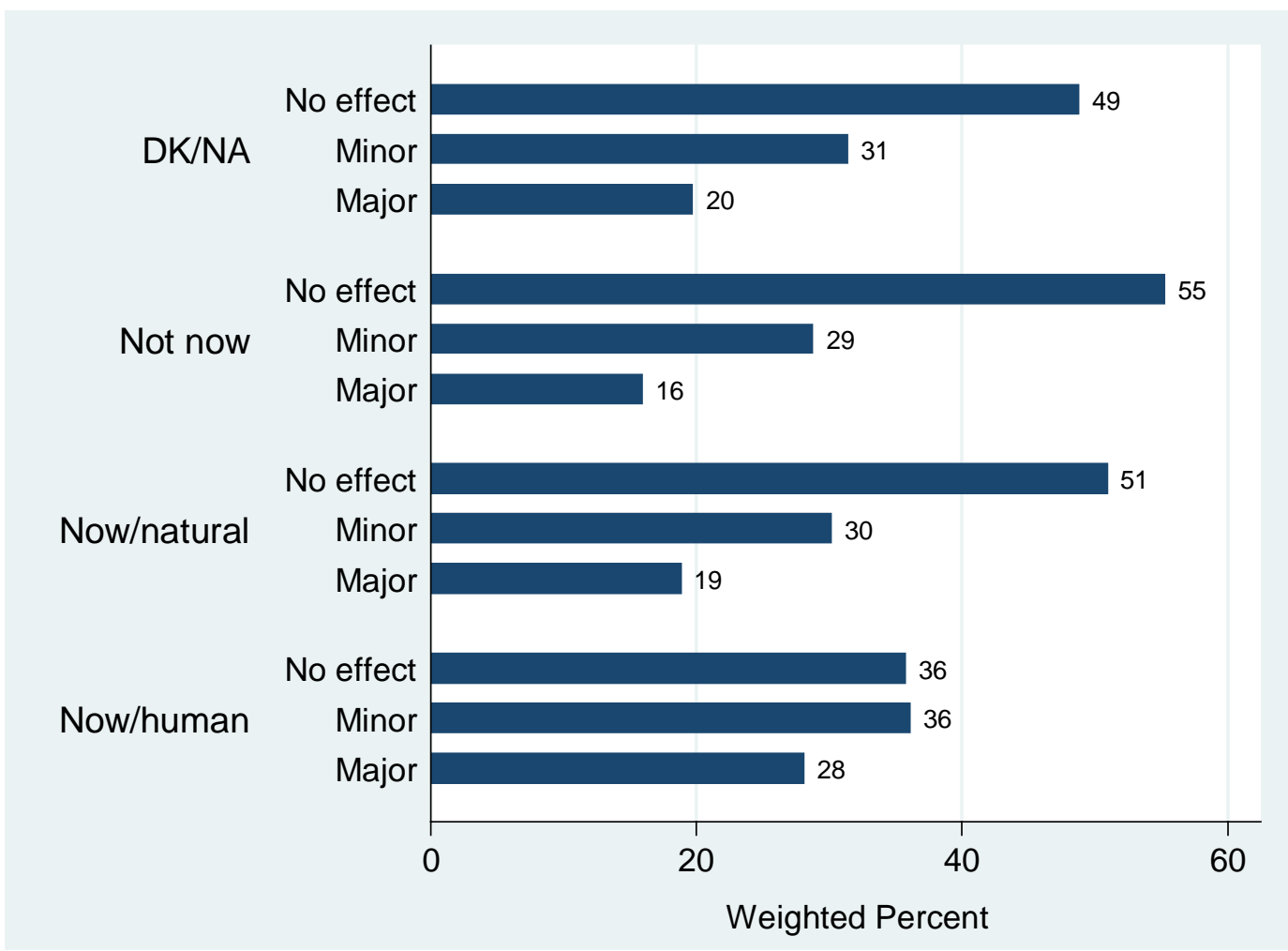

Figure 4.4: Weighted percent of respondents' 'extreme/unusual weather effects perceptions,' by beliefs about climate change (all regions combined).

\subsubsection{Hypothesis $\mathrm{H3}$}

Social privilege or position indicators (such as household income) and socioeconomic context (such as county poverty rates) affect perceptions about extreme or unusual weather events.

Individual-level socioeconomic position and socioeconomic context were hypothesized to affect perceptions about extreme or unusual weather events. In bivariate analysis, both household income and county level poverty rates were significantly related to respondents' perceptions about the effects of extreme or unusual weather on their families or communities. Figure 4.5 demonstrates the relationship between respondents' household incomes and percent responding extreme or unusual weather events had effects on their families or communities over the five 
years preceding the survey. Only half of individuals living in households earning $\$ 160,000$ per year reported effects, as compared to $61 \%$ of those in households earning less than $\$ 20,000$ per year. As household income decreases, the likelihood of individuals reporting effects from extreme or unusual weather increases. Even individuals in households earning between $\$ 90,000$ and $\$ 160,000$ were more likely to report effects from extreme or unusual weather than those in households earning more than $\$ 160,000$ per year.

Socioeconomic context was also hypothesized to have an influence on individual perceptions of the effects of extreme or unusual weather events. County poverty, as measured by the ACS 5-year estimate, was significantly predictive of individual level perceptions of extreme or unusual weather. Figure 4.6 charts the relationship between county poverty rates and survey respondents' perceptions of the effects of extreme or unusual weather events. The general trend reveals that individuals were more likely to report effects from extreme or unusual weather events in counties that had higher poverty rates. Several counties were outside of the confidence interval, suggesting that other local factors influenced individual perceptions in those particular places. For example, Plaquemines Parish, Louisiana, was much harder hit by severe storm events than other counties surveyed, thus respondents there were more likely to report effects than respondents from counties in other regions with similar county poverty levels. 


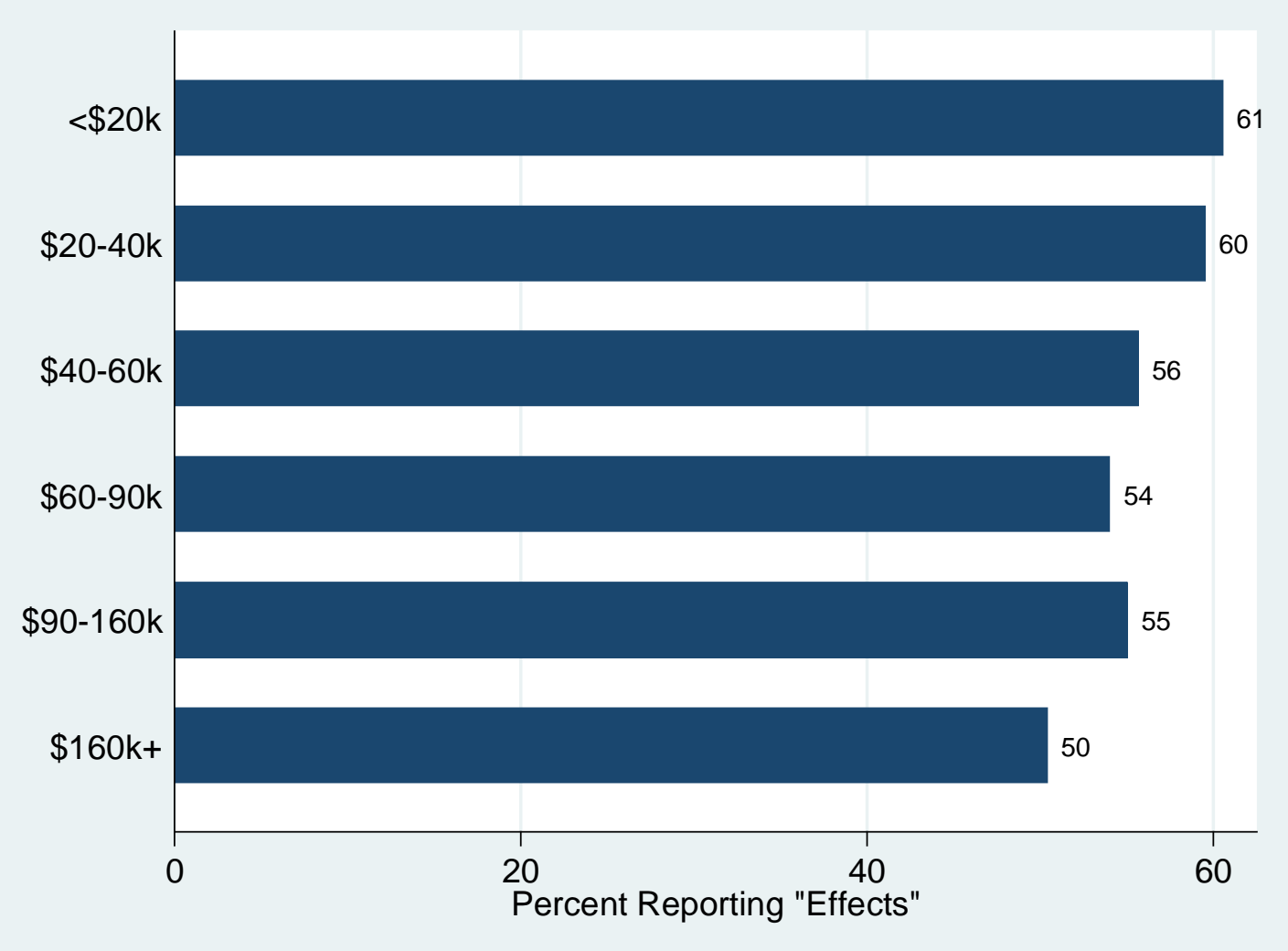

Figure 4.5: Weighted percent of survey respondents' 'extreme/unusual weather effects' perceptions by household income (all regions included) 


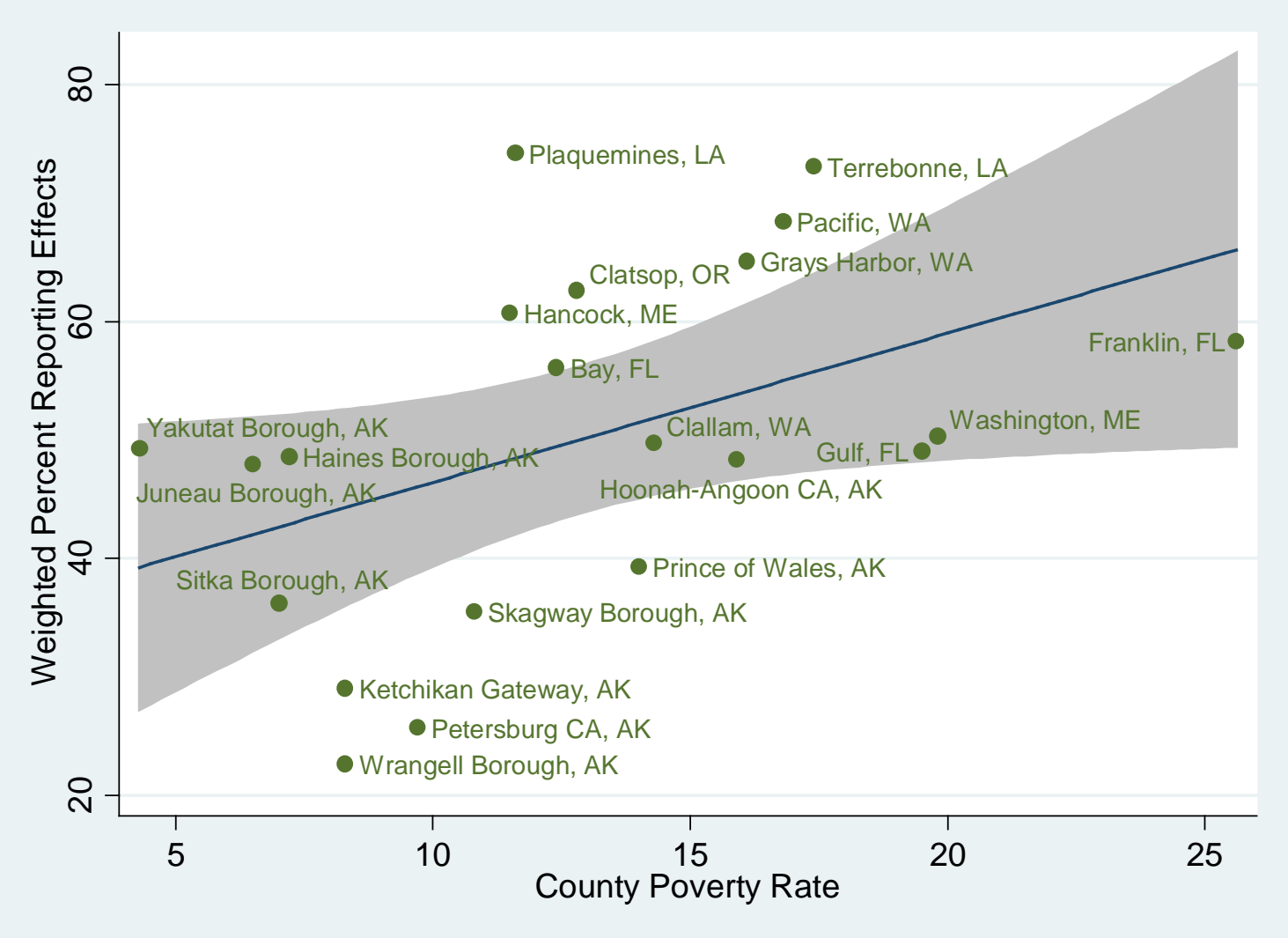

Figure 4.6: Weighted percent of survey respondents reporting effects of 'extreme or unusual weather events' vs the percent of people in poverty at the county level

\subsection{Multivariate Analysis}

The preceding sections examined relationships between perceived weather impacts and its hypothesized predictors. Such bivariate relationships may turn out to be spurious, however, and the picture may change as we take many predictors into account at once. To test for spuriousness, develop more robust findings, and incorporate the interaction hypotheses, I now shift to multivariate analysis. Mixed-effects models provide appropriate methods for these multilevel data, which combine individual survey responses from different regions with regionallevel socioeconomic and weather indicators. This approach can also test hypothesis H5: the 
existence of place-to-place variation not explained by the individual- and county-level variables in the model.

I employed a mixed-effects, binary logit regression to model perceiving any effects (minor or major) as a function of both individual and county level predictors, including weather events. Binary logit suits the dichotomous structure of this dependent variable: reporting any extreme weather effects (minor or major), coded as 1, and reporting no effects or "do not know," the base category coded as 0 . The mixed-effects approach helps to deal with regional clustering of data which can bias results in a single-level model (Hamilton 2009). It also accounts for the potential for effects to vary among units "by allowing for random variation in intercepts... to capture the heterogeneity across units," (Hamilton et al, 2010). I included random intercepts with each model, to capture "everything else" besides the predictor variables that might cause the dependent variables to vary systematically between counties. This approach was particularly useful for these data since extreme or unusual weather events can have disproportionate effects on different regions due to variation in severity, vulnerability, history, and other conditions.

Table 4.1 summarizes results from these regressions of extreme weather perceptions on individual and county level predictors. Odds ratios for these logit regressions are given because they offer more intuitive interpretations. Odds ratios indicate how much the odds increase or decrease multiplicatively with a one-unit change in the independent variable. Odds are related to probabilities in that "...the odds of success are defined as the ratio of the probability of success over the probability of failure," (IDRE). Odds ratios run from 0 to positive infinity, with an odds ratio of 1.0 indicating "no effect." The relationship between predictor and outcome could be termed "positive" with odds ratios above one and "negative" with odds ratios below one. 
Independent variables or predictors used in Table 4.1 generally follow the same coding scheme presented in Table 3.2, but some of the predictors were centered to reduce collinearity problems and simplify the interpretation with interaction. Age is treated as a continuous variable and runs from 18 to 96 . Sex is coded as 0 for male and 1 for female. Race is coded as 0 for "white" and 1 for "non-white." Degree refers to respondents' educational attainment, is orderedcategorical, and coded -1 for "high school or less," 0 for "some college/technical school," 1 for "college graduate," and 2 for "post-graduate." Income refers to respondents' 2009 household income and is ordered-categorical. Codes after centering income on its median category are -2 for "less than $\$ 20,000, "$ - 1 for "\$20,000 to 40,000 ," 0 for "\$40,000 to $60,000, " 1$ for "\$60,000 to 90,000," 2 for " $\$ 90,000$ to $160,000, "$ and 3 for $" \$ 160,000$ or more."

Own vs. rent refers to whether respondents' own or rent their homes and is coded 0 for "rent" and 1 for "own." Newcomer refers to whether respondents moved to their current communities as adults and is coded 0 for "no" and 1 for "yes." Rules refers to respondents' views about the effects of conservation rules on local communities and is coded 1 for "bad here," 2 for "no effect," and 3 for "good here." Climate beliefs refers to respondents’ personal beliefs about climate change and is coded 1 for "don't know," 2 for "not happening now," 3 for "happening now due mainly to natural causes," and 4 for "happening now due mainly to human activities." Finally among individual-level predictors, party refers to the respondents' political party identification and is coded -1 for "Democrat," 0 for "Independent," and 1 for "Republican." Table 3.2 summarizes these variable definitions and coding schemes used in the multivariate analysis.

The effects of four county-level independent variables, metropolitan/rural status, poverty rate, 5-year severe thunderstorm events total, and 5-year property damage total from severe 
weather events of all types, were tested in the mixed effects, binary logit regressions presented in Table 4.1. Metropolitan refers to whether respondents' county of residence is designated metropolitan (micropolitan included) or rural by the 2010 US Census and is coded 0 for "rural" and 1 for "metro/micro." Both the total thunderstorm events and property damage from all severe event types were log-transformed in order to reduce outliers and skew. The pre- and posttransformation distributions are given in Appendix B. The log-transformed event and property damage totals were mean-centered (log10(events) mean = 1.15 and log10(damage) mean = 1.08). Finally, poverty refers to the percent of all people in poverty in respondents' county, according to the 2010 ACS 5-year estimates.

Table 4.1 also presents results from a mixed effects regression of the outcome on the same set of predictors, using multiple imputation to work around missing values. Multiple imputation was utilized for the pre-estimation imputation of missing cases in certain predictors, especially income. Wayman (2003) provided a clear explanation of how multiple imputation deals with missing data:

“In multiple imputation, missing values for any variable are predicted using existing values from other variables. The predicted values, called “imputes”, are substituted for the missing values, resulting in a full data set called an "imputed data set." This process is performed multiple times, producing multiple imputed data sets (hence the term “multiple imputation”). Standard statistical analysis is carried out on each imputed data set, producing multiple analysis results. These analysis results are then combined to produce one overall analysis.”

Multiple imputation was a useful technique to this research because missing values on the income indicator could have biased results. For instance, those who declined to report household incomes might also have been more likely to have been affected by extreme weather events than their forthcoming counterparts in the sample, or vice versa (depending upon how income relates 
to impact vulnerabilities). Therefore, multiple imputation is preferred over simply dropping observations with missing values from the analysis (casewise deletion). It's important to note that multiple imputation is not "guessing," but rather "creating imputes is a mechanism to deliver an analysis making use of all available information," (Wayman 2003). Also, multiple imputation aims to restore natural variability in the missing data, and the method incorporates "the uncertainty caused by estimating missing data," (Wayman 2003). For more detailed information, output from analyses run in STATA 12 are provided in full in Appendix B.

Alternative approaches to regressing the outcome on this set of predictors, such as OLS, ordered, and multinomial logit, were tested, but binary logit was preferred for a number of reasons. Results were essentially identical across all variations on the outcome and in the various regression techniques mentioned, however (see Appendix B). Treatment of the outcome as a dichotomous variable did not adversely affect results in any meaningful way. This is directly related to the second reason for choosing to stay with a dichotomy, namely that impacts from extreme weather are easiest to speak of in terms of respondents' either having perceived at least some effects or no effects at all. There were no salient differences between those who reported minor or major effects. The independent variables behave similarly as predictors of those perceiving minor or major effects (see Appendix B).

As a final note to the multivariate analyses in Table 4.1, I have four distinct models corresponding to the analyses run with and without MI, and with and without the climate beliefs variable. Models 1 and 2 refer to analyses including climate beliefs, with and without missing values imputed respectively. Models 3 and 4, however, refer to analyses without climate beliefs because the "climate change beliefs" item was not included on the Downeast Maine CERA 
survey. Therefore, Models 1 and 2 do not include survey respondents from Downeast Maine, whereas Models 3 and 4 capture the entire sample.

Since the severe thunderstorm event indicator was particularly weak as a predictor of perceptions and as a measure brings with it a number of significant limitations, I have run the analyses without the thunderstorm event indicator and displayed the results in Table 4.2. The results in Table 4.2 are the refined analyses and represent the final analyses referred to in the discussion in Chapter 5.

\subsubsection{Effects of Objective Weather Events}

H1: Impact and frequency of severe weather events, objectively measured by the 5-year, county-level total of severe weather events and property damage in dollars, will influence subjective individual perceptions of extreme or unusual weather events.

Extreme or unusual weather perceptions increased among residents in counties that sustained higher property damage in dollars from severe weather events of all types. As presented in Model 1 (Table 4.2), the odds of respondents who reported effects of extreme or unusual weather events increased by $45.3 \%$ for each factor of 10 increase in property damage from severe weather events. Model 2 (Table 4.1) demonstrates that this effect persisted through imputation of missing values on important predictors such as household income. Therefore, measurement and analysis of objective impacts on communities from severe weather events proved useful and important in the prediction of individuals' severe weather perceptions. This makes logical sense given that high dollar value impacts from severe weather have visible consequences in these areas and may affect respondents personally, such as seeing, hearing from other residents, or experiencing damage to homes and the burden of reconstruction/repairing in 
the aftermath of storms. Additionally, this finding confirms that the bivariate relationship between property damage and weather perceptions was not a spurious one (see Figure 4.1).

In contrast to this finding, however, the total number of severe thunderstorm events at the county level was not found to influence individual perceptions of extreme or unusual weather events net of other individual- and county-level predictors. This is unsurprising given the relatively weak bivariate relationship between severe thunderstorm events and perceptions (Figure 4.2). This also indicates that the total number of severe thunderstorm events is not as useful a measure as initially anticipated for this type of research. Not only is it limited in the fact that it is purely a frequency and does not incorporate a measure of magnitude of storms, but it is also only reporting severe thunderstorm events and therefore does not cover some of the most impactful weather types unrelated to thunderstorms occurring in the variety of regions surveyed for this sample. For instance, Southeast Alaska had very few severe thunderstorms reported in these data, suggesting that thunderstorms are unlikely to stand out among the variety of other weather affecting the region. While storm events were relatively mild, Southeast Alaska did experience record high temperatures over the 5-year period preceding survey administration.

\subsubsection{Effects of Individual values or beliefs}

H2: Values, as measured by political identity, beliefs about the effects of conservation rules, and beliefs about climate change, also influence perceptions of extreme or unusual weather events.

Among the individual-level characteristics found to affect extreme/unusual weather effects perceptions were individuals' age, sex, educational attainment, and political party affiliation. Generally, younger, female, higher educated, and Democratic respondents were more likely to perceive effects from extreme weather than their older, male, lower educated, and 
Republican counterparts. These findings are entirely consistent with prior research (Van Liere and Dunlap 1980; Guagnano and Markee 1995; Dietz et al 2007; Hamilton 2008) on environmental attitudes and beliefs, but this study extends the pattern to perceptions of the impact of "environmental events," specifically extreme weather in this case.

Another contribution of this study is the investigation of how individuals' "environmental values" might influence their perceptions of extreme weather events. Both beliefs about conservation rules and climate change were found to be predictive of individuals' perceptions of the effects of extreme or unusual weather events (Table 4.1). According to Model 1 of Table 4.1, the odds of reporting extreme or unusual events increased by $15.1 \%$ for a unit increase in the conservation rules indicator, meaning that individuals who believed conservation rules were good for their communities or had at least no discernible effect were more likely to perceive extreme weather effects than individuals who viewed conservation rules as bad for their local communities. Also, the odds of reporting effects from extreme or unusual weather were $14.6 \%$ higher among those who believed climate change is happening now due mainly to human activities compared to those who held other climate change beliefs. These two findings reinforce one another as important predictors of extreme weather since conservation and climate change are two major areas in the trade-off between the environment and the economy. Typically, those who favored conservation rules were more likely to believe climate change is happening now, due to human activities than those who believe climate change is a natural phenomenon or isn't happening at all right now.

While individuals' sex was not included in $\mathrm{H} 2$, it did present an interesting phenomenon within the models as it related to climate change beliefs and the inclusion of Downeast Maine, in which climate beliefs were not assessed. With climate beliefs included in the models (Models 1 
and 5), sex did not emerge as a significant predictor of weather perceptions. Once I included Downeast Maine by taking out the climate beliefs variable, individuals’ sex was a significant and relatively strong predictor of weather perceptions, such that females more often reported effects than male respondents. Due to this difference between models with and without Maine included, I removed climate beliefs from the models without Maine as well to be sure this was not isolated to Downeast Maine. Without climate beliefs in a model that did not include Downeast Maine, sex did in fact become a significant predictor of weather perceptions, suggesting that the variation in perceptions from individuals' sex was mediated by individuals’ beliefs about climate change. One possible explanation for this could lie in the fact that women are more likely to believe that climate change is happening now, due to human activities, but this could also be related the predominant finding among studies on risk that women are more likely to express concern about environmental hazard risks than men (Kahan et al 2011; McCright and Dunlap 2013; Finucane et al 2000; Kahan et al 2007; Kalof et al 2002; Shao et al 2014).

\subsubsection{Effects of Social Position and Socioeconomic Context}

H3: Social privilege or position indicators (such as household income) and socioeconomic context (such as county poverty rates) affect perceptions about extreme or unusual weather events.

Household income and homeownership versus renting statuses exhibited effects on individuals' perceptions of extreme or unusual weather. As presented in Model 1 of Table 4.1, the odds of reporting effects from extreme or unusual weather events were $40.5 \%$ higher among homeowners as compared to their home-renting counterparts. On the other hand, the odds of reporting effects from extreme or unusual weather events decreased by $13.4 \%$ for a unit increase 
in household income. Perhaps one of the reasons lower income is associated with increased effects perceptions is because individuals who make less tend to live in areas that might be more susceptible to environmental catastrophes or disasters, i.e. low-lying territory in Gulf Coast Louisiana. Another explanation could be that individuals who have less disposable income or are unable to afford expensive home insurance policies might be more adversely affected by extreme or unusual weather events than higher earning individuals. Since homeowners have been found to generate higher incomes over time than renters (Di 2007), the findings from this study present a challenge to what we might have expected based on previous literature. The interaction between median-centered income and the dichotomous owning versus renting variable was tested and nothing significant emerged, so homeownership and lower incomes appear to independently affect weather perceptions.

In the multivariate analyses (Table 4.1), county-level poverty rates were not found to be predictive of individuals' perceptions of extreme or unusual weather. Net of individual-level characteristics and county-level weather events and property damage, socioeconomic context did not significantly improve our ability to predict individuals' perceptions of extreme weather events. Individuals' values and particular social and economic circumstances appear to be more important in determining how individuals' perceive the impacts of extreme or unusual weather events than the broader socioeconomic situation in the areas where individuals reside.

\subsubsection{Interaction Effects}

H4: Individual values and social position indicators will exhibit interaction effects, such that they moderate the relationship between objectively-measured weather events, and individual perceptions about the impacts of weather events. 
Previous research has reported a number of interactions involving education or knowledge and politics, in other kinds of climate or environmental data. I tested for such effects here, and also for analogous events*politics and events*income interactions. The education*politics and similar effects did not prove significant, but events*politics (and damage*income) did. Such interactions have not previously been reported in this literature, and might be unique to event perceptions rather than more general environmental concern.

Despite expectations based on findings from many studies in the previous literature (McCright 2011), there was no significant interaction between respondents' political party affiliation and educational attainment. This suggests that extreme weather events are less amenable to the "powerful filter" of ideology than overarching environmental issues, such as climate change or the related potential risks to society (Hamilton 2008). That being said, political party affiliation was predictive of weather effects perceptions such that the odds of reporting either major or minor effects of extreme or unusual weather decreased among those who identified as Republicans.

Political party affiliation, however, was found to interact with the number of severe thunderstorm events at the county level. This effect is depicted visually in Figure 4.7. In counties with fewer events, there was a wider divide between Democrats and Republicans on the issue of extreme weather effects in comparison with counties that had a higher total number of severe thunderstorm events over the 5 years preceding the date of survey administration. Even though the partisan gap closed as events increased, there was still a difference between how Democrats, Independents, and Republicans viewed the effects of extreme or unusual weather. The most pronounced differences, however, were in counties where few, if any, severe 
thunderstorm events occurred. In those areas, the odds of reporting effects from extreme weather increased by almost a factor of two among Democrats compared to Republicans.

As we might expect, independents landed directly in the middle of Democrats and Republicans in terms of their extreme weather effects perceptions. This partisan divide is strikingly similar to those found in analyses of climate change attitudes and beliefs which have demonstrated increased probabilities among Democrats (compared to Republicans) of seeing climate change as a threat or believing climate change is happening now and caused mainly by human activities (Hamilton 2008; Hamilton, Cutler, and Schaefer 2012; McCright and Dunlap 2010; Hamilton 2011; Leiserowitz 2006; Kahan et al 2011; Xiao and McCright 2007). Some researchers have attributed this phenomenon to process theories which essentially argue that the development of environmental beliefs is based on values determined by a variety of individuals' social-psychological characteristics and their relative social positions (Wood and Vedlitz 2007; Stern 2000, Shwom et al 2008; Dietz et al 2007; Dietz et al 2005). While process theories have provided substantial contributions to the explanation of environmental attitudes, individual-level processes are couched within place-specific contexts and localized meanings based on shared circumstances. 
Table 4.1 Imputed and Non-imputed Mixed Effects Logistic Regression of Perceiving Effects of Extreme/Unusual Weather on Individual- and County-level Characteristics

\begin{tabular}{|c|c|c|c|c|}
\hline & $\begin{array}{r}\text { Model } 1 \text { - w/o } \\
\text { Maine, non- } \\
\text { imputed }\end{array}$ & $\begin{array}{r}\text { Model } 2 \text { - w/o } \\
\text { Maine, imputed }\end{array}$ & $\begin{array}{r}\text { Model 3-Full } \\
\text { Sample, non- } \\
\text { imputed }\end{array}$ & $\begin{array}{r}\text { Model 4-Full } \\
\text { Sample, imputed }\end{array}$ \\
\hline PREDICTORS & $\begin{array}{l}\text { Odds Ratio[95\% } \\
\text { conf.] }\end{array}$ & $\begin{array}{l}\text { Odds Ratio[95\% } \\
\text { conf.] }\end{array}$ & $\begin{array}{l}\text { Odds Ratio[95\% } \\
\text { conf.] }\end{array}$ & $\begin{array}{l}\text { Odds Ratio[95\% } \\
\text { conf.] }\end{array}$ \\
\hline \multicolumn{5}{|l|}{$\begin{array}{l}\text { INDIVIDUAL- } \\
\text { LEVEL }\end{array}$} \\
\hline Age & $\begin{array}{l}0.993 * *[0.988, \\
0.998]\end{array}$ & $\begin{array}{l}0.994 * * *[0.990 \\
0.997]\end{array}$ & $\begin{array}{l}0.991 * * *[0.987 \\
0.995]\end{array}$ & $\begin{array}{l}0.992 * * *[0.988 \\
0.995]\end{array}$ \\
\hline Sex & $\begin{array}{l}\text { 1.132[0.987, } \\
1.298]\end{array}$ & $\begin{array}{l}1.118[0.995 \\
1.257]\end{array}$ & $\begin{array}{l}1.183^{* *}[1.050 \\
1.333]\end{array}$ & $\begin{array}{l}1.169 * *[1.052 \\
1.299]\end{array}$ \\
\hline Race & $\begin{array}{l}0.991[0.802, \\
1.225]\end{array}$ & $\begin{array}{l}1.009[0.846, \\
1.204]\end{array}$ & $\begin{array}{l}0.968[0.793 \\
1.181]\end{array}$ & $\begin{array}{l}0.990[0.837, \\
1.172]\end{array}$ \\
\hline Degree & $\begin{array}{l}1.136 * * *[1.058 \\
1.221]\end{array}$ & $\begin{array}{l}1.139 * * *[1.071 \\
1.211]\end{array}$ & $\begin{array}{l}1.132 * * *[1.064 \\
1.204]\end{array}$ & $\begin{array}{l}1.141 * * *[1.081 \\
1.205]\end{array}$ \\
\hline Income & $\begin{array}{l}0.866 * * *[0.820 \\
0.915]\end{array}$ & $\begin{array}{l}0.860 * * *[0.819 \\
0.903]\end{array}$ & $\begin{array}{l}0.911 * * *[0.869 \\
0.954]\end{array}$ & $\begin{array}{l}0.896 * * *[0.859 \\
0.934]\end{array}$ \\
\hline Own vs. Rent & $\begin{array}{l}1.405 * * *[1.157 \\
1.708]\end{array}$ & $\begin{array}{l}1.407 * * *[1.189, \\
1.664]\end{array}$ & $\begin{array}{l}1.241 *[1.042, \\
1.477]\end{array}$ & $\begin{array}{l}1.274 * *[1.092 \\
1.486]\end{array}$ \\
\hline Rules & $\begin{array}{l}1.151 * * *[1.049 \\
1.264]\end{array}$ & $\begin{array}{l}1.154 * * *[1.066, \\
1.250]\end{array}$ & $\begin{array}{l}1.172 * * *[1.081 \\
1.271]\end{array}$ & $\begin{array}{l}1.185 * * *[1.103 \\
1.273]\end{array}$ \\
\hline Newcomer & $\begin{array}{l}0.994[0.852 \\
1.160]\end{array}$ & $\begin{array}{l}0.933[0.819 \\
1.064]\end{array}$ & $\begin{array}{l}1.052[0.920, \\
1.204]\end{array}$ & $\begin{array}{l}0.988[0.878 \\
1.112]\end{array}$ \\
\hline Party & $\begin{array}{l}0.791 * * *[0.726 \\
0.863]\end{array}$ & $\begin{array}{l}0.794 * * *[0.734 \\
0.858]\end{array}$ & $\begin{array}{l}0.741 * * *[0.692 \\
0.794]\end{array}$ & $\begin{array}{l}0.741 * * *[0.695 \\
0.789]\end{array}$ \\
\hline Climate beliefs & $\begin{array}{l}1.146 * * *[1.255 \\
1.703]\end{array}$ & $\begin{array}{l}1.545 * * *[1.354 \\
1.761]\end{array}$ & ---- & ---- \\
\hline \multicolumn{5}{|l|}{ COUNTY-LEVEL } \\
\hline Metropolitan & $\begin{array}{l}1.119[0.852, \\
1.468]\end{array}$ & $\begin{array}{l}\text { 1.132[0.857, } \\
1.496]\end{array}$ & $\begin{array}{l}0.962[0.734, \\
1.261]\end{array}$ & $\begin{array}{l}0.975[0.739, \\
1.286]\end{array}$ \\
\hline log10(Events) & $\begin{array}{l}0.937[0.589, \\
1.490]\end{array}$ & $\begin{array}{l}0.966[0.614, \\
1.519]\end{array}$ & $\begin{array}{l}1.115[0.829, \\
1.499]\end{array}$ & $\begin{array}{l}1.117[0.833, \\
1.497]\end{array}$ \\
\hline $\log 10$ (Damage) & $\begin{array}{l}1.453 * * *[1.224 \\
1.724]\end{array}$ & $\begin{array}{l}1.494 * * *[1.251 \\
1.784]\end{array}$ & $\begin{array}{l}1.397 * * *[1.216 \\
1.605]\end{array}$ & $\begin{array}{l}1.421 * * *[1.231 \\
1.641]\end{array}$ \\
\hline Poverty & $\begin{array}{l}1.007[0.974, \\
1.041]\end{array}$ & $\begin{array}{l}1.010[0.976, \\
1.044]\end{array}$ & $\begin{array}{l}0.984[0.956, \\
1.014]\end{array}$ & $\begin{array}{l}0.988[0.959 \\
1.018]\end{array}$ \\
\hline \multicolumn{5}{|l|}{ INTERACTIONS } \\
\hline Party x log10(Events) & $\begin{array}{l}1.141 *[1.001, \\
1.300]\end{array}$ & $\begin{array}{l}\text { 1.101[0.980, } \\
1.236]\end{array}$ & $\begin{array}{l}1.184 * *[1.066, \\
1.314]\end{array}$ & $\begin{array}{l}1.154 * *[1.048 \\
1.270]\end{array}$ \\
\hline $\begin{array}{c}\text { Income x } \\
\log 10(\text { Damage). }\end{array}$ & $\begin{array}{l}1.095 * * *[1.046 \\
1.146]\end{array}$ & $\begin{array}{l}1.092 * * *[1.046 \\
1.138]\end{array}$ & $\begin{array}{l}1.057 * *[1.018, \\
1.099]\end{array}$ & $\begin{array}{l}1.059 * * *[1.022 \\
1.097]\end{array}$ \\
\hline Fixed Intercept & $\begin{array}{l}1.081[0.499, \\
2.340]\end{array}$ & $\begin{array}{l}1.028[0.486, \\
2.172]\end{array}$ & $\begin{array}{l}2.579 * *[1.394, \\
4.772]\end{array}$ & $\begin{array}{l}2.401 * *[1.314 \\
4.387]\end{array}$ \\
\hline Random Effect & Estimate & Estimate & Estimate & Estimate \\
\hline County Intercept & $\begin{array}{l}0.149 * *[0.076 \\
0.292]\end{array}$ & $\begin{array}{l}0.173 * * *[0.099 \\
0.301]\end{array}$ & $\begin{array}{l}0.186^{* * *}[0.115 \\
0.302]\end{array}$ & $\begin{array}{l}0.205^{* * *}[0.132 \\
0.319]\end{array}$ \\
\hline Est. Sample & $n=3964$ & $n=5579$ & $n=5089$ & $n=6704$ \\
\hline
\end{tabular}


Table 4.2 Mixed Effects Logistic Regression of Perceiving of Extreme/Unusual Weather on Individual- and County-level Characteristics, with and without Downeast Maine.

\begin{tabular}{|c|c|c|}
\hline & Model 5 - w/o Downeast ME & Model 6 - Full Sample \\
\hline PREDICTORS & Odds Ratio(95\% conf.) & Odds Ratio(95\% conf) \\
\hline \multicolumn{3}{|l|}{ INDIVIDUAL-LEVEL } \\
\hline Age & $0.992 * *(0.988,0.997)$ & $0.991 * * *(0.986,0.995)$ \\
\hline Sex & $1.137(0.992,1.304)$ & $1.186 * *(1.053,1.337)$ \\
\hline Race & $0.985(0.797,1.217)$ & $0.962(0.788,1.174)$ \\
\hline Degree & $1.145 * * *(1.066,1.300)$ & $1.136 * * *(1.068,1.208)$ \\
\hline Income & $0.865 * * *(0.818,0.914)$ & $0.911 * * *(0.869,0.954)$ \\
\hline Own vs. Rent & $1.403 * * *(1.155,1.704)$ & $1.251 *(1.051,1.489)$ \\
\hline Rules & $1.189 * * *(1.085,1.303)$ & $1.194 * * *(1.102,1.294)$ \\
\hline Newcomer & $0.998(0.855,1.165)$ & $1.049(0.917,1.200)$ \\
\hline Party & $0.749 * * *(0.691,0.812)$ & $0.747 * * *(0.697,0.800)$ \\
\hline Climate Beliefs & $1.186 * * *(1.089,1.291)$ & 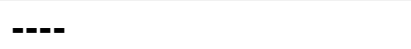 \\
\hline \multicolumn{3}{|l|}{ COUNTY-LEVEL } \\
\hline Metropolitan & $1.187(0.917,1.537)$ & $1.044(0.732,1.490)$ \\
\hline log10(Damage) & $1.548 * * *(1.355,1.769)$ & $1.516 * * *(1.268,1.813)$ \\
\hline Poverty & $1.016(0.991,1.042)$ & $1.017(0.985,1.049)$ \\
\hline \multicolumn{3}{|l|}{ INTERACTIONS } \\
\hline Income $x$ log10(Damage) & $1.097 * * *(1.048,1.148)$ & $1.063 * *(1.023,1.104)$ \\
\hline Fixed Intercept & $0.629(0.325,1.220)$ & $1.405(0.741,2.665)$ \\
\hline Random Effect & & \\
\hline County Intercept & $0.162 * *(0.086,0.303)$ & $0.275^{* * *}(0.183,0.411)$ \\
\hline Est. Sample & 3,964 & 5,089 \\
\hline
\end{tabular}




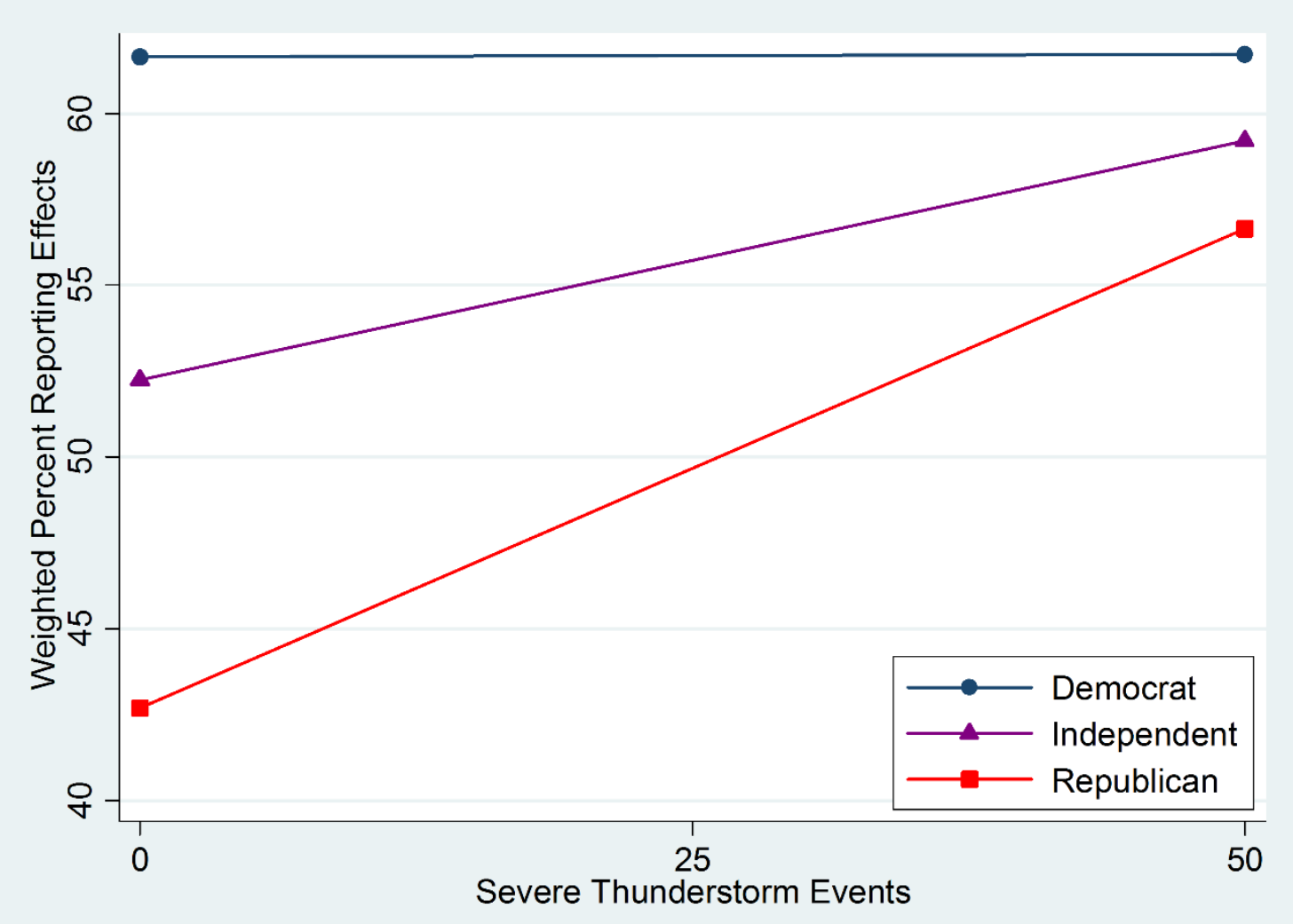

Figure 4.7: Adjusted marginal plot showing effect on perceived weather impacts, from the interaction of objective, 5-year total thunderstorm events and respondent political party. Based on weighted logit model analogous to Model 3 of Table 4.1, adjusting for other predictors.

My research contributes to the literature by expanding the study of environmental attitudes into locally- and contextually-based phenomena such as extreme or unusual weather. Though individual-level process theories are useful here, they are not sufficient to explain the formation of attitudes or perceptions of environmental phenomena that vary by place. In the following section, I will provide a proposal for a revised approach to environmental beliefs based on the concept of emergence.

A second significant interaction was found between respondents' household incomes and property damage in dollars at the county level. This interaction effect is depicted visually in Figure 4.8. 


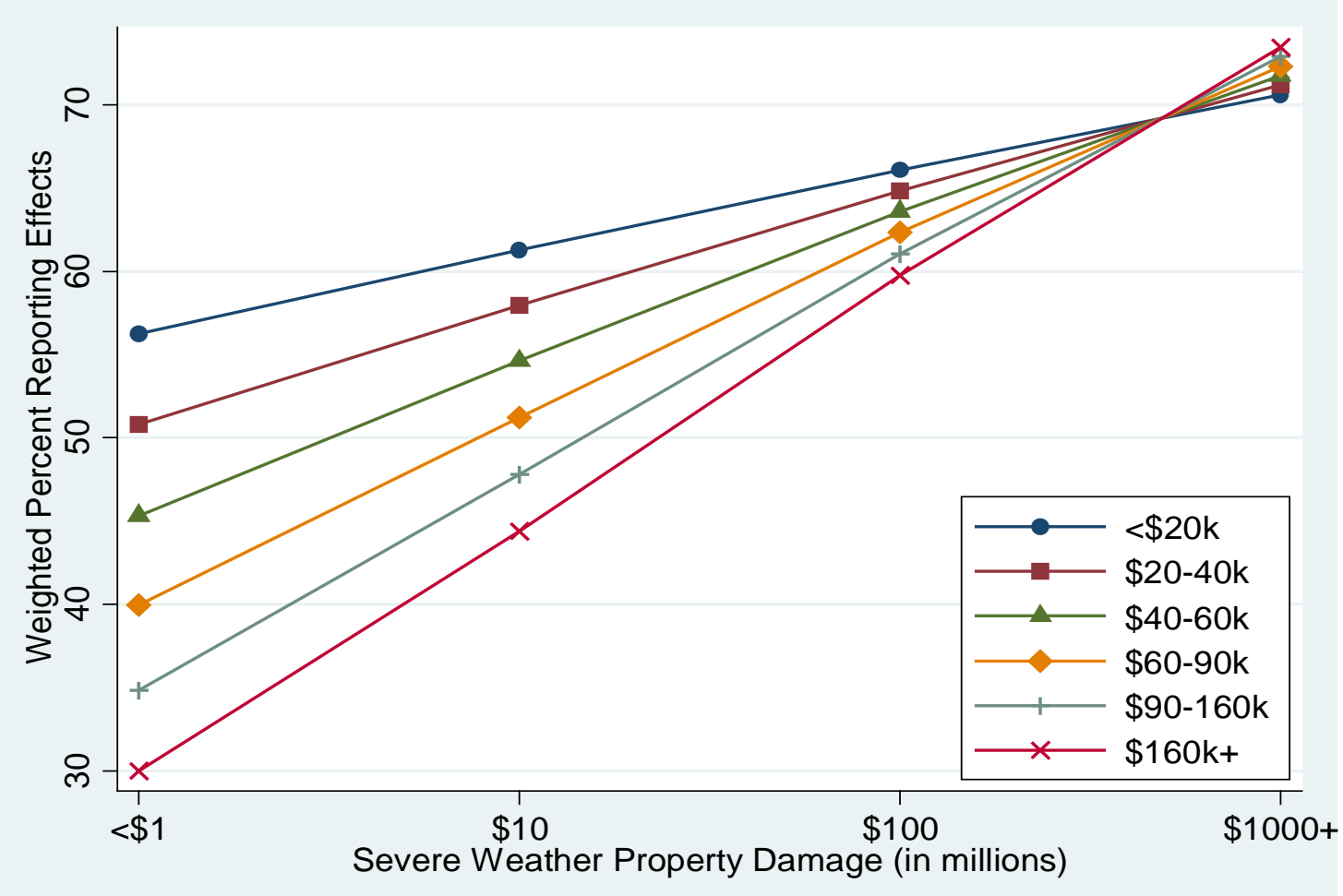

Figure 4.8: Adjusted marginal plot showing effect on perceived weather impacts, from the interaction of objective property damage of severe weather and respondent household income. Based on weighted logit model analogous to Model 3 of Table 4.1, adjusting for other predictors.

The relationship between perceived and actual weather effects became stronger among higher-income respondents. In areas with high property damage, there was little or no difference in views about the effects of extreme or unusual weather between high and low income individuals. In fact, higher income individuals were slightly more likely to report extreme or unusual weather effects than lower income individuals. This finding is interesting for a number of reasons, but there are two particular issues related to this interaction that are worth noting. First, property damage appears to be a salient measure of the magnitude of impacts on human societies from extreme or unusual weather events. Regardless of income, individuals in high property damage areas express relatively greater effects from these events. This finding is strikingly similar to the interaction between the number of severe thunderstorm events and 
political party affiliation, which also suggests the difference in perceptions are attenuated by the incidence of events.

Social and contextual variables, however, remain integral to understanding the formation of individual perceptions of weather events. Not only were several main effects significant between individual-level social characteristics and the dependent variable, but political party affiliation and household income mattered to the ways in which individuals perceived weather events in lieu of impactful experiences with them. Democrats in areas with few or no severe thunderstorm events still reported at least some effects from extreme or unusual weather events on their families and/or communities. Similarly, low income individuals more often reported effects than their higher earning counterparts even in areas with low property damage. The income and property damage interaction might be explained by the possibility that lower income households have difficulty recovering or avoiding the effects from even a handful of severe weather events (Cutter 2001; Zhang and Peacock 2010; Peacock 2003; Zahran et al 2008). Those in lower socioeconomic positions are more vulnerable to harm from bad weather (see Cutter et al 2003; Cutter 2012) because they may be more likely to live on lower ground or may live in homes with leaky roofs, siding, or basements.

Political party affiliation, on the other hand, is less straightforward as a predictor of extreme weather event perceptions. On its face, ideology seems wholly unrelated to how individuals view the effects of severe weather, but in the current context of the politicization of environmental issues ideological predispositions tend to seep into the subconscious perceptual level of individual understanding. For instance, the issue of anthropogenic climate change is one of the most politically polarizing contemporary issues and is often linked in the public discourse to severe weather events. Therefore, perceptions of the effects of severe weather events can be 
influenced by beliefs about the nature and causes of global climate change, which can in turn be traced back with consistency to political party affiliation or ideological predispositions. My results lend strong evidence to this explanation. Democrats were more sensitive than Republicans to the effects of unusual or extreme weather even if their particular area of residence had comparatively few major and damaging events. This finding is logical given that Democrats were more likely to believe climate change is happening now and caused mainly by human activities and severe weather events have been construed as indicators of what we can expect to come from a changing global climate.

Figure 4.9 depicts the above mentioned causal associations between social, material, and place-based influences and extreme weather perceptions. I see place as causally prior to social position and values due to the insignificance of the "newcomer" variable (i.e. that having recently moved to the area had no significant influence on whether individuals perceived effects from extreme weather) and because of insights drawn from prior literature on place and environmental concern, as well as neighborhood-level effects on other perceptual and attitudinal measures (see Sampson 2012). However, social position could also affect place of residence such that socioeconomic constraints restrict individuals' from moving into wealthier neighborhoods or moving out of poorer neighborhoods. Perhaps better measures of community attachment, collective efficacy, or place-related social mobility could help to tease out this possibility in future research on perceptions of weather events. 


\subsubsection{Place-to-place variation}

H5: There will be significant, systematic place-to-place variations in perceptions about weather impacts, even after controlling for objective weather indicators, values and other individual- or county-level socioeconomic characteristics.

Mixed effects modeling allows for the identification of unexplained variation in the dependent variable net of all individually- and group-based fixed effects. Statistical models in Table 4.2 display the county-level random effect on the dependent variable, extreme/unusual weather effects. The effect was significant in both the multiply-imputed and non-imputed models. This means that there still remain important differences in the perceptions of extreme or unusual weather events among counties surveyed net of all individual-level variables and even county-level weather events and dollar-value impacts. Figure 4.10 shows the random intercepts from mixed effects regressions reported in Table 4.2. This finding suggests that deeper field research, case studies, or historical analyses are necessary to illuminate the factors that might help to explain the place-based variation in perceptions of weather events. While I did not include these methods in my research, some basic inferences will be drawn in the following chapter using information about the counties’ economies and socio-economic and -demographic profiles.

From a comparison of Models 1 and 2 in Table 4.1, the multiple imputation technique did not add any predictive power or reveal any problems associated with missing values. All of the significant predictors remained significant and in the same directions across non-imputed and multiply imputed models. The coefficients increased or decreased slightly in certain cases, but for the purposes of interpretation the effects were essentially the same. This means that missing values, especially those on income, do not substantially alter or bias the results in any 
meaningful ways. This is an important determination because missing values may at times be missing for reasons related to undetected phenomena that might bias results. For instance, respondents who do not volunteer information about their incomes might have something in common with each other which could be related to how they perceive unusual or extreme events, such as residence in areas of concentrated poverty or wealth. The similarity of imputed and nonimputed model results suggests, however, that the bias from casewise deletion (setting aside observations with missing values) is not severe in this instance.

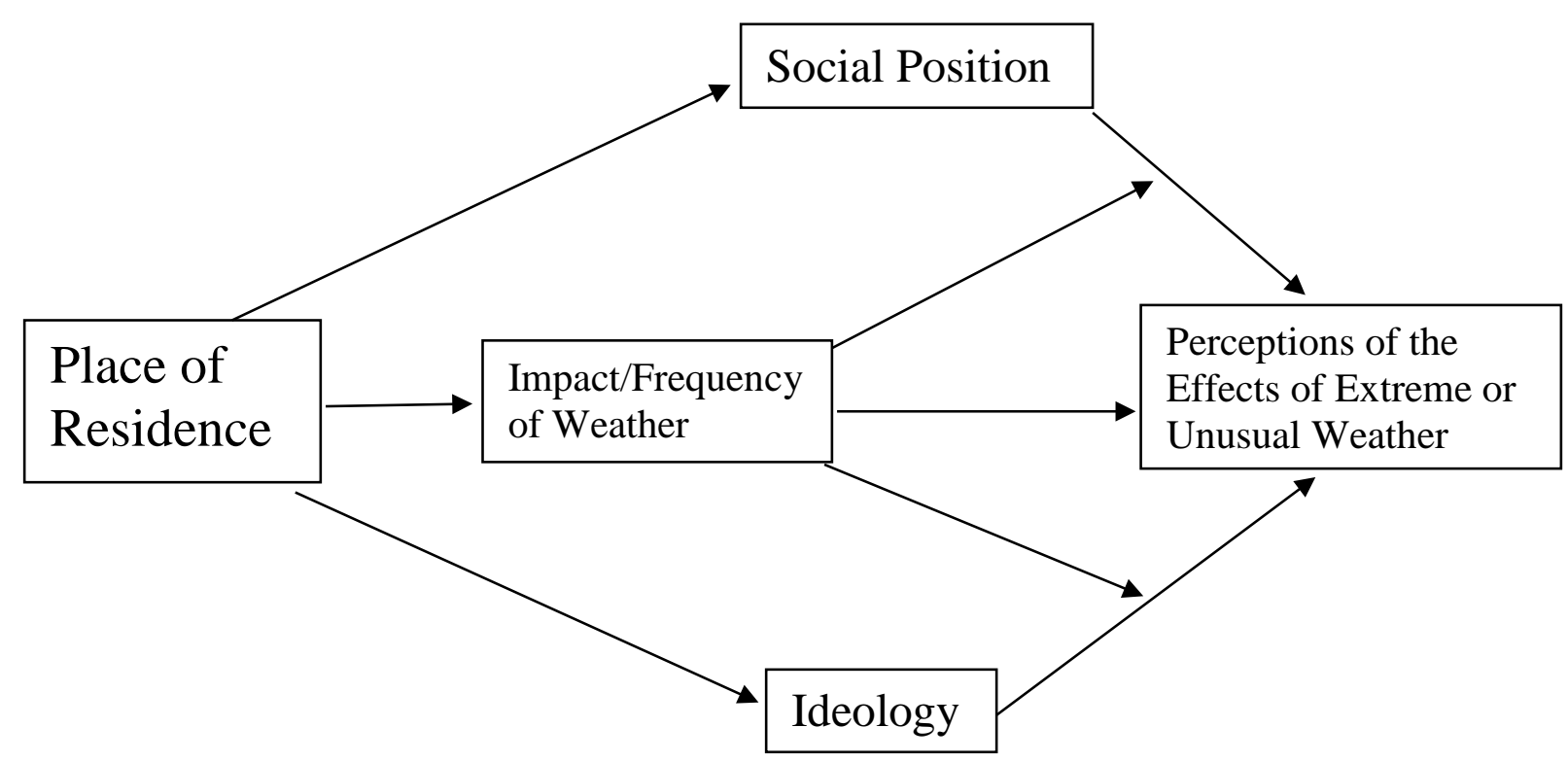

Figure 4.9: Causal/Theoretical Model 


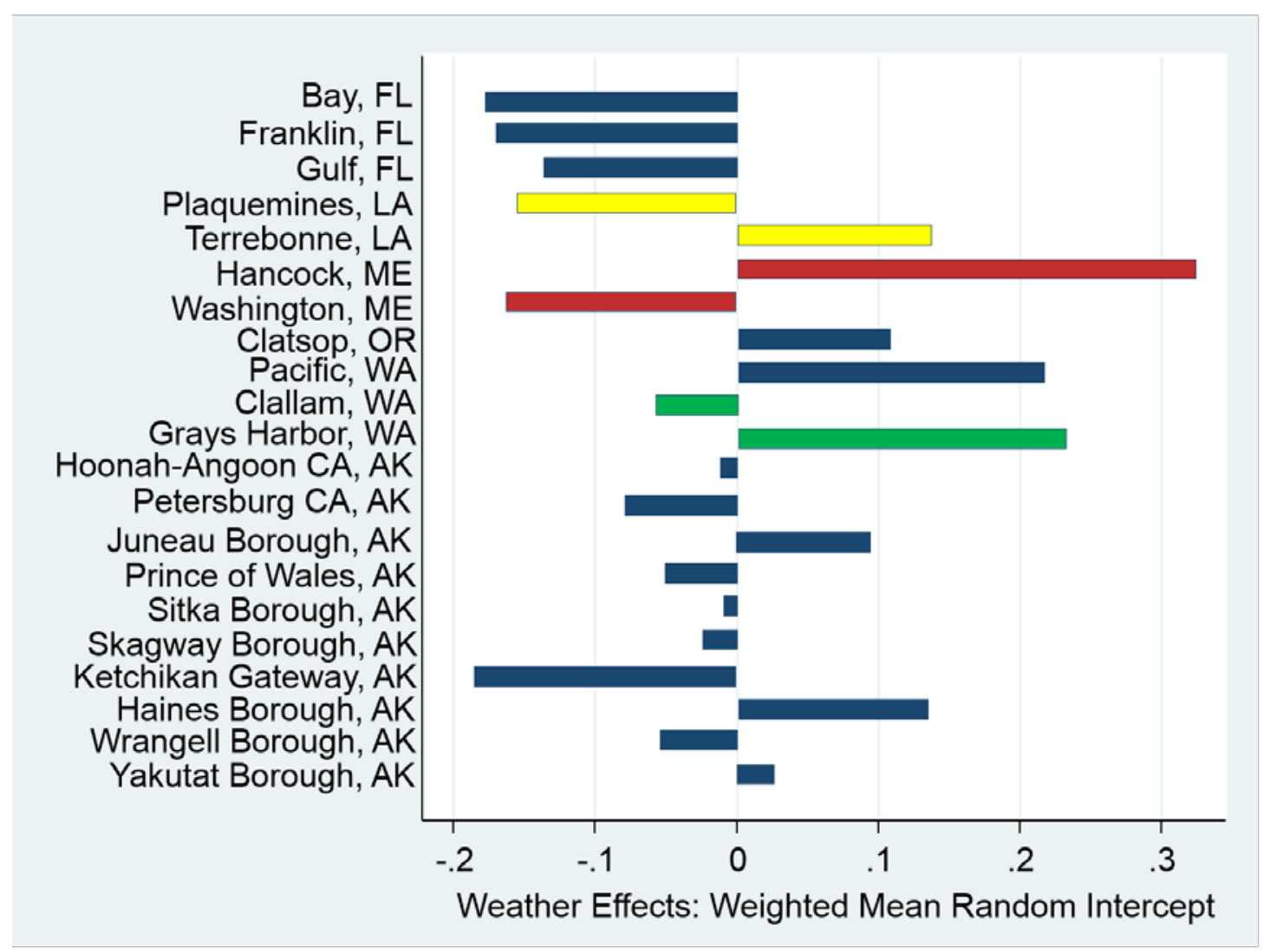

Figure 4.10: Mean of Random Intercepts by County, from Model 3 in Table 4.1.

\section{$\underline{4.3 \text { Summary }}$}

I found important individual-level effects, county-level-effects, and interaction effects on individual perceptions about extreme or unusual weather perceptions. Additionally, there was significant unexplained variation at the level of the county net of all individual- and place-based variables and their interactions. My analysis suggests that perceptions about extreme or unusual weather events are influenced by extreme weather itself, but also by a number of values or socioeconomic characteristics unrelated to weather. Moreover, such characteristics can moderate the influence of weather itself. Controlling for several indicators of actual extreme events, 
individuals’ age, sex, income, educational attainment, residential status, and environmental and political values all significantly predicted perceptions about extreme or unusual weather events affecting their families or communities. In particular, the odds of reporting effects from extreme or unusual weather were higher among younger, female, lower income, better educated, homeowning, and politically liberal persons with the belief that conservation rules are good for their communities and climate change is happening now due mainly to human activities. Conversely, the odds of reporting such weather effects were lower among older, male, higher income, less educated, renting, and politically conservative persons with the belief that conservation rules have been bad for their communities and climate change is not happening now or is mainly a natural phenomenon.

Adding depth to these findings, individual-level characteristics were also found to interact with county-level weather data. The number of severe thunderstorm events interacted with political party affiliation such that Democrats and Republicans diverged most in their perceptions of extreme or unusual weather events in areas that experienced few or no severe thunderstorm events over the 5-year period preceding the date of the survey. Republicans’ perceptions appeared more closely tied to objective measures of events. There remained gaps between Democrats and Republicans in areas with relatively high severe event totals. In this respect, Republicans appeared to be more realistic about effects from extreme weather than Democrats. That said, the severe thunderstorm events indicator was not directly predictive of perceptions and is problematic as a measure for a number of reasons, most notably it is only a frequency and does not capture the variety of weather experienced by individuals living across these diverse regions. 
Similar in fashion to the party and event total interaction, income interacted with property damage totals such that low, middle, and high income individuals diverged most in areas that experienced the least property damage from weather events of all types over the 5-years preceding the survey date. In areas with the least property damage from severe weather events, the odds of perceiving extreme weather impacts were highest among low-income respondents, while relatively lower among higher-income respondents. As property damage increased, the odds of perceived effects also increased for all incomes, but the change was most pronounced (i.e., most sensitive to actual damage) among higher-income respondents. High, middle, and low income levels converged to eventually agree about weather event impacts in areas with the highest property damage totals. This suggests that property damage as expected is a salient variable in the explanation of individual-level extreme weather perception formation, but income is also necessary to consider especially due to its moderating influence on this relationship between property damage and effects perceptions.

In the next chapter I will discuss the theoretical and practical significance of these findings, as well as the particular contribution of my study to the broader literature in environmental sociology. My research suggests that both micro- and macro-level processes are involved in shaping individual perceptions of extreme weather. There were important differences in perceptions by both individual-level characteristics and county-level random effects. Also, I found both social and objective material conditions to be predictive of perceptions. Taken together, these findings provide the potential rationale for transcending realist-constructivist and micro-macro divisions in research on societal-environmental interactions. I discuss in detail how this can take place and what it will mean for research efforts going forward. 


\section{CHAPTER V}

\section{DISCUSSION}

\section{$\underline{5.1 \text { Summary of findings }}$}

\subsubsection{Impact and frequency of weather events}

HI: Impact and frequency of severe weather events, objectively measured by the 5-year, countylevel total of severe weather events and property damage in dollars, will influence subjective individual perceptions of extreme or unusual weather events.

Results presented Table 4.2 in Chapter 4 show that impacts of extreme weather, measured by county-level property damage in dollars, were significantly related to individuals' perceptions about the effects of extreme or unusual weather. On the other hand a narrower indicator for extreme events, the severe thunderstorm count, did not significantly affect perceptions. Taken together, these findings suggest that individuals more often perceive effects of extreme weather events when the objective costs or damage to their communities are higher, but may not be as sensitive to the mere frequency of extreme events. Links between the objective, or "felt," effects of the climate and environmental concern have been suggested in prior research (Hamilton and Keim 2009; Hamilton and Stampone 2013), but a unique aspect of my research is the inspection of extreme weather perceptions among residents in this coastal, multi-region CERA sample. 
The property damage effect was consistent with the first hypothesis (H1). However, the main effect of the number of thunderstorm events was not found to be significant, so H1 was only partially supported. Hypothesis H1 was stated in very general terms, however. These mixed results highlight the need for greater specificity --- better to ask not just whether extreme events affect perceptions, but which events and how. These results also highlight the deficiencies inherent in utilizing frequency measures of a single storm type in a cross-regional comparative context such as this. As mentioned in Chapters 3 and 4, severe thunderstorms, although possible anywhere and at any time, do not occur with the same frequency across all of the regions surveyed and thus the regions experienced either very many, or relatively very few, severe thunderstorms depending upon their relative susceptibilities. Another important deficiency of this measure is that it does not report magnitude or intensity. Simple frequencies, even when tallying severe events, are not sufficient for detailing the relative intensities of multiple different severe events occurring across a variety of geographically diverse regions.

That property damage influenced perceptions supports the realist perspective on societalenvironmental interactions, namely that indicators of material conditions of the environment should be included in sociological analyses of perceptions of environmental issues. How individuals perceive the effects of extreme weather is tied to their objective experience with extreme weather (or at least the experiences of those around them and closest to them). It is still important to emphasize that individual experiences and perceptions of environmental phenomena are shaped within social contexts, but material conditions matter at least insofar as they have objective impacts on the built environment. This finding presents a challenge to the 
environmentally-agnostic view from constructivists that environmental issues are strictly a matter for problematizing within the confines of social phenomena alone.

Rather than developing only in relation to the social characteristics of individuals, weather perceptions appear to emerge out of a combination of the objective experiences and social characteristics of individuals. This research provides a case for emergence as an appropriate theoretical construct to explain how individuals develop perceptions of environmental phenomena. As discussed below, certain social variables remain important, but individual weather perceptions are not formulated within the context of their social circumstances alone. Individuals experience extreme weather in the context of their social circumstances and thus perceive the impacts extreme weather through the lens of cultural and socioeconomic characteristics. In other words, it is not simply a matter of seeing to believe, but rather an emergent process of both seeing and believing -individuals experiencing extreme weather and interpreting the impacts against the backdrop of social and economic circumstances central to and surrounding their lives.

\subsubsection{Political and Environmental Values}

H2: Values, as measured by political identity, beliefs about the effects of conservation rules, and beliefs about climate change, also influence perceptions of extreme or unusual weather events.

Objectively measured impacts of extreme events affected perceptions, which in this respect are realistic. However, I also found significant effects from all three "values" indicators, so these perceptions also have a less realistic, socially constructed component. The main effect of 
political party affiliation (Table 4.2) suggested that Democrats, or politically liberal persons, were more likely to perceive effects from extreme or unusual weather events than Republicans, or politically conservative persons. This finding echoes the long-established link between political identity and environmental concern (Van Liere and Dunlap 1980; Mohai and Bryant 1998; O'Connor et al 2002; Uyeki and Holland 2000; Dietz et al 2007; Hamilton 2008), but it is distinct from prior research in that perceptions of the effects of environmental issues have not been investigated as much as general concern for environmental issues. Political liberals, or Democrats, might be more likely to perceive effects from extreme or unusual weather events because they are more concerned about environmental issues in general than their Republican, or politically conservative, counterparts (Dunlap 2008). A reasonable speculation here might be that Democrats/liberals are more concerned about environmental hazards, including climate change, while Republicans/conservatives are less likely (Hamilton 2011; Hamilton and Safford 2014; McCright and Dunlap 2011).

Individuals' beliefs about the effects of conservation rules on their communities were also significantly related to their perceptions of the effects of extreme or unusual weather events. Results presented in Chapter 4 suggested that respondents who believed conservation rules were good where they lived were more likely to perceive the effects of extreme or unusual weather events than those who believed conservation rules were bad (Table 4.2). This finding is suggestive of a relationship between individuals' "environmental values" (Dietz et al 2005) and their perceptions of the impacts of extreme weather events.

Prior studies utilizing CERA data have found that political identity is significantly related to individuals' beliefs about conservation rules. Using CERA surveys from the project's first 
stage, researchers found a significant link between political party identification and beliefs about the effects of conservation rules, such that political conservatives, or Republicans, are less likely to believe conservation rules have been good where they live than political liberals, or Democrats (Hamilton et al 2010). In fact, Democrats and Republicans diverge in their beliefs about most environmental issues (Hamilton 2008; Dietz et al 2005; Dunlap 2008; Hamilton and Safford 2014; Hamilton et al 2013). As mentioned in the previous chapter, however, my measure of political identity did not distinguish between Tea Party and non-Tea Party Republicans, so there could have been significant variation between the two conservative groups on extreme weather similar to the differences found in prior research on environmental and science-related issues (Hamilton and Saito 2014). Political identity is closely linked to views about the environment and, according to new findings from my research, both political identity and environmental views are linked to perceptions about the impacts of extreme weather events. This suggests that individual political orientations, and in turn their environmental values, shape perceptions of objectively real meteorological events, such as extreme or unusual weather.

Individuals' beliefs about the issue of climate change were also related to their perceptions of the impacts from extreme or unusual weather events. Results presented in Chapter 4 suggested that individuals who believed climate change is happening now due mainly to human activities were more likely to perceive effects from extreme or unusual weather than those who believed climate change is happening now due to natural phenomena or is not happening at all (Table 4.2). Climate change is a highly politicized issue (see McCright and Dunlap 2011), but my study adds to the broader literature by providing evidence of a relationship between individuals' beliefs about climate change and their perceptions of the impacts of climatic 
events. The Yale Project on Climate Change Communication has presented evidence in recent years suggesting that at least half of all Americans believe there has been a connection between extreme weather events to broader anthropogenic climate change (Leiserowitz et al 2014). In sum, there was strong evidence in support of hypothesis H2, namely that values influence perceptions of the effects of extreme or unusual weather events. All three values indicators --- respondents' political identities, their beliefs about conservation rules, and their beliefs about climate change --- were significantly related to their perceptions of the effects of extreme or unusual weather. Values did not operate in a vacuum, however, to influence perceptions of extreme weather among respondents. As mentioned above, objectively-measured weather impacts also exert influence over individuals’ perceptions. In addition to the objective influence of weather impacts, there was also significant county-level variation net of all individual-level and county-level fixed characteristics (Table 4.2). This combination of evidence points to the likelihood of perceptions of extreme weather as emerging from a combination of material and social conditions unique to the individuals' geographic location and their social characteristics. They should therefore be examined with careful attention to the cultural, social, biophysical, and infrastructural contexts within which they arise.

\subsubsection{Social Position and Socioeconomic Context}

H3: Social privilege or position indicators (such as household income) and socioeconomic context (such as county poverty rates) affect perceptions about extreme or unusual weather events. 
Household income, the individual-level social position indicator, was significantly related to individuals' perceptions of the effects of extreme or unusual weather. Results presented in Chapter 4 suggested that individuals in lower-income households were more likely to report effects from extreme or unusual weather events than individuals in higher-income households (Table 4.2). Lower-income households have more difficulty recovering in the aftermath of extreme weather events than higher-income households, or lower incomes may put households at a disadvantage when it comes to safeguarding and insuring homes against destructive consequences of extreme weather events.

Also, objective vulnerabilities stemming from socioeconomic disadvantage may be linked to increased subjective perceptions of vulnerabilities among disadvantaged individuals. In other words, those who are objectively more likely to be at risk for adverse consequences from environmental hazards may also be more likely to feel at risk due to their socioeconomic position and past experiences with environmental hazards. Recent studies have documented increased hazard risk among socioeconomically disadvantaged and minority groups, especially flooding in the aftermath of major storm events such as Hurricane Katrina (Bullard and Wright 2009; Mohai et al 2009; Cutter 2012; Levy 2012; Chakraborty et al 2014). Specifically, Bryan Boruff, Christopher Emrich, and Susan Cutter (2005) found that socioeconomic characteristics are particularly salient in the Gulf Coast of Louisiana, as compared to Atlantic and Pacific Coasts, in predicting vulnerability to coastal erosion. The authors argue that risk mitigation policies should be place-based and should attempt to improve social conditions rather than focus on "short-lived erosion control by beach nourishment or hardened structures, such as seawalls,” (Boruff et al 2005). 
Although individual position mattered, community-level socioeconomic context --- as measured by the county poverty rate --- had no significant net effect on individual perceptions. This suggests that local socioeconomic context may not influence how individuals perceive the effects of extreme or unusual weather. It was hypothesized that socioeconomic context would influence individual perceptions. Some recent research found effects from local context on individual beliefs about environmental and economic protection and resource issues (Hamilton et al 2010; Hamilton and Safford 2012; Hamilton et al 2013), but it did similarly affect perceptions of extreme events. County poverty showed no effect net of other individual-level characteristics and county-level weather impacts. Thus, there was only partial support for hypothesis H3, namely that individual-level social position influences individuals' perceptions of the effects of extreme weather events but not the county poverty rates. Perhaps local socioeconomic context is less important when it comes to safeguarding against (or recovering in the aftermath of) extreme weather events because the burdens from events studied here were more focused on specific individuals, families, or households.

My findings contribute to the broader literature on the social bases of environmental concern by connecting the socioeconomic characteristics of individuals' to their perceptions of environmental issues affecting their communities and families. Prior research has found inconsistent results on income as a predictor of environmental concern. Other characteristics, notably political identity and educational attainment (Guagnano and Markee 1995; Hamilton 2008), have shown more consistent influence on individual-level environmental concern. Additionally, survey questions utilized as dependent variables in prior research may have tapped less directly into individuals' perceptions of environmental phenomena happening in their 
communities. For instance, survey questions utilized in the investigation of the social bases of environmental concern have typically focused on broader environmental issues affecting humans and ecosystems on a global scale (see Dunlap 2008), with the exception of the CERA studies of which my research is a part (Hamilton et a 2013; Hamilton and Safford 2014). The results of my study suggest that income is an important predictor of perceived local impacts from damaging events, a different kind of "environmental concern.”

\subsubsection{Interaction Effects}

H4: Individual values and social position indicators will exhibit interaction effects, such that they moderate the relationship between objectively-measured weather events, and individual perceptions about the impacts of weather events.

My fourth hypothesis predicts that individual values and social position interact with objectively-measured weather events, such that political party affiliation and household income moderate the relationship between objectively-measured weather events or property damage and individual perceptions about such events. Results presented in Chapter 4 showed that political identity moderated the relationship between the number of severe thunderstorm events and individual perceptions (Table 4.1), and income moderated the relationship between property damage and individual perceptions (Table 4.2). Democrats were more likely to perceive effects of extreme weather even if there were fewer severe thunderstorm events in their counties, whereas among Republicans perceived impacts rose more directly with the actual number of events. Republicans’ perceptions track more closely with changes in the actual number of events 
happening in their communities. Alternatively, Democrats may expect more extreme weather and be more sensitive to events or impacts that do occur. As stated in earlier chapters, however, the thunderstorm events measure has a number of limitations related to its validity and may not reflect the reality of severe weather in these regions as closely as the property damage indicator or another measure which takes into account the most common weather affecting these regions.

Where property damage was low, individuals in lower-income households were more likely to report effects of extreme or unusual weather than those in higher-income households. In contrast, where property damage was higher, individuals in both high- and low-income households were more likely to report effects from extreme weather. This finding suggests that lower-income households are impacted adversely by extreme weather even in areas that have relatively little overall damage from such events, thus contributing to the broader environmental justice and hazards/social vulnerability literature which has found socioeconomic factors to be predictive of environmental hazard risks (Chakraborty et al 2014; Eisenman et al 2007; Finch et al 2010; Brulle and Pellow 2007; Levy 2012; Cutter et al 2003). Susan Cutter and Christopher Emrich (2006) defined social vulnerability as "the susceptibility of social groups to the impacts of hazards, as well as their resiliency, or ability to adequately recover from them.” Socially and economically disadvantaged segments of the population have been more susceptible to environmental hazards because of a variety of confounding factors related to socioeconomic status, such as a lack of personal wealth, social capital, and access to "lifelines," or "emergency response personnel, goods, and services,” (Cutter and Emrich 2006).

As it relates to extreme weather vulnerability, low-income homes may be at elevated risk of damage from extreme weather for a number of reasons. First, they may not have adequate 
home insurance policies and struggle to pay for damages in the aftermaths of extreme weather events. Second, homes built for low-income owners may have been constructed in low-lying locations vulnerable to flash floods or sustained flooding events. Third, inexpensive homes available to low-income individuals may be poorly constructed or constructed without the best technology to defend the home from some of the more insidious problems associated with extreme weather events, such as leaking roofs, windows, or doorways. Past research has shown that the quality of housing, among a number of other indicators of social vulnerability, has been related to disaster susceptibility at the county level. Specifically, those who reside in mobile homes and in areas with a lack of community resources and emergency response capacities have been cited as particularly vulnerable to major disaster events (Cutter et al 2003).

These interaction effects were particularly interesting because few studies in the past have integrated survey data with objectively-measured environmental or climatic data (see Hamilton and Stampone 2013; Hamilton and Keim 2009). My study extends previous work by showing moderating effects of individual values and social position on the relationship between objective measures of an environmental issue and individuals' concerns or perceptions about the environmental issue itself. As stated previously, weather perceptions appear to emerge out of a combination of objective experiences and social circumstances of individuals. These interactions lend evidence to validate the application of emergence to explain how individuals’ form perceptions of extreme weather. Individuals' perceptions are influenced by their social position in light of actual experiences with extreme weather impacts. Thus, perceptions of extreme weather emerge out of the interplay of individuals' social characteristics and the objective material circumstances tied to their geographic locations and socioeconomic positions. 


\subsubsection{Place-to-Place Variation}

H5: There will be significant, systematic place-to-place variations in perceptions about weather impacts, even after controlling for objective weather indicators, values and other individual- or county-level socioeconomic characteristics.

The results from mixed-effects regression analysis presented in Chapter 4 showed that the county-level random intercept was significant (Table 4.2). This means that there was systematic place-to-place variation in perceptions about weather impacts net of objective weather indicators and other individual- and county-level characteristics. There may be a variety of factors that make individual perceptions vary significantly from place to place. One place to begin when considering factors related to place-to-place variation is local economic context. Extreme weather events may have had greater long-term impacts on the local economies of coastal Louisiana than coastal Florida. Plaquemines and Terrebonne Parishes have been heavily dependent on their seafood and fishing industries (Louisiana State University Agricultural Center 2014; Greater New Orleans, Inc. 2014), whereas the Florida panhandle has had vibrant timber and agricultural industries and has benefited from increased tourism since the late 1990s and early 2000s (PBS 2003). Louisiana's seafood industries along the coastline were critically impaired by Hurricane Katrina and were estimated to have lost millions of dollars in the sale of crab, freshwater fish, oysters, shrimp, and saltwater shrimp (Alford 2005). The economic impacts of extreme weather in coastal Louisiana may account for some of the significant placeto-place variation found in this study.

Figure 4.10 shows mean of the random intercepts by county from Model 6 in Table 4.2. Several interesting findings emerge from an inspection of the mean random intercepts. First, 
residents in all three of the Gulf Coast Florida counties (Bay, Franklin, and Gulf) were more likely to report no effects from extreme or unusual weather events. As mentioned in above paragraph, perhaps Floridians were not dependent upon industries impacted by extreme weather events. Also, some Gulf Coast Floridians may not have been year-round residents and as such may have avoided the area during hurricane season. Panama City is the seat of Bay County and likely attracts a large number of semi-permanent or vacationing residents as opposed to yearround, permanent residents who are dependent on local economies and industries for their livelihoods. Another important factor to consider is the political milieu of the Gulf Coast of Florida. All three Florida counties favored the Republican candidate in the 2008 election, John McCain. Republicans reported fewer impacts from extreme or unusual weather events than their Democrat counterparts (see Table 4.2), so it seems likely that local political culture may have influenced Gulf Coast Floridians in their perceptions of extreme or unusual weather events.

Unlike Gulf Coast Florida, the two parishes surveyed in Gulf Coast Louisiana presented contrasting viewpoints on the impacts of extreme or unusual weather events. According to Figure 4.10, residents of Terrebonne Parish were more likely to report effects from extreme or unusual weather, whereas Plaquemines Parish residents were less likely to report effects from such events. Both parishes have had significant seafood and oil industries. Terrebonne Parish has accounted for about $20 \%$ of the seafood production in Louisiana and Plaquemines Parish has been the largest producer of crude oil in the state. Both parishes also have had important sea ports involved in the shipment of cargo and offshore oil. Given the similarities in economic production of the two parishes, we might expect residents to have had similar perceptions of the impacts of extreme or unusual weather. Instead, Terrebonne and Plaquemines Parish residents 
diverged in their perceptions, suggesting that economic considerations might actually have been quite different among residents of each parish, as well as other local cultural or political contexts. Terrebonne Parish has diversified its economy in recent years and seafood production has taken on a more significant role than oil production, especially given the downfall of the HoumaTerrebonne economy in the aftermath of the oil crises of the late 1970s and early 1980s. Extreme or unusual weather events, such as Hurricane Katrina, may have had devastating impacts for those Terrebonne residents who have become dependent on the seafood production of their community.

Another interesting contrast comes from the comparison of the adjacent Washington and Hancock Counties in Downeast Maine. As depicted in Figure 4.10, Hancock County residents were more likely to report effects from extreme or unusual weather events, whereas Washington County residents were less likely to report effects from such events. Washington County had the highest poverty rate of all counties in Maine in 2008, whereas Hancock County benefited from increased tourism and housing development due to the scenic environment and draw of Acadia National Park (Safford and Hamilton 2010). Hancock residents who have either purchased new homes or have been reliant on the tourism and service sectors of the economy may have been more sensitive to the impacts from extreme or unusual weather events. Washington County residents, on the other hand, have relied on fishing and forestry jobs to support their local economies. While these industries are not immune to the impacts of extreme weather, they may be less sensitive than the tourism- and service-related industries at the core Hancock County’s economy. 
These divergent perceptions among residents of adjacent counties provide further evidence of the emergent nature of extreme weather perceptions. While the objective material conditions of Terrebonne and Plaquemines Parishes, as well as Hancock and Washington Counties, appeared similar according to the weather events measures, the local economic and social contexts likely contributed to the stark differences in perceptions between residents of these places. Material conditions matter to individuals’ perceptions, but are interpreted against the backdrop of local social and economic circumstances. In theoretical terms, we can understand individuals’ perceptions of extreme weather as emergent from social and material conditions tied to individuals’ geographic locations. I explore this implication further in the following section.

\section{$\underline{5.2}$ Theoretical Implications}

\subsubsection{Moving beyond the social-interactional level}

As discussed in Chapter 2, Paul Stern and Thomas Dietz developed the values-beliefsnorms (VBN) theory to explain environmental concern and behavior. The basic postulate of the theory is that individuals' values influence their personal beliefs about the environment and related issues, which in turn influence whether or not and the extent to which they will act with regard to environmental issues (Dietz et al 2005; Dietz et al 2007; Stern 2000). VBN is primarily a social-psychological theory, meaning that it seeks to explain how individual thoughts and actions are influenced by others. Social interaction has also been a major component of the theoretical considerations in the study of environmental risk perception (Overdevest and 
Christiansen 2013; Kahan et al 2011) and the consumption of environmental information (Wood and Vedlitz 2007; Darmofal 2005; Kahan et al 2011). While social interaction is undoubtedly an important factor to consider, the study of environmental concern will benefit from a broader investigation of possible influential factors, such as economical, infrastructural, and biophysical determinants.

More recent studies have included place and contextual factors in their analyses. As outlined in Chapter 2, Larry Hamilton, Tom Safford, and colleagues investigated the influence of local social and economic conditions (Hamilton et al 2010; Hamilton et al 2013; Safford and Hamilton 2012), recent shifts in climate and weather patterns (Hamilton and Keim 2009; Hamilton and Stampone 2013), and recent environmental disasters (Safford et al 2012; Hamilton et al 2012) on individual views of environmental issues. Other recent studies have found links between individuals' attachment to their place of residence and their environmental values (Brehm et al 2006; Brown and Raymond 2007; Brehm et al 2012; Larson et al 2013), as well as individuals' social capital (i.e. occupational prestige, social connections, and civic engagement) and their environmental concern (Macias and Nelson 2011). While these studies have opened research on environmental concern to the investigation of contextual and place-based determinants, there has been less attention to the theoretical explanation of the relationship between place, context, and environmental concern.

Part of the reason there has been little consensus regarding a coherent theoretical framework to explain the social and contextual factors underlying environmental concern is that environmental sociology has been marked by a persistent division between those who study the social and cultural components of the human-environment relationship and those who focus 
more on objective interactions between society and the environment. This cleavage in the literature has been famously referred to as the "realist-constructivist divide" (Hannigan 2006; Dunlap 2010).

In Chapter 2, I discussed John Hannigan's (2006) proposition of the "emergence framework" as a useful tool going forward in environmental sociology. Hannigan highlights three "Herculean labours" that lie ahead for those of us attempting to "[p]ropel the analysis of societal-environmental relations forward into new territory (Hannigan 2006). These include a confrontation of the nature-society divide, a synthesis of the strengths of both the conceptual and empirical pursuits, and a reconciliation of the "macro-level, European-style" sociology of the environment with the "more particularistic data analysis characteristic of American environmental sociology," (Hannigan 2006). Hannigan argues that "an emergence framework" is well-poised to handle these tasks because "it allows for a range of phenomena -- infectious diseases, ice storms and tsunamis, uncertainties and risks, scientific boundary organizations, and environmental movements," and it is "equally useful" at the local and global levels. Hannigan provides the example of examining social interaction in the aftermath of disasters.

Although Hannigan explained why emergence should be seriously considered going forward by sociologists studying environment and society, he left much on the table regarding what exactly "emergence" refers to and how it can be applied in environmental sociology. In the following subsection, I give a conceptual definition of emergence and apply it to the research findings of the present study. 


\subsubsection{Perceptions of extreme weather as emergent properties}

In Chapter 2, I gave a brief history of the concept of emergence in sociological inquiry. In the course of that description, I presented a couple different conceptual definitions which have been offered by sociologists working in very different areas of specialization. R. Keith Sawyer, on the topic of Durkheim's work, argued that Durkheim's sui generis is essentially synonymous with emergence ${ }^{14}$. John Hannigan gave a somewhat vague definition of emergence as, "...fundamentally fluid, dynamic, and adaptive [processes that ] ... percolate from the grassroots rather than pass from the top downwards," (Hannigan 2006). In his research on "neighborhood effects," Robert Sampson referred to emergent properties as "social-interactional and institutional processes that involve collective aspects of community," (Sampson 2012). Though these conceptions of emergence in sociology were used to explain different phenomena, there are strains of similarity that essentially draw them all back to one central theme: emergent properties are social products that form from the interaction of factors spanning social and physical worlds on both micro- and macro-levels.

Regarding the micro-macro distinction in social science research, my study also points to the need for bridging the micro- and macro-analytical perspectives in research on environmentalsocietal interactions. Broad, overarching features of society and inter-subjective, localized meanings must be considered in conjunction with one another in order to reveal the complete picture of environmental concern among individuals. The realist-constructivist divide is not equivalent to the micro-macro distinction, so part of my goal in bridging the realist-constructivist

\footnotetext{
${ }^{14}$ According to Sawyer (2002), although Durkheim didn't use the term "emergence," his concept of sui generis refers to essentially the same thing, i.e. something that cannot be reduced to any of its parts and is more than just the mere sum of its parts.
} 
gap will also be to link the micro- and macro-analytical perspectives, especially in terms of suggesting pathways for future research. As I have suggested throughout, the emergence framework can provide the theoretical and conceptual grounds for connecting both realistconstructivist and micro-macro divisions in environmental-societal research.

By its very nature (and perhaps ironically), the concept of emergence is difficult to narrow down to a single definitional statement. Philosophers have discussed the concept with a series of empirical examples to illuminate how it operates in everyday reality. For example, Sawyer (2002) references traffic on highways or the "flying V" formation of a flock of birds in order to illustrate emergence. ${ }^{15}$ These demonstrate how "higher-level regularities are often the result of quite simple rules and interactions at the lower level," (Sawyer 2002). The physical and biological sciences refer to phenomena like these as "complex adaptive systems" because they are made up of many different interconnected parts and change based on experiences. Typical examples include ant colonies, the human immune system, cells and embryos, and even the brains of insects and animals.

My study provides evidence to suggest that perceptions of the effects of extreme weather are emergent properties as well. By emergent properties, I mean that individuals' perceptions of extreme weather are not reducible to the individuals themselves, but rather the consequence of multiple social and physical factors all converging to create systems of shared perceptions between individuals. In calling them "shared perceptions," I am not inferring that individuals have the exact same perceptions as those nearest them. Instead, I am suggesting based on the

\footnotetext{
${ }^{15}$ Sawyer (2002) gives the example of the "V" shape bird flocks take on in flight. According to Sawyer, none of the birds in the flock decides to lead, and the birds behind the front are not following the direction of a single leader. Instead, as Sawyer points out, the V shape emerges out of interactions between each adjacent pair of birds in the flock.
} 
evidence that we can understand individuals' perceptions in terms of their shared realities tied to place (and all of the socio- and biophysical-contextual factors embedded in place). On the other hand, there may exist multiple different and often conflicting perceptive realities in the same geographic space. For example, Democrats and Republicans within the same community may have different perceptions despite the common objective experience of place. While environmental experiences and beliefs may be rooted in place in ways that may be suggestive of shared experience, the experience itself is reinterpreted against the backdrop of values that can cause divergence rather than similarity. Several findings from my study illustrate the emergent nature of extreme weather perceptions as either shared or divergent.

First, several individual-level characteristics were predictive of individuals' perceptions of the effects of extreme weather controlling for the number of severe thunderstorm events and the amount of property damage from all severe event types at the county level. Perhaps the most interesting among the individual-level effects were the influences of the "values" indicators. Political party affiliation, beliefs about conservation rules, and beliefs about climate change were all significantly related to perceptions of the effects of extreme weather. Individuals' political identities are usually tied to family and peer-network socialization, as well as local political, economic, and cultural circumstances. Moreover, beliefs about the effect of conservation rules on local communities are implicitly tied to place. Both of these indicators were important to explain individuals' perceptions of the effects of extreme weather, suggesting individual perceptions of objectively-measured environmental phenomena emerge from place-related valuesystems, among other factors. 
Climate change beliefs, like political identities, are at least in some part connected to the national political context given the scope and politicization of the topic. In the case of extreme weather events, the influence of individuals' climate change beliefs might be reflective of what Bert Klandermans referred to as "consensus mobilization" (Klandermans 1984). According to Klandermans (1984), consensus mobilization "is the process by which a social movement tries to obtain support for its point of view. It is directed towards influencing knowledge, beliefs, and attitudes." Climate change denial has developed as a major social movement among conservatives in response to perceived threats to the "American way of life" (Jacques et al 2008). Extreme weather has been attributed to climate change by some scientists and environmentalist groups (see Natural Resources Defense Council 2014; World Resources Institute 2012; National Wildlife Federation 2010), so extreme weather may be viewed by the climate-skeptic movement as something conjured by the environmentalists to rally support around their side of the issue of climate change. Therefore, extreme weather events may be used by social movements on either side of the debate to develop their consensus mobilization.

Evidence for this is suggested by Figure 4.7, which shows that Democrats were more likely to report effects from extreme or unusual weather events than their Republican counterparts even in places where few severe events have occurred. Hannigan (2006) described consensus mobilization as an emergent phenomenon because it involves "'...ideas, beliefs, and norms [which] are in the process of being formulated."' This is precisely how I conceptualize perceptions of the effects of extreme weather. Perceptions are emergent in that they are "in the process of being formulated" by factors related to place-specific contexts (i.e. political values, socio-economic conditions, and objectively-measured weather impacts) and in light of 
contemporary macro-level circumstances (i.e. climate change, politics, and broad economic forces). Additionally, perceptions help to mobilize consensus in that they rally support for social movements on both sides of the climate change issue. Further evidence for this is suggested by the positive relationship between climate change beliefs and perceptions of the effects of extreme weather (Table 4.2). The odds of reporting effects of extreme weather increased among those who believed climate change is happening now due to human activities. It is important to note that anthropogenic climate change is a scientific consensus and climate science has made some connections between some extreme weather and climate change, so this particular group may be making a larger connection between the weather hazard and climate change (perhaps climate change as a hazard in and of itself).

Another important finding of my study provides evidence that perceptions of the effects of extreme weather are emergent properties of place-specific contexts. The county-level random effect showed that there was place-to-place variation in perceptions of extreme weather net of individual-level characteristics, county-level characteristics, and objectively-measured, countylevel weather events and property damage. This means that the counties represented in this sample contained some factors or combination of factors that were unique in influencing their residents' perceptions of extreme weather events. For example, the fishing industries in Terrebonne and Plaquemines parishes, Louisiana, may have something to do with this placebased variation and the influence may extend beyond those employed in fishing industries. In their study of public support for climate change policy, Rachael Shwom and colleagues (2008) found significant place-based variation in levels of policy support between Virginia and Michigan residents controlling for survey respondents' employment (or family 
members' employment) in the auto industry. Specifically, they found that Michigan residents were less likely to support climate change policies than Virginia residents, and employment in the automobile industry did not affect policy support. The authors argue that the automobile industry may subtly affect residents in Michigan because it is such a pervasive industry in that region and has some influence over the shaping and framing of information about issues such as climate change (Shwom et al 2008). A similar phenomenon may have occurred in Terrebonne and Plaquemines parishes in Louisiana, where the fishing industries have been so pervasive in local social and cultural milieus that their disruption as a result of extreme weather caused a ripple effect throughout the entire counties.

In contrast to the perceptions of residents of Gulf Coast Louisiana, respondents in Gulf Coast Florida were less likely to report effects from extreme or unusual weather events (Figure 3.3), even though the amount of property damage in dollars was relatively high in Gulf Coast Florida (Table 3.4). Though in the opposite direction, this relationship is also suggestive of place-specific contexts contributing to individual perceptions of extreme weather effects. All three Florida counties represented in this sample, Bay, Gulf, and Franklin, have supported Republican candidates in the 2000, 2004, and 2008 presidential elections (Federal Election Commission 2000; Federal Election Commission 2004; Federal Election Commission 2008). Additionally, all three counties have overwhelmingly supported Republican candidates for other national- and state-level offices (Bay County Supervisor of Elections 2000; Bay County Supervisor of Elections 2004; Bay County Supervisor of Elections 2008; Franklin County Supervisor of Elections 2004; Franklin County Supervisor of Elections 2008; Gulf County Supervisor of Elections 2008). Reinforcing these statistics, the sample of Bay, Franklin, and Gulf 
counties in this research was $48 \%$ Republican and $40 \%$ Democrat, and $45 \%$ of respondents believed climate change is happening due to natural phenomena as opposed to only $34 \%$ who believed it is happening due to human activities. The conservative political cultures of these counties may have influenced residents' perceptions of extreme weather through an emergent process such as consensus mobilization, whereby the climate change denial movement may have subtly influenced the shaping and framing of information about extreme or unusual weather affecting these Florida counties.

Objective local conditions also helped to illustrate the emergent nature of individuals' perceptions of the effects of extreme weather. Property damage from all severe weather events was significantly related to perceptions of the effects of extreme or unusual weather, such that the odds of reporting effects increased in places with higher property damage (Table 4.2). This suggests that individuals are more likely to perceive effects of extreme weather when the impacts from severe weather, as measured by damage in dollars, are objectively greater. In conjunction with individual-level characteristics, the effect of objective local conditions demonstrated how perceptions emerge out of both experiential and socio-political and -cultural contexts. Therefore, the symbolic, ideational, and cultural realms are as important as the material and biophysical in the explanation of individuals' perceptions of extreme or unusual weather events. My study represents yet another reason for the reconciliation of realist and constructivist camps in environmental sociology. 


\subsection{Limitations and Future Research}

\subsubsection{Limitations of the present study}

One of the limitations of my study is that the "objectively-measured" severe weather events and property damage variables may not have been precise or may not have accurately reflected the actual lived experiences of individuals with respect to severe weather events. As acknowledged in Chapter 3, the SED only provided an estimation of damages based on a variety of sources. Also, the STEA only reported on thunderstorm events and only if the events met certain criteria in order to be qualified as "severe." Although thunderstorm events can occur anywhere in the United States and therefore make cross-regional comparisons easier, they likely do not capture the full range of "extreme or unusual" weather sufficiently. Droughts, hurricanes, winter storms, and other destructive events were not captured at all by the thunderstorm indicator. The SED property damage variable did include all weather event types, but it estimated the dollar-value based on reported damages and not all damage is necessarily reported to officials, insurance agencies, or local news media. Moreover, not all severe weather events necessarily cause losses in dollars from damage to property, and damages may extend far beyond property loss in terms of trauma or mental and emotional stress.

Despite these limitations, the property damage indicator appeared to be a much better objective measure than the simple frequency of severe thunderstorms. Not only was the property damage indicator directly related to perceptions, but it was likely to be a better approximation of the actual “on-the-ground” experiences of individuals with severe or extreme weather events. The frequency of severe thunderstorms, on the other hand, was likely an inaccurate estimation of the actual severe weather experienced on the ground in the variety of regions surveyed. More 
broadly, any frequency measure will likely be insufficient without an accompanying or combined measure of magnitude or intensity. While the property damage estimate was intended to get at this aspect of severe weather, it was not tied to the severe thunderstorm frequencies and was not an actual measure of storm magnitude or intensity.

Another limitation of my study is the scope of its findings. Only a section of coastal regions were represented in this research. The differing social, cultural, or economic conditions of inland versus coastal communities likely make for disparate perceptions of extreme weather. Industries along coastal regions, and those employed with them, may be more susceptible to extreme storms than inland industries. On the other hand, the kinds of weather events that disrupt inland industries, such as drought, may not be captured by this research. On a related note, inland regions experience different quantities and qualities of severe weather events than coastal regions. While coastal regions might experience more intense storms, both tropical and extratropical (extra-tropical storms cause more storm surges along northeast coastlines (ME) than tropical storms), inland regions face hotter temperatures and higher potential for drought. The limited scope of these findings prevented this research from inferences about the experiences of those living inland.

With respect to values and political identity, my research was not able to parse out the potential differences between individuals on the political extremes and those who were politically more moderate in their views. The measure of political identity I utilized was perhaps too rigid and did not allow for me to distinguish between those who identify as extremely liberal or conservative, or some other prominent political identity not captured by the “Democrat/Independent/Republican” trichotomy. Recent research on environmental concern has 
found self-identified “Tea Party” Republicans to be significantly less likely to believe that the climate is changing now due to human activities than their non-Tea Party Republican peers (Hamilton and Saito 2014). This difference signals the necessity for disaggregating political parties into more specific categories, especially in the case of Tea Party and non-Tea Party Republicans. While my research was not able to accomplish this task, future studies should be careful to measure and/or analyze the finer distinctions of political identity and values within the broader political party designations.

\subsubsection{Future Research}

My research opens a number of interesting possibilities for future study. Regarding the limited scope of this research, future studies should investigate a wider range of event types and the perceptions of inland residents. Research on individuals living across a variety of geographic locations will be needed in order to understand the spectrum of experiences with extreme weather. It will also be important to include individuals living in a variety of cultural, social, economic conditions. As demonstrated in my study, the character of individuals' experiences with extreme weather depends in part on the social contexts of their communities.

In addition to expanding the scope of the research, case studies will be important components to include in future studies. Due to their natural variability, extreme weather events will likely affect communities differently from one event to the next. Human experiences with extreme weather could even vary widely within a single event. For instance, a tornado could destroy one neighborhood while leaving the adjacent neighborhood intact. The same could be true for flash floods, lightning strikes, wind and rain damage, and the list goes on. Case studies 
of particular extreme events and on specific individuals, families, and communities will be useful in order to provide in-depth knowledge of lived experiences and micro-level social processes occurring between individuals and their families or communities. Human losses (i.e. injuries and fatalities) were not captured by my research and could be best understood using a qualitative interview method of research in future research.

Historical research will also be necessary in future studies of extreme weather events for a variety of reasons. First, communities could have cultural milieus that include experiences with past extreme or unusual weather events. Tapping into these historical-cultural elements of communities could prove useful to understand how and why individuals in certain communities react the way they do to present weather events. People often invoke past experiences with weather tied to a particular area when discussing the occurrence of present day weather events, especially when weather events are perceived as "extreme" or "unusual." Another important reason for including historical research is that it adds contextualization of communities' social, political, and economic circumstances, which may help explain how communities prepare for extreme weather or respond in the aftermath. Finally, this can also be an opportunity for community education and outreach. A better understanding of how a community perceives a hazard could be useful for determining how best to communicate hazards.

\section{$\underline{5.4 \text { Concluding Remarks }}$}

In this study I provided evidence to suggest that individuals' perceptions of the effects of extreme or unusual weather events are couched within the social contexts and objective material 
conditions of their communities. All five hypotheses were at least partially supported. First (H1), objectively-measured property damage was related to individuals' perceptions of extreme or unusual weather such that increased damage was associated with increased perceptions of the effects of events. Second (H2), political and environmental values were related to individuals' perceptions of extreme or unusual weather such that politically liberal, environmentallyconscious individuals exhibited increased perceptions of the effects of events over their politically conservative, less-environmentally-conscious counterparts. Third (H3), social position, as measured by household income, was related to individuals' perceptions of extreme or unusual weather such that lower-income households exhibited increased perceptions of the effects of events over their higher-earning counterparts.

Fourth (H4), social position and political identity interacted with property damage and events totals such that household income moderated the effect of damage on individuals' perceptions and political identity moderated the effect of the number of events on individuals' perceptions. The effects of income appeared different in places with lower or higher objective damage. Partisan identity also showed different effects in places with lower or higher thunderstorm frequency. Democrats were significantly more likely to report effects from extreme or unusual events in places with fewer or no severe thunderstorms. Finally (H5), there was significant, systematic place-to-place variation in individuals' perceptions of extreme or unusual weather events net of all individual- and county-level fixed effects.

The patterns found in this study suggest that individuals' perceptions of the effects of extreme weather events are emergent properties of objective local conditions, particular individual characteristics related to social and cultural milieus, and place-specific contexts. 
Results echo Hannigan's (2006) claim that "our relationship with nature should be conceptualized as both fluid and emergent." As Hannigan astutely pointed out, our relationship is not just a matter of socially-constructed perceptions and definitions, but also the result of the "substance and patterns of nature."

The methodological approach and results of my study also advance the study of society and the environment toward a unified front, supporting elements of both realist and constructivist perspectives. My study arose in part as a response to Dunlap's (2010) concern that although the realist-constructivist battles have subsided there is still a broader division between "...environmental sociologists who confine their analyses to the symbolic/ideational/cultural level and those who examine material conditions--." I believe it is not only possible but necessary to conduct research on society-environment interactions with both social and material conditions in view. My research is an attempt to advance that approach. The evidence suggests that human interactions with the environment are emergent properties of both material and social conditions. 


\section{REFERENCES}

Alford, Jeremy. 2005. "Seafood Industries Devastated by Hurricane." nytimes.com, September 8. Retrieved August 13, 2014 (http://www.nytimes.com/2005/09/08/national/nationalspecial/08cndfisheries.html? $\mathrm{r}=0$ ).

Ash, Kevin D., Cutter, Susan L., and Emrich, Christopher T. 2013. “Acceptable losses? The relative impacts of natural hazards in the United States, 1980-2009.” International Journal of Disaster Risk Reduction. 5:61-72.

Bay County Supervisor of Elections. 2000. General Election Summary Report. Panama City, Florida. Bay County Supervisor of Elections. http://www.voterfocus.com/hosting/bay/ew_pages/2000/2000GeneralSummary.htm (accessed August 2014).

Bay County Supervisor of Elections. 2004. General Election Summary Report. Panama City, Florida. Bay County Supervisor of Elections.

http://www.voterfocus.com/hosting/bay/ew_pages/2004/GeneralSummary.htm (accessed August 2014).

Bay County Supervisor of Elections. 2008. General Election Summary Report. Panama City, Florida. Bay County Supervisor of Elections. http://www.voterfocus.com/hosting/bay/ew_pages/2008/GENSummary.htm (accessed August 2014).

Beck, Ulrich. 1992. Risk Society: Towards a New Modernity. London: Sage Publications.

Beck, Ulrich, Bonss, Wolfgang, and Lau, Christoph. 2003. "The Theory of Reflexive Modernization: Problematic, Hypotheses, and Research Programme.” Theory, Culture, \& Society. 20(2):1-33.

Boruff, Bryan J., Emrich, Christopher, and Cutter, Susan L. 2005. "Erosion Hazard Vulnerability of US Coastal Counties.” Journal of Coastal Research. 21(5):932-942.

Brechin, Steven R. 2003. "Comparative Public Opinion and Knowledge on Global Climatic Change and the Kyoto Protocol: The U.S. versus the World?" International Journal of Sociology and Social Policy. 23(10):106-134.

Brehm, Joan M., Eisenhauer, Brian W., and Krannich, Richard S. 2006. "Community Attachments as Predictors of Local Environmental Concern: The Case for Multiple Dimensions of Attachment." American Behavioral Scientist. 50(2):142-165. 
Brehm, Joan M., Eisenhauer, Brian W., and Stedman, Richard C. 2012. "Environmental Concern: Examining the Role of Place Meaning and Place Attachment." Society and Natural Resources. 0:1-17.

Brown, Gregory and Raymond, Christopher. 2007. "The relationship between place attachment and landscape values: Toward mapping place attachment." Applied Geography. 27:89111.

Brulle, Robert J. and Pellow, David N. 2006. "Environmental Justice: Human Health and Environmental Inequalities.” Annual Review of Public Health. 27:103-124.

Bullard, Robert D. and Johnson, Glenn S. 2000. "Environmental Justice: Grassroots Activism and Its Impact on Public Policy Decision Making.” Journal of Social Issues. 56(3):555578.

Bullard, Robert D. and Wright, Beverly (eds). 2009. Race, Place, and Environmental Justice After Hurricane Katrina: Struggles to Reclaim, Rebuild, and Revitalize New Orleans and the Gulf Coast. New York, NY: Westview Press.

Cable, Sherry, Walsh, Edward J., and Warland, Rex H. 1988. "Differential Paths to Political Activism: Comparisons of Four Mobilization Processes After the Three Mile Island Accident.” Social Forces. 66(4):951-969.

Carlton, Stuart J. and Jacobson, Susan K. 2013. "Climate change and coastal environmental risk perceptions in Florida." Journal of Environmental Management. 130:32-39.

Chakraborty, Jayajit, Collins, Timothy W., Montgomery, Marilyn C., and Grineski, Sara E. 2014. "Social and Spatial Inequalities in Exposure to Flood Risk in Miami, Florida." Natural Hazards Review. 15.

Cutter, Susan L and Emrich, Christopher T. 2006. "Moral Hazard, Social Catastrophe: The Changing Face of Vulnerability along the Hurricane Coasts." Annals of the American Academy of Political and Social Science. 604:102-112.

Cutter, Susan L. 2012. Hazards Vulnerability and Environmental Justice. New York, NY: Earthscan.

Cutter, Susan L, Boruff, Bryan J., and Shirley, W. Lynn. 2003. "Social Vulnerability to Environmental Hazards.” Social Science Quarterly. 84(2):242-261.

Cutter, Susan L. 2001. American Hazardscapes: the regionalization of hazards and disasters. Washington, D.C.: Joseph Henry Press. 
Di, Zhu Xiao. 2007. "Do Homeowners Have Higher Future Household Income?" Housing Studies. 22(4):459-472.

Dietz, Thomas, Frisch, Ann Stirling, Kalof, Linda, Stern, Paul C., and Guagnano, Gregory A. 1995. "Values and Vegetarianism: An Exploratory Analysis." Rural Sociology. 60(3):533-542.

Dietz, Thomas, Dan, Amy, and Shwom, Rachael. 2007. "Support for Climate Change Policy: Social Psychological and Social Structural Influences." Rural Sociology. 72(2):185-214.

Dietz, Thomas, Fitzgerald, Amy, and Shwom, Rachael. 2005. "Environmental Values." Annual Review of Environment and Resources. 30:335-372.

Dunlap, Riley E. 2010. "The maturation and diversification of environmental sociology: from constructivism and realism to agnosticism and pragmatism." The International Handbook of Environmental Sociology. Northhampton, MA: Edward Elgar Publishing, Inc

Dunlap, Riley E. and Brent K. Marshall. 2007. "Environmental Sociology." Pp. 329-340 in C. D. Bryant and D. L. Peck (eds.), 21st Century Sociology: A Reference Handbook, Vol. 2. Thousands Oaks, CA: Sage.

Dunlap, R.E., and Van Liere, K.D. 1978. "The "New Environmental Paradigm”: A proposed measuring instrument and preliminary results." The Journal of EnvironmentalEducation. 9(4):10-19.

Dunlap, Riley E., and Van Liere, Kent. D. 1984. "Commitment to the Dominant Social Paradigm and Concern for Environmental-Quality." Social Science Quarterly. 65(4):1013-1028.

Dunlap, R.E. and W. Michelson (eds) 2002. Handbook of Environmental Sociology. Westport, CT: Greenwood Press.

Dunlap, Riley and McCright, Aaron M. 2008. "A Widening Gap: Republican and DemocraticViews on Climate Change." Environment. 50(5):26-35.

Eder, Klaus and Ritter, Mark Trans. 1996. The Social Construction of Nature: A sociology of ecological enlightenment. Sage.

Egan, Patrick J. and Mullin, Megan. 2014. "Psychology: Local weather and climate concern.” Nature Climate Change. 4(2):89-90.

Eisenman, David P., Cordasco, Kristina M., Asch, Steve, Golden, Joya F., and Glik, Deborah. 2007. "Disaster Planning and Risk Communication With Vulnerable 
Communities: Lessons From Hurricane Katrina.” American Journal of Public Health. 97(S1):S109-S115.

Eos. 2012. "Weather- and Climate-Related Extreme Events: Teachable Moments.” 93(11, 13).

Federal Election Commission. 2000. "Federal Elections 2000: Election Results for the U.S. President, the U.S. Senate and the U.S. House of Representatives." http://www.fec.gov/pubrec/fe2000/cover.htm (accessed August 2014).

Federal Election Commission. 2004. "Federal Elections 2004: Election Results for the U.S. President, the U.S. Senate and the U.S. House of Representatives." http://www.fec.gov/pubrec/fe2004/federalelections2004.pdf (accessed August 2014).

Federal Election Commission. 2008. "Federal Elections 2008: Election Results for the U.S. President, the U.S. Senate and the U.S. House of Representatives." http://www.fec.gov/pubrec/fe2008/federalelections2008.pdf (accessed August 2014).

Finch, Christina, Emrich, Christopher T., and Cutter, Susan L. 2010. "Disaster disparities and differential recovery in New Orleans.” Population \& Environment. 31:179-202.

Finucane, M., P. Slovic, C.K. Mertz, J. Flynn, and T.A. Satterfield. 2000. “Gender, race, and perceived risk: The ‘white male’ effect.” Health, Risk and Society 2(2): 159-72.

Franklin County Supervisor of Elections. 2004. General Election Summary Report. Appalachicola, Florida. Franklin County Supervisor of Elections. http://franklin.electionsfl.org/portals/franklin/documents/2004generalsummary.pdf (accessed August 2014).

Franklin County Supervisor of Elections. 2008. General Election Summary Report. Appalachicola, Florida. Franklin County Supervisor of Elections. http://franklin.electionsfl.org/portals/franklin/documents/2008generalelectionsum maryreport.pdf (accessed August 2014).

Freudenburg, William R. 1991. "Rural-Urban Differences in Environmental Concern: A Closer Look." Sociological Inquiry. 61(2):167-198.

Gieryn, Thomas F. 2000. "A Space for Place in Sociology." Annual Review of Sociology. 26:463-496.

Goebbert, Kevin, Jenkins-Smith, Hank C., Klockow, Kim, Nowlin, Matthew C., and Silva, Carol L. 2012. "Weather, Climate, and Worldviews: The Sources and Consequences of Public Perceptions of Changes in Local Weather Patterns.” Weather, Climate, and Society. 4(2):132-144. 
Greater New Orleans Inc. Regional Economic Development. Plaquemines Parish. http://gnoinc.org/explore-the-region/plaquemines-parish/ (accessed August 2014).

Greider, Thomas and Garkovich, Lorraine. 1994. "Landscapes: The social construction of nature and the environment.” Rural Sociology. 59(1):1-24.

Guagnano, Gregory A. and Markee, Nancy. 1995. "Regional Differences in the Sociodemographic Determinants of Environmental Concern." Population and Environment. 17(2):135-149.

Gulf County Supervisor of Elections. 2008. General Election Summary Report. Port St. Joe, Florida. Gulf County Supervisor of Elections. http://www.votegulf.com/portals/gulf/documents/ElectionData/general2008summary.htm (accessed August 2014).

Habermas, Jürgen. 1984. The Theory of Communicative Action: Vol 1. Reason and the Rationalization of Society. (T. McCarthy, Trans.). Boston, MA: Beacon Press.

Hamilton, L.C. and Stampone, M.D. 2013. "Blowin' in the Wind: Short-term weather and belief in anthropogenic climate change." Weather, Climate, and Society. 5:112-119.

Hamilton, Lawrence C. 2008. "Who Cares about Polar Regions? Results from a Survey of U.S. Public Opinion." Arctic, Antarctic, and Alpine Research. 40(4):671-678.

Hamilton, Lawrence C. and Keim, Barry D. 2009. "Short Communication: Regionvariation in perceptions about climate change." International Journal of Climatology. 29:2348-2352.

Hamilton, Lawrence C. 2011. "Education, politics, and opinions about climate change: evidence for interaction effects." Climatic Change. 104:231-242.

Hamilton, Lawrence C., Colocousis, Chris R., and Duncan, Cynthia M. 2010. "Place Effects on Environmental Views." Rural Sociology. 75(2):326-347.

Hamilton, Lawrence C., Cutler, Matthew J., and Schaefer, Andrew. 2012. "Public Knowledge and concern about polar-region warming." Polar Geography. 35(2):155-168.

Hamilton, Lawrence C., Safford, Thomas G., and Ulrich, Jessica D. 2012. "In the Wake of the Spill: Environmental Views Along the Gulf Coast." Social Science Quarterly. 93(4):1053-1064. 
Hamilton, Lawrence C., Hartter, Joel, Safford, Thomas G., and Stevens, Forrest R. 2013. "Rural Environmental Concern: Effects of Position, Partisanship, and Place." Rural Sociology. 79(2):257-281.

Hamilton, Lawrence C., Hamilton, Leslie R., Duncan, Cynthia M., and Colocousis, Chris R. 2008. "Place Matters: Challenges and Opportunities in Four Rural Americas." Carsey Institute Reports on Rural America. 1(4).

Hamilton, Lawrence C. and Safford, Thomas G. 2014. "Environmental Views from the Coast: Public Concern about Local to Global Marine Issues.” Society \& Natural Resources: An International Journal. 0:1-18

Hamilton, Lawrence C. and Saito, Kei. 2014. “A four-party view of US environmental concern.” Environmental Politics. 1-16.

Hamilton, Lawrence C. and Lemcke-Stampone, Mary. 2014. “Arctic warming and your weather: public belief in the connection.” International Journal of Climatology. 34(5):1723-1728.

Hannigan, John. 2006. Environmental Sociology (2nd ed). New York, NY: Routledge.

Howe, Peter D. and Leiserowitz, Anthony. 2013. "Who remembers a hot summer or a cold winter? The asymmetric effect of beliefs about global warming on perceptions of local climate conditions in the U.S.” Global Environmental Change. 23(6):1488-1500.

IDRE. Stata Frequently Asked Questions: How do I interpret odds ratios in logistic regression? UCLA: Statistical Consulting Group. from http://www.ats.ucla.edu/stat/stata/faq/oratio.htm (accessed March 2014).

Jacques, Peter J., Dunlap, Riley E., and Freeman, Mark. 2008. "The organisation of denial: Conservative think tanks and environmental scepticism." Environmental Politics. 17(3):349-385.

Kahan, D.M., D. Braman, J. Gastil, P. Slovic, and C.K. Mertz. 2007. "Culture and identityprotective cognition: Explaining the white-male effect in risk perception.” Journal of Empirical Legal Studies. 4: 465-505.

Kahan, Dan M., Jenkins-Smith, Hank, and Braman, Donald. 2011. "Cultural cognition of scientific consensus." Journal of Risk Research. 14(2):147-174.

Kahan, Dan M., Wittlin, Maggie, Peters, Ellen, Slovic, Paul, Ouellette, Lisa Larrimore, Braman, Donald, and Mandel, Gregory N. 2011 "The Tragedy of the Risk- Perception Commons: Culture Conflict, Rationality Conflict, and Climate Change." Temple University Legal Studies Research Paper No. 2011-26; Cultural Cognition Project Working Paper No. 89; Yale Law \& Economics Research Paper No. 435; Yale Law School Public Law Working 
Paper No. 230. Available at SSRN:

http://ssrn.com/abstract=1871503 orhttp://dx.doi.org/10.2139/ssrn.1871503.

Karp, David Gutierrez. 1996. "Values and their Effect on Pro-Environmental Behavior." Environment and Behavior. 28(1):111-133.

Kalof, L., T. Dietz, G. Guagnano, and P.C. Stern. 2002. "Race, gender, and environmentalism: The atypical values and beliefs of white men.” Race, Gender, \& Class. 9: 1-19.

Kalof, Linda, Dietz, Thomas, Stern, Paul C., and Guagnano, Gregory A. 1999. "Social Psychological and Structural Influences on Vegetarian Beliefs." Rural Sociology. 64(3):500-511.

Klandermans, Bert. 1984. "Mobilization and participation: Social-psychological expansions of resource mobilization theory." American Sociological Review. 49(5):583-600.

Lang, Corey. 2014. "Do weather fluctuations cause people to seek information about climate change.” Climatic Change. 125(3-4):291-303.

Larson, Silva, De Freitas, Debora M., and Hicks, Christina C. 2013. "Sense of place as a determinant of people's attitudes towards the environment: Implications for natural resources management and planning in the Great Barrier Reef, Austrailia." Journal of Environmental Management. 117:226-234.

Lash, Scott, Szerszynski, Bronislaw, and Wynne, Brian, eds. 1996. Risk, environment, and modernity: towards a new ecology. Vol 40. Sage.

Leiserowitz, Anthony. 2006. "Climate Change Risk Perception and Policy Preferences: The Role of Affect, Imagery, and Values." Climatic Change. 77:45-72.

Leiserowitz, Anthony, Maibach, Edward, Roser-Renouf, Connie, Feinberg, Geoff, Rosenthal, Seth, Marlon, Jennifer, and Howe, Peter. 2014. Extreme Weather and Climate Change in the American Mind, November, 2013. Yale University and George Mason University. New Haven, CT: Yale Project on Climate Change Communication.

Levy, Brian L. 2012. "Bayou Blues: The Social Structure of Hurricane Katrina’s Damage.” Sociological Spectrum. 32:424-435.

Lorenzoni, Irene, and Pidgeon, Nick F. 2006. "Public Views on Climate Change: European and USA Perspectives." Climatic Change. 77:73-95.

Louisiana State University Agricultural Center. About the Parish. from http://www.lsuagcenter.com/en/our_offices/parishes/Terrebonne/Features/About/ Terrebonne-Parish.htm (accessed August 2014). 
Lowe, George D. and Pinhey, Thomas K. "Rural-urban differences in support for environmental protection." Rural Sociology. 47(1):114-128.

Luke, Douglas A. (Ed.) 2004. Multilevel modeling. Vol. 143. Sage.

Macias, Thomas and Nelson, Elysia. 2011. "A Social Capital Basis for Environmental Concern: Evidence from Northern New England." Rural Sociology. 76(4):562-581.

Macnaghten, Phil and Urry, John. 1998. Contested Natures. Vol 54. Sage.

Malka, Ariel, Krosnick, Jon A., and Langer, Gary. 2009. "The Association of Knowledge with Concern About Global Warming: Trusted Information Sources Shape Public Thinking." Risk Analysis. 29(5):633-647.

Marquart-Pyatt, Sandra T., McCright, Aaron M., Dietz, Thomas, and Dunlap, Riley E. 2014. "Politics eclipses climate extremes for climate change perceptions." Global Environmental Change. 29:246-257.

McAdam, Doug and Boudet, Hilary Schaffer. 2012. Putting Social Movements in their Place: Explaining Opposition to Energy Project in the United States, 2000-2005. New York, NY: Cambridge University Press.

McAdam, Doug, Boudet, Hilary Schaffer, Davis, Jennifer, Orr, Ryan J., Scott, W. Richard, and Levitt, Raymond E. “'Site Fights”: Explaining Opposition to Pipeline Projects in the Developing World.” Sociological Forum. 25(3):401-427.

McCright, Aaron M. and Dunlap, Riley E. 2013. "Bringing Ideology in: the conservative white male effect on worry about environmental problems in the USA." Journal of Risk Research. 16(2):211-226.

McCright, A.M., and Dunlap, R.E. 2011. "The Politicization of Climate Change and Polarization in the American Public's Views of Global Warming, 2001-2010." The Sociological Quarterly. 52(2):155-194.

McCright, Aaron M. 2011. "Political orientation moderates Americans' beliefs and concern about climate change: An editorial comment." Climatic Change. 104:243-253.

McCright, Aaron M., Dunlap, Riley E., and Xiao, Chenyang. 2007. "Perceived scientific agreement and support for government action on climate change in the USA." Climatic Change. 119:511-518. 
McCright, Aaron M., Dunlap, Riley E., and Xiao, Chenyang. 2014. “The impacts of temperature anomalies and political orientation on perceived winter warming." Nature Climate Change. 4(12):1077-1081.

Mohai, Paul, Pellow, David, and Roberts, J. Timmons. 2009. “Environmental Justice.” Annual Review of Environment and Resources.34:405-430.

Mohai, Paul and Twight, Ben W. 1987. "Age and Environmentalism: An Elaboration of the Buttel Model Using National Survey Evidence." Social Science Quarterly. 68(4):798815.

Mohai, P., \& Bryant, B. 1998. “Is there a "race" effect on concern for environmental quality?.” Public Opinion Quarterly. 475-505.

National Wildlife Federation. 2010. "Extreme Heat in Summer 2010: A Window on the Future." http://www.nwf.org/Wildlife/Threats-to-Wildlife/Global-Warming/Global-Warming-isCausing-Extreme-Weather/Heat-Waves.aspx (accessed August 2014).

Natural Resources Defense Council. 2014. "Extreme Weather: Impacts of Climate Change." http://www.nrdc.org/globalwarming/climate-change-impacts/ (accessed August 2014).

Nerlich, Brigitte and Jaspal, Rusi. 2014. "Images of Extreme Weather: Symbolising Human Responses to Climate Change." Science as Culture. 23(2):253-276.

Nielsen, Søren Feodor. 2003. "Proper and improper multiple imputation." International Statistical Review. 71(3): 593-607.

Nordlund, Annika M. and Garvill, Jörgen. 2002. "Value Structures behind Pro-environmental Behavior." Environment and Behavior. 34(6):740-756.

O'Connor, Robert E., Bord, Richard J., Yarnal, Brent, and Wiefek, Nancy. 2002. "Who Wants to Reduce Greenhouse Gas Emissions?" Social Science Quarterly. 83(1):1-17.

Overdevest, Christine and Christiansen, Lisa. 2013. "Using "Cultural Cognition" to Predict Environmental Risk Perceptions in a Florida Water-Supply Planning Process." Society and Natural Resources. 26:987-1007.

Peacock, Walter Gillis. 2003. "Hurricane Mitigation Status and Factors Influencing Mitigation Status among Florida’s Single-Family Homeowners.” Natural Hazards Review. 4(3):149158.

PBS. 2003. "The Future of the Florida Panhandle." http://www.pbs.org/now/society/panhandle.html (accessed August 2014). 
Prati, Gabriele and Zani, Bruna. 2012. "The Effect of the Fukushima Nuclear Accident on Risk Perception, Antinuclear Behavioral Intentions, Attitude, Trust, Environmental Beliefs, and Values." Environment and Behavior. 45(6):782-798.

Rubin, Donald B. 2003. “Discussion on Multiple Imputation.” International Statistical Review. 71(3):619-625.

Sampson, Robert J. 2012. Great American City: Chicago and the Enduring Neighborhood Effect. Chicago, IL: University of Chicago Press.

Safford, Thomas G. and Hamilton, Lawrence C. 2010. "Ocean views: coastal environmental problems as seen by downeast Maine residents.” The Carsey Institute at the Scholars' Repository. Paper 95.

Safford, Thomas G. and Hamilton, Lawrence C. 2012. "Demographic change and shifting views about marine resources and the coastal environment in Downeast Maine." Population and Environment. 33:284-303.

Safford, Thomas G., Ulrich, Jessica D., and Hamilton, Lawrence C. 2012. "Public perceptions of the response to the Deepwater Horizon oil spill: Personal experiences, information sources, and social context." Journal of Environmental Management. 113:31-39.

Sawyer, R. Keith. 2002. "Durkheim's Dilemma: Toward a Sociology of Emergence." Sociological Theory. 20(2):227-247.

Shao, Wanyun, Keim, Barry D., Garand, James C., and Hamilton, Lawrence C. 2014. "Weather, Climate, and the Economy: Explaining Risk Perceptions of Global Warming, 2001-10.” Weather, Climate, and Society. 6(1):119-134.

Shao, Wanyun. 2015. "Are actual weather and perceived weather the same? Understanding perceptions of local weather and their effects on risk perceptions of global warming." Journal of Risk Research. (ahead-of-print): 1-21.

Schultz, P. Wesley and Zelezny, Lynnette. 1999. "Values as Predictors of Environmental Attitudes: Evidence for Consistency Across 14 Countries." Journal of Environmental Psychology. 19:255-265.

Shwom, Rachael, Dan, Amy, and Dietz, Thomas. 2008. "The effects of information and state of residence on climate change policy preferences." Climatic Change. 90:343-358.

Stern, Paul C. and Dietz, Thomas. 1994. "The Value Basis of Environmental Concern." Journal of Social Issues. 50(3):65-84. 
Stern, Paul C. 2000. "Toward a Coherent Theory of Environmentally Significant Behavior." Journal of Social Issues. 56(3):407-424.

U.S. Census Bureau. 2009. American Community Survey 5-Year Release Details. from http://www.census.gov/acs/www/data_documentation/2009_5yr_data/ (accessed March 2014).

Uyeki, Eugene S. and Holland, Lani J. 2000. "Diffusion of Pro-Environment Attitudes?" American Behavioral Scientist. 43(4):646-663.

Van Liere, K. D., and Dunlap, R.E. 1980. "The Social Bases of Environmental Concern: A Review of Hypotheses, Explanations, and Empirical Evidence." Public Opinion Quarterly. 44(2):181-197.

Vorkinn, Marit and Riese, Hanne. 2001. "Environmental Concern in a Local Context: The Significance of Place Attachment." Environment and Behavior. 33:249-263.

Vose, Russell S., Applequist, Scott, Bourassa, Mark A., Pryor, Sara C., Barthelmie, Rebecca J., Blanton, Brian, Bromirski, Peter D., Brooks, Harold E., DeGaetano, Arthur T., Dole, Randall M., Easterling, David R., Jensen, Robert E., Karl, Thomas R., Katz, Richard W., Klink, Katherine, Kruk, Michael C., Kunkel, Kenneth E., MacCracken, Michael C., Peterson, Thomas C., Shein, Karsten, Thomas, Bridget R., Walsh, John E., Wang, Xiaolan L., Wehner, Michael F., Wuebbles, Donald J., and Young, Robert S. 2014. "Monitoring and Understanding Changes in Extremes: Extratropical Storms, Winds, and Waves.” Bulletin of the American Meteorological Society. 95(3):377-386.

Walsh, Edward J. 1981. "Resource Mobilization and Citizen Protest in Communities around Three Mile Island.” Social Problems. 29(1):1-21.

Wayman, Jeffrey C. 2003. "Multiple imputation for missing data: What is it and how can I use it." Annual Meeting of the American Educational Research Association, Chicago, IL (pp. 2-16).

Wood, B. Dan and Vedlitz, Arnold. 2007. "Issue Definition, Information Processing, and the Politics of Global Warming." American Journal of Political Science. 51(3):552-568.

World Resources Institute. 2012. "Fact Sheet: The Connection Between Climate Change and Recent Extreme Weather Events." http://www.wri.org/publication/fact-sheet-connectionbetween-climate-change-and-recent-extreme-weather-events (accessed August 2014).

Wynne, Brian. 1996. “A Reflexive View of the Expert-Lay Knowledge Divide.” Risk, Environment, and Modernity: Towards a new ecology. 40:44-80. 
Xiao, Chenyang and McCright, Aaron M. 2007. "Environmental Concern and Sociodemographic Variables: A Study of Statistical Models." The Journal of Environmental Education. 38(2):3-14.

Zahran, Sammy, Brody, Samuel D., Peacock, Walter Gillis, Vedlitz, Arnold, and Grover, Himanshu. 2008. "Social vulnerability and the natural and built environment: a model of flood casualties in Texas.” Disasters. 32(4):537-560.

Zaval, Lisa, Keenan, Elizabeth A., Johnson, Eric J., and Weber, Elke U. 2014. "How warm days increase belief in global warming.” Nature Climate Change. 4(2):143-147.

Zhang, Yang and Peacock, Walter Gillis. 2010. "Planning for Housing Recovery? Lessons Learned From Hurricane Andrew.” Journal of the American Planning Association. 76(1):5-24. 


\section{APPENDIX A}

"Organized severe thunderstorm episodes can occur anywhere in the United States in any month of the year. The synoptic environments in which these storms develop can vary in many ways depending on region of the country and time of the year. Climatologically most of the severe thunderstorm episodes in the United States occur in an area bound by the continental divide on the west side and a line approximately 1000 - 1200 miles east of the continental divide on the east side. The part of the United States east of this high frequency area has a large number of severe thunderstorm episodes but not near the number in the high frequency area. The part of the United States west of the continental divide has an extremely low frequency of severe thunderstorms when compared to the high frequency area and the eastern area.

Experience in using the tools needed to forecast severe thunderstorm episodes is extremely important and essential if a forecaster is to be successful in forecasting these storms. Forecasters located outside the high frequency area mentioned above have limited exposure to severe thunderstorm situations and therefore are limited in being able to increase their skill and confidence in forecasting them. Individual forecasters, at locations outside the high frequence area, may work a severe thunderstorm situation only once or twice a year. At some locations west of the continental divide, some forecasters may only work one or two severe thunderstorm situations in their entire career.

One of the ways to augment a forecaster's experience is to study various synoptic analyses and other tools that describe the environment in which severe thunderstorms develop. The purpose of 
this web document is to identify organized severe thunderstorm episodes and to organize them chronologically. The events provided will appear as a somewhat standardized package of synoptic analyses and other tools so an interested forecaster can review and compare them to other severe thunderstorm episodes and/or to a current situation. The set of events provided here is not intended to be a set of case studies. The more detailed analysis required for case studies is left to the individual. This set of events will provide forecasters and researchers a quick look at the synoptic environments related to various severe thunderstorm episodes and allow them to decide if further study of a specific event is desirable.

The selection procedure used here is more structured than it was in the previous technical memorandums containing events from July 1985 through June 1992. The selection criteria which follow will reveal that the thresholds used in and west of the Rocky Mountains are somewhat lower than those used east of the Rocky Mountains and may vary a little from the strict definition of severe thunderstorm...Definition: A severe thunderstorm is a thunderstorm which produces hail 3/4 inch, and/or damaging winds or wind 50 knots, and or a tornado. Since the major focus of this web document is on organized severe thunderstorm episodes, the criteria for determining which days are to be used will be those days when there is considerable severe thunderstorm activity confined to a relative small area (ranging from approximately the size of Kansas to about four times the size of Kansas) and over a relatively short time interval (6, 12, and 24 hours). These severe thunderstorm events are keyed to well-organized severe thunderstorm events most capable of damage and/or injury. They are not intended to cover every isolated or marginally severe thunderstorm. Pulse-type thunderstorms, consisting primarily of solitary brief severe downdrafts are not considered to be organized. Convection of this type and thunderstorms barely 
meeting severe thunderstorm criteria will not be considered when determining severe thunderstorm cases for this web document except on days when unusually dense and/or large areas of marginally severe thunderstorms are reported.

\section{Event Day Selection Guidelines for Areas East of the Rocky Mountains}

- When two or more F2 or 1 or more F3 or greater tornadoes (Fujita and Pearson, 1973) are reported regardless of time period or area coverage.

- When 30 reports of hail 1 inch and wind events and tornadoes, or 30 reports of hail 1 inch and wind events, or 30 reports of hail 1 inch and tornadoes, or 30 reports of hail or 30 reports of wind events and tornadoes, or 30 reports of wind events, or 10 tornadoes occur within an area of 60,000 square miles and within a 6 hour time interval.

- When 60 reports of hail 1 inch and wind events and tornadoes, or 60 reports of hail 1 inch and wind events, or 60 reports of hail 1 inch and tornadoes, or 60 reports of hail or 60 reports of wind events and tornadoes, or 60 reports of wind events, or 20 tornadoes occur within an area of 120,000 square miles and within a 12 hour time interval.

- When 120 reports of hail 1 inch and wind events and tornadoes, or 120 reports of hail 1 inch and wind events, or 120 reports of hail 1 inch and tornadoes, or 120 reports of hail or 120 reports of wind events and tornadoes, or 120 reports of wind events, or 40 tornadoes occur within an area of 240,000 square miles and within a 24 hour time interval. 
- In the period September 30 through March 31, the number of reports will be reduced by one half.

- Any tornadoes, and/or wind damage, and/or hail that result in 1 or more fatalities, 10 or more injuries, or damage $\$ 1,000,000$ or more.

- Seriously consider days with an area of unusually dense but marginally severe reports or a large area with a large number of marginally severe reports even though they did not quite meet the number criteria suggested above. The Storm Prediction Center (SPC) Science and Operations Officer (SOO) and/or the National Severe Storms Laboratory ( NSSL)/Forecast Research and Development Division (FRDD) /Mesoscale Applications Group (MAG) Leader were consulted as needed.

- All days when Moderate or High Risk are forecast.

- Day suggested by a SPC Lead Forecaster and/or SPC SOO. Inclusion of such cases was approved by the SPC SOO and NSSL/FRDD/MAG Leader.

- Day suggested by a NSSL Scientist. Inclusion of such cases was approved by the NSSL/FRDD/MAG Leader and SOO for approval. 


\section{Event Day Selection Guidelines for Areas in and West of the Rocky Mountains}

- Any tornado report regardless of F rating.

- When 10 reports of hail 1 inch and wind events, or 10 reports of hail 1 inch, or 10 reports of wind events occur within an area of 120,000 square miles and within a 12 hour time interval

- When 20 reports of hail 1 inch and wind events, or 20 reports of hail 1 inch, or 20 reports of wind events occur within an area of 240,000 square miles and within a 24 hour time interval.

- Any tornado, and/or wind damage, and/or hail that resulted in 1 or more fatalities, 3 or more injuries, or damage $\$ 500,000$ or more.

- In the period September 30 through March 31, the number of reports will be reduced by one half.

- Seriously consider days with an area of unusually dense but marginally severe reports or a large area with a large number of marginally severe reports even though they did not quite meet the number criteria suggested above. The SPC SOO and/or NSSL/FRDD/MAG Leader were consulted as needed.

- All days when Moderate or High Risk are forecast. 
- Day suggested by a SPC Lead Forecaster and/or SPC SOO. Inclusion of such cases was approved by the SPC SOO and NSSL/FRDD/MAG Leader.

- Day suggested by a NSSL Scientist. Inclusion of such cases was approved by the NSSL/FRDD/MAG Leader and SPC SOO. (http://www.spc.noaa.gov/exper/archive/events/introduction.html).” 


\section{APPENDIX B}

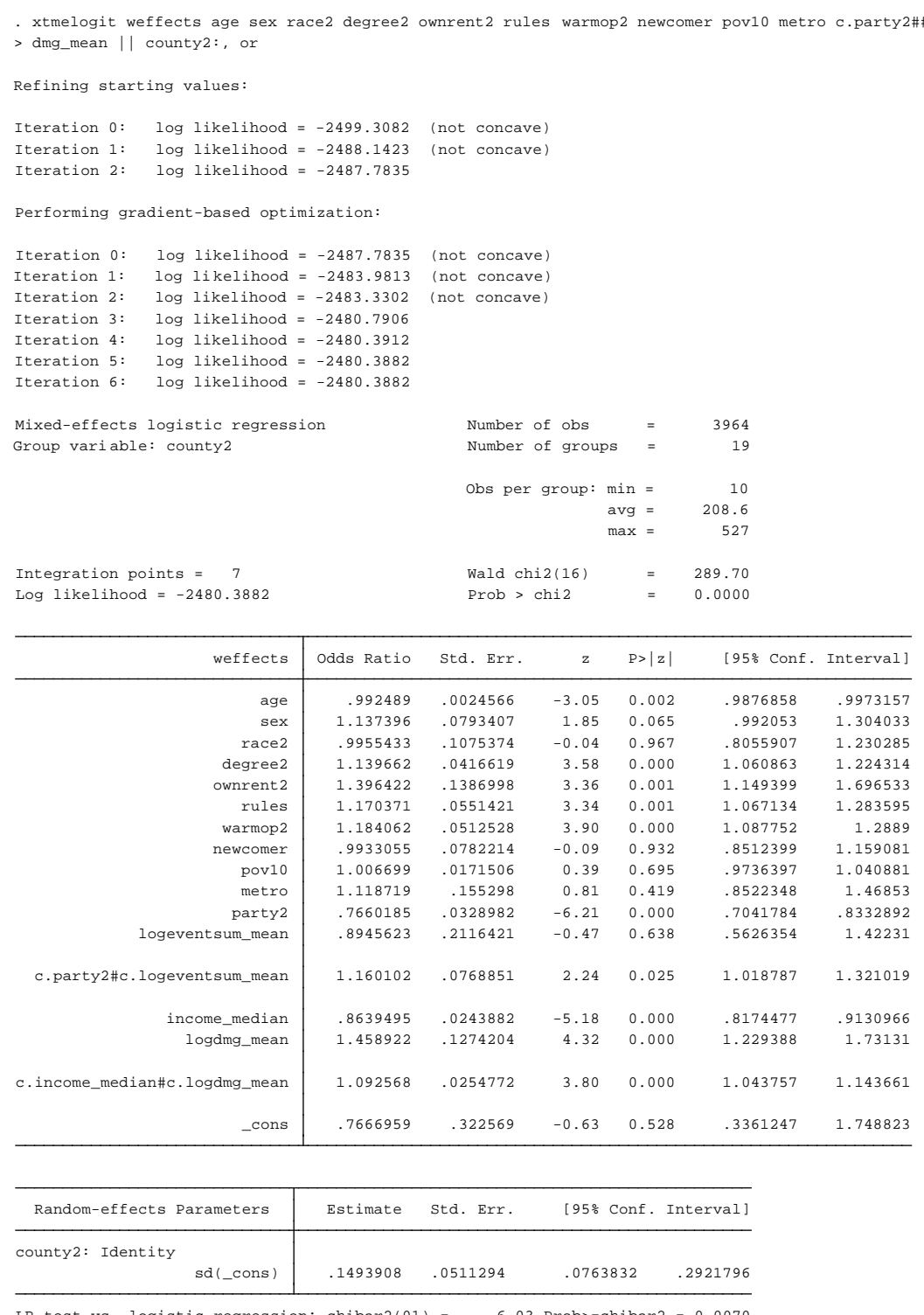

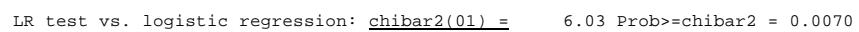


. xtmelogit weffects age sex race 2 degree2 ownrent2 rules warmop2 newcomer pov10 metro c.party2 c.income_median\#\#c.logdmg_mean || county2: $>$, or

Refining starting values:

Iteration $0: \quad \log$ likelihood $=-2501.5228$ (not concave)

Iteration 1: $\quad \log$ likelihood $=-2490.7319$ (not concave)

Iteration 2: $\quad \log$ likelihood $=-2490.7259$

Performing gradient-based optimization:

Iteration $\odot: \quad \log$ likelihood $=-2490.7259$ (not concave)

Iteration 1: $\log$ likelihood $=-2490.6089$ (not concave)

Iteration 2: $\quad \log$ likelihood $=-2487.9438$ (not concave)

Iteration 3: $\log$ likelihood $=-2484.8823$

Iteration 4: $\quad \log$ likelihood $=-2483.8589$

Iteration 5: $\quad \log$ likelihood $=-2483.5027$

Iteration 6: $\log$ likelihood $=-2483.4997$

Iteration 7: $\log$ likelihood $=-2483.4997$

Mixed-effects logistic regression

Group variable: county2

$\begin{array}{llr}\text { Number of obs } & = & 3964 \\ \text { Number of groups } & = & 19 \\ \text { Obs per group: } \min & = & 10 \\ \text { avg } & = & 208.6 \\ \max & = & 527 \\ & & \\ \text { Wald chi2(14) } & = & 278.24 \\ \text { Prob }>\text { chi2 } & = & 0.0000\end{array}$

Integration points $=7$

Log likelihood $=-2483.499$

Prob $>$ chi2 $=0.0000$

\begin{tabular}{r|rrrrrr}
\hline weffects & Odds Ratio & Std. Err. & $\mathrm{z}$ & $\mathrm{P}>|\mathrm{z}|$ & [95\% Conf. Interval] \\
\hline age & .9923201 & .0024508 & -3.12 & 0.002 & .9875282 & .9971352 \\
sex & 1.137449 & .0792697 & 1.85 & 0.065 & .9922271 & 1.303926 \\
race2 & .9847767 & .1063762 & -0.14 & 0.887 & .7968755 & 1.216985 \\
degree2 & 1.144923 & .0417578 & 3.71 & 0.000 & 1.065936 & 1.229763 \\
ownrent2 & 1.402718 & .1392248 & 3.41 & 0.001 & 1.154744 & 1.703944 \\
rules & 1.189057 & .055486 & 3.71 & 0.000 & 1.085132 & 1.302936 \\
warmop2 & 1.185665 & .0513235 & 3.93 & 0.000 & 1.089221 & 1.290647 \\
newcomer & .9980453 & .0785617 & -0.02 & 0.980 & .8553571 & 1.164536 \\
pov10 & 1.016315 & .0131741 & 1.25 & 0.212 & .9908196 & 1.042467 \\
metro & 1.187381 & .1562238 & 1.31 & 0.192 & .9174819 & 1.536678 \\
party2 & .7487175 & .0308087 & -7.03 & 0.000 & .6907043 & .8116033 \\
income_median & .8649001 & .0243855 & -5.15 & 0.000 & .818402 & .91404 \\
logdmg_mean & 1.548138 & .1054599 & 6.42 & 0.000 & 1.354644 & 1.769269 \\
& & & & & & \\
c.income_median\#c.logdmg_mean & 1.097201 & .0255271 & 3.99 & 0.000 & 1.048292 & 1.148391 \\
& & & & & & \\
_cons & .6292988 & .2123171 & -1.37 & 0.170 & .3248425 & 1.219105 \\
\hline
\end{tabular}

\begin{tabular}{ll|llll}
\hline \multicolumn{2}{c|}{ Random-effects Parameters } & Estimate & Std. Err. & [95\% Conf. Interval] \\
\hline county2: Identity & sd(_cons) & .1617316 & .0518462 & .086283 & .3031546 \\
&
\end{tabular}

LR test vs. logistic regression: $\underline{\operatorname{chibar} 2(01)=7.68 \text { Prob }>=\operatorname{chibar} 2=0.0028}$ 
. mi impute mvn income_median party2 degree2 race2 weffects newcomer ownrent2 age = pov10 logeventsum_mean logdmg_mean metro warmop2 sex $r$ ules, add(20) rseed(1234) force

Performing EM optimization:

observed $\log$ likelihood $=-16583.292$ at iteration 10

Performing MCMC data augmentation ...

Multivariate imputation

Multivariate normal regression

Imputed: $m=1$ through $m=20$

$\begin{aligned} \text { Imputations }= & 20 \\ \text { added }= & 20 \\ \text { updated }= & 0\end{aligned}$

Prior: uniform

$\begin{array}{rr}\text { Iterations }= & 2000 \\ \text { burn-in }= & 100\end{array}$

between $=100$

\begin{tabular}{r|rrr|r}
\hline & \multicolumn{4}{|c}{ Observations per $m$} \\
\cline { 2 - 5 } Variable & Complete & Incomplete & Imputed & Total \\
\hline income_median & 5829 & 1248 & 971 & 7077 \\
party2 & 6373 & 704 & 603 & 7077 \\
degree2 & 6992 & 85 & 66 & 7077 \\
race2 & 6941 & 136 & 112 & 7077 \\
weffects & 6988 & 89 & 71 & 7077 \\
newcomer & 6934 & 143 & 135 & 7077 \\
ownrent2 & 6883 & 194 & 162 & 7077 \\
age & 7018 & 59 & 54 & 7077 \\
\hline
\end{tabular}

(complete + incomplete $=$ total; imputed is the minimum across $\mathrm{m}$

of the number of filled-in observations.)

Note: right-hand-side variables (or weights) have missing values; model parameters estimated using listwise deletion 
. mi estimate, or: xtmelogit weffects age sex race2 degree2 ownrent2 rules newcomer pov10 metro c.party2\#\#c.logeventsum_mean c.income_medi $>$ an\#\#c.logdmg_mean || county2:

Multiple-imputation estimates Mixed-effects logistic regression

Group variable: county2

Integration points $=7$

DF adjustment: Large sample

Model $\mathrm{F}$ test: $\quad$ Equal FMI

\begin{tabular}{|c|c|c|}
\hline Imputat & ions & 20 \\
\hline Number & of obs & 6704 \\
\hline Number & of groups & 21 \\
\hline obs per & group: min & 11 \\
\hline & avg & 319.2 \\
\hline & $\max$ & 721 \\
\hline Average & RVI & 0.0348 \\
\hline Largest & FMI & 0.1556 \\
\hline DF : & $\min$ & 805.88 \\
\hline & avg & $=7.73 \mathrm{e}+06$ \\
\hline & $\max$ & $=9.50 \mathrm{e}+07$ \\
\hline$F(15$, & 195292.9) & $=21.57$ \\
\hline Prob > & & 0.0000 \\
\hline
\end{tabular}

\begin{tabular}{r|rrrrrr}
\hline weffects & Odds Ratio & Std. Err. & $\mathrm{t}$ & $\mathrm{P}>|\mathrm{t}|$ & [95\% Conf. Interval] \\
\hline age & .9915912 & .0018456 & -4.54 & 0.000 & .9879804 & .9952152 \\
sex & 1.169062 & .0628668 & 2.90 & 0.004 & 1.052117 & 1.299007 \\
race2 & .9962166 & .0864007 & -0.04 & 0.965 & .8404756 & 1.180816 \\
degree2 & 1.141198 & .0321588 & 4.69 & 0.000 & 1.079871 & 1.206007 \\
ownrent2 & 1.27168 & .0993559 & 3.08 & 0.002 & 1.091118 & 1.482122 \\
rules & 1.184848 & .0431998 & 4.65 & 0.000 & 1.103131 & 1.272617 \\
newcomer & .9898239 & .0598829 & -0.17 & 0.866 & .8791443 & 1.114437 \\
pov10 & .988061 & .015073 & -0.79 & 0.431 & .958958 & 1.01805 \\
metro & .9752558 & .1371895 & -0.18 & 0.859 & .7402523 & 1.284865 \\
party2 & .7414326 & .024749 & -8.96 & 0.000 & .6944098 & .7916396 \\
logeventsum_mean & 1.108998 & .1654068 & 0.69 & 0.488 & .8278815 & 1.48557 \\
& & & & & & \\
c.party2\#c.logeventsum_mean & 1.158225 & .0569292 & 2.99 & 0.003 & 1.051823 & 1.275391 \\
& & & & & & \\
income_median & .8972596 & .0199523 & -4.88 & 0.000 & .858953 & .9372746 \\
logdmg_mean & 1.420664 & .1039159 & 4.80 & 0.000 & 1.230919 & 1.639659 \\
& & & & & & \\
c.income_median\#c.logdmg_mean & 1.059102 & .0188678 & 3.22 & 0.001 & 1.022747 & 1.096749 \\
& & & & & & \\
_cons & 2.38656 & .7353468 & 2.82 & 0.005 & 1.304647 & 4.36568 \\
\hline
\end{tabular}

\begin{tabular}{lr|llll}
\hline \multicolumn{2}{c|}{ Random-effects Parameters } & Estimate & Std. Err. & [95\% Conf. Interval] \\
\hline county2: Identity & $\operatorname{sd}($ cons) & .2044085 & .0460607 & .1314294 & .3179111 \\
&
\end{tabular}




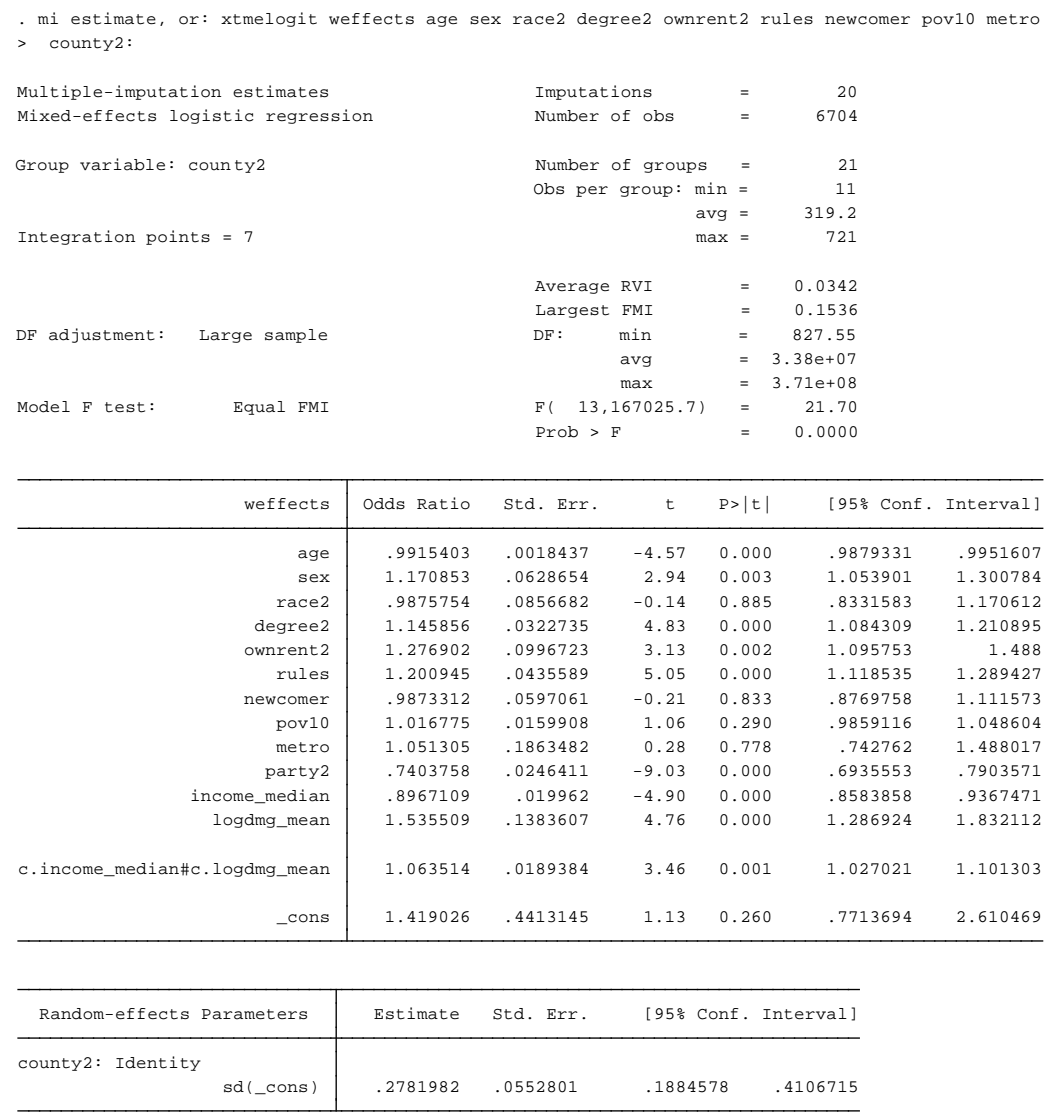




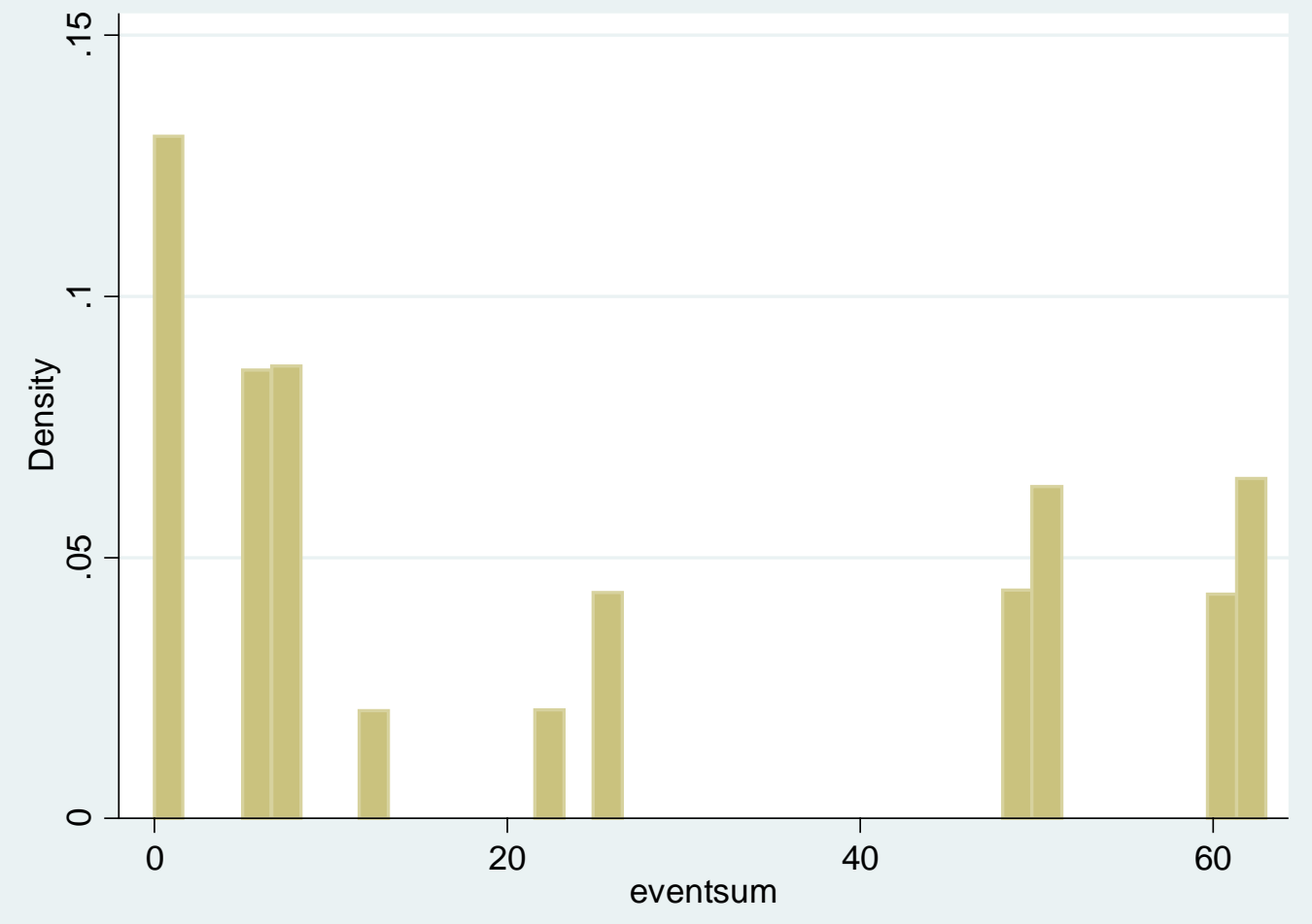

Figure B.1. Severe thunderstorm events frequency. 


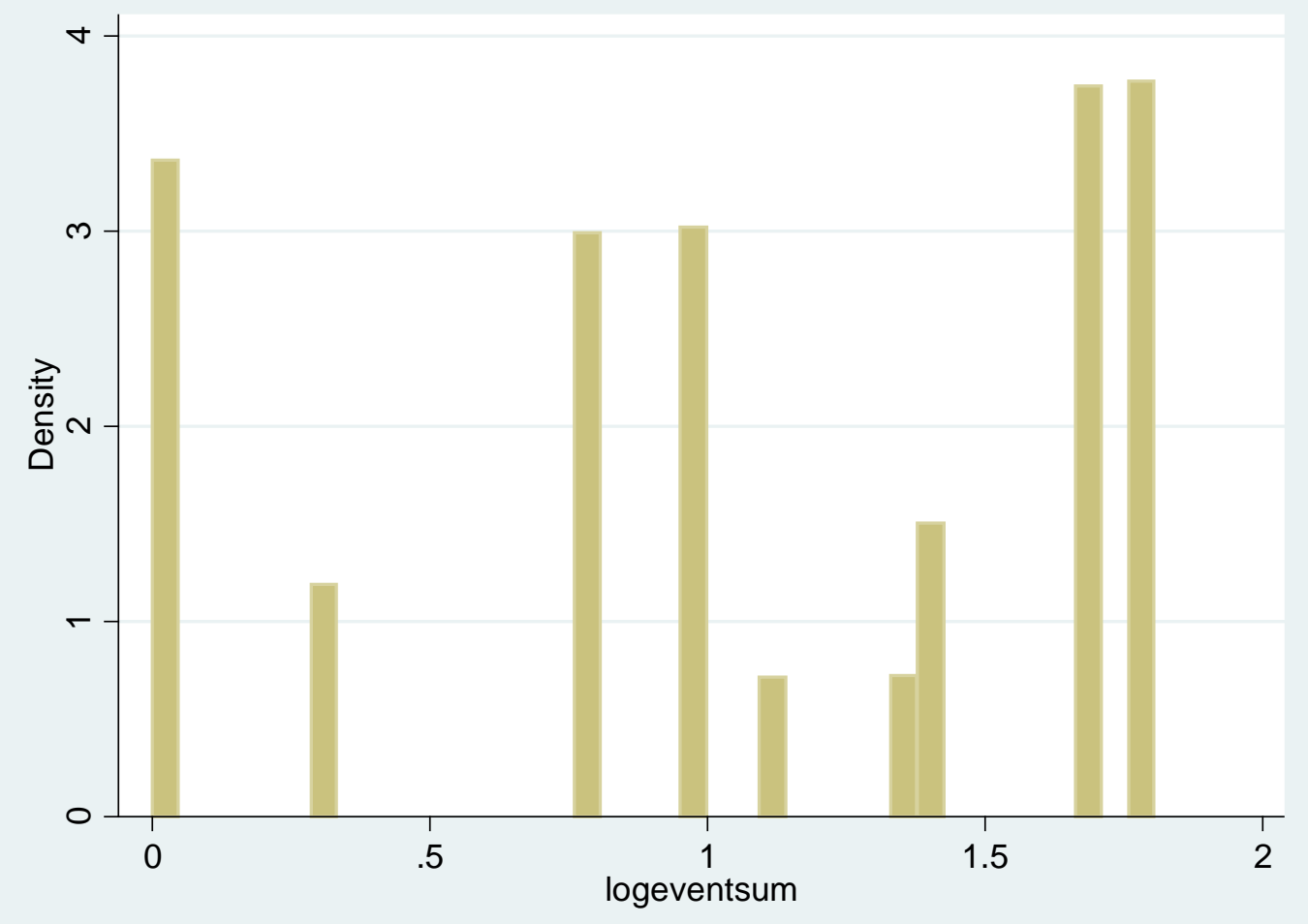

Figure B.2. Log-transformed severe thunderstorm events frequency. 


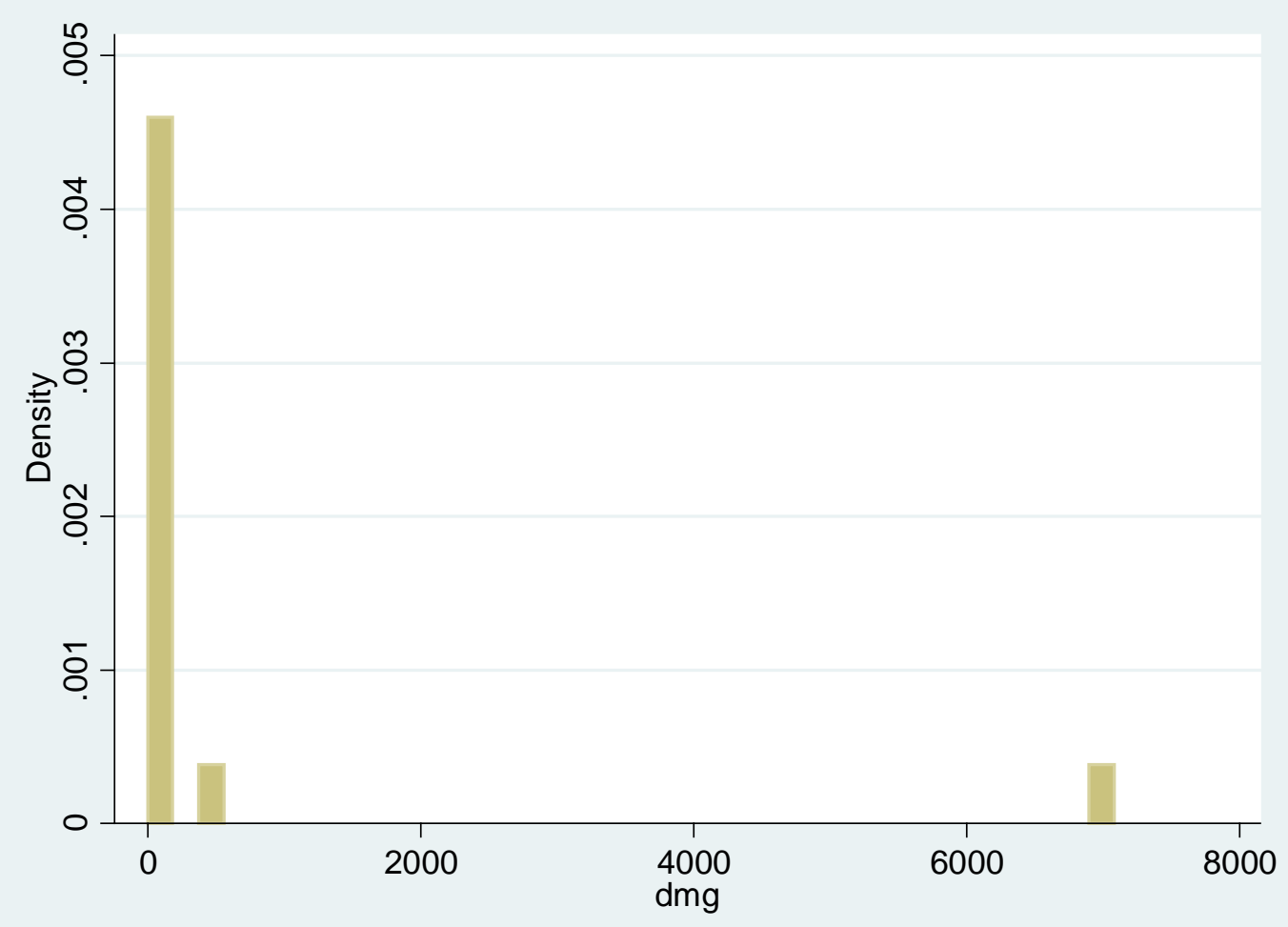

Figure B.3. Property Damage (in dollars) from all severe weather event types. 


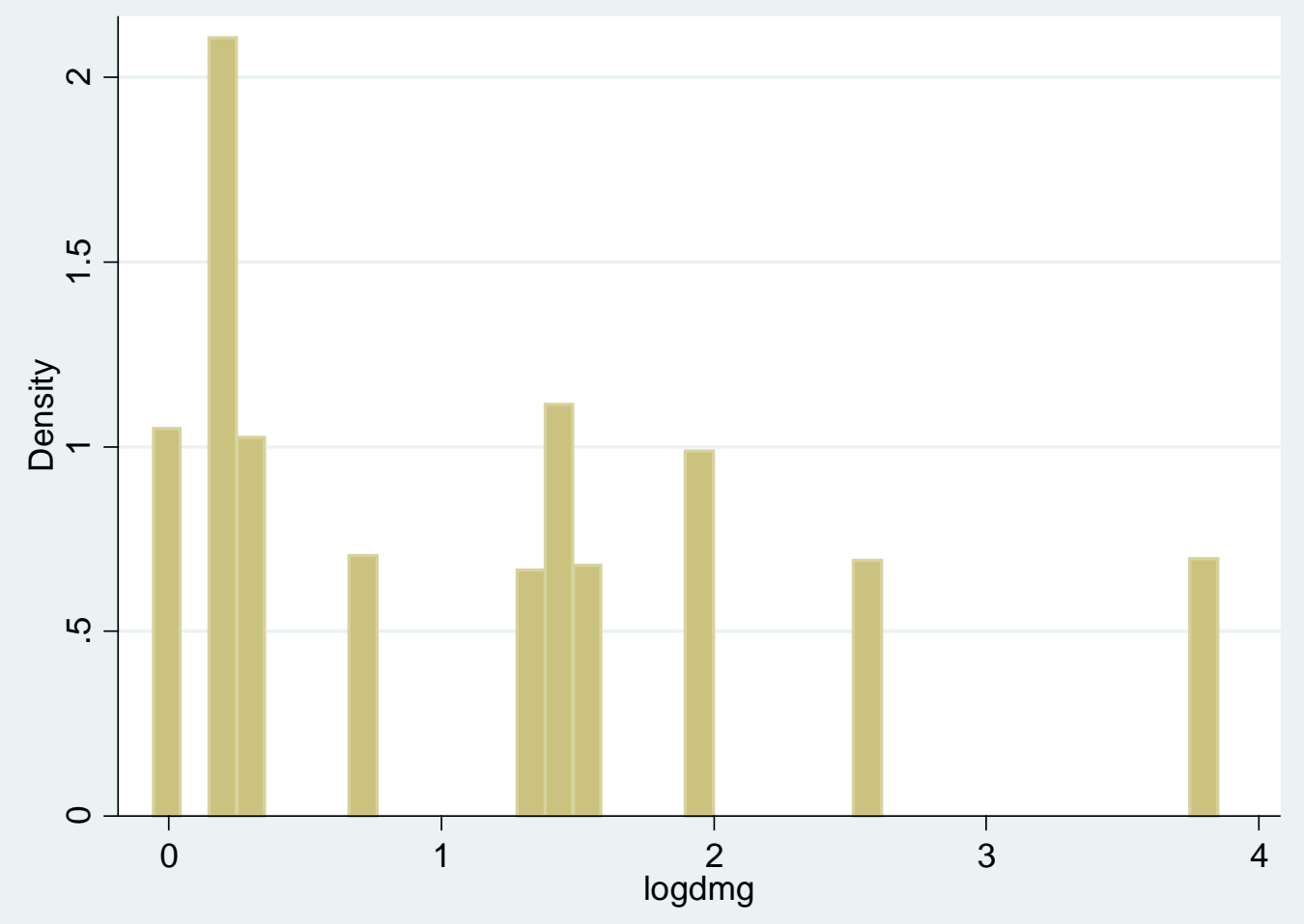

Figure B.4. Log-transformed property damage (in dollars) from all severe weather event types. 
ologit weather age sex race2 degree2 ownrent2 rules warmop2 newcomer pov10 metro c.party2\#\#c.logeventsum_mean c.income_median\#\#c.logdmg_ $>$ mean, or

Iteration $\odot: \quad \log$ likelihood $=-4225.5246$ Iteration 1: $\quad \log$ likelihood $=-3885.0671$ Iteration 2: $\quad \log$ likelihood $=-3881.3843$

Iteration 3: $\quad \log$ likelihood $=-3881.3777$

Iteration 4: $\quad \log$ likelihood $=-3881.3777$

ordered logistic regression

$\begin{array}{llr}\text { Number of obs } & = & 3964 \\ \text { LR chi2(16) } & = & 688.29 \\ \text { Prob > chi2 } & = & 0.0000 \\ \text { Pseudo R2 } & = & 0.0814\end{array}$

Log likelihood $=-3881.3777$

\begin{tabular}{r|rrrrrr}
\hline weather & Odds Ratio & Std. Err. & $\mathrm{z}$ & $\mathrm{P}>|\mathrm{z}|$ & \multicolumn{2}{c}{ [95\% Conf. Interval] } \\
\hline age & .9925748 & .0022168 & -3.34 & 0.001 & .9882394 & .9969292 \\
sex & 1.134798 & .0718551 & 2.00 & 0.046 & 1.002353 & 1.284743 \\
race2 & .9883952 & .0953733 & -0.12 & 0.904 & .8180796 & 1.194169 \\
degree2 & 1.15288 & .0377698 & 4.34 & 0.000 & 1.08118 & 1.229336 \\
ownrent2 & 1.312514 & .1188956 & 3.00 & 0.003 & 1.098998 & 1.567513 \\
rules & 1.089348 & .0467485 & 1.99 & 0.046 & 1.001471 & 1.184937 \\
warmop2 & 1.206653 & .0482253 & 4.70 & 0.000 & 1.11574 & 1.304973 \\
newcomer & .9763427 & .0685617 & -0.34 & 0.733 & .8508018 & 1.120408 \\
pov10 & 1.012301 & .0105852 & 1.17 & 0.242 & .9917659 & 1.033262 \\
metro & 1.139947 & .0992365 & 1.50 & 0.132 & .9611354 & 1.352026 \\
party2 & .7663381 & .0294893 & -6.92 & 0.000 & .710666 & .8263715 \\
logeventsum_mean & .8432122 & .1381597 & -1.04 & 0.298 & .611601 & 1.162534 \\
& & & & & & \\
c.party2\#c.logeventsum_mean & 1.144812 & .0689919 & 2.24 & 0.025 & 1.017271 & 1.288343 \\
income_median & .8736149 & .0222777 & -5.30 & 0.000 & .8310246 & .918388 \\
logdmg_mean & 1.746786 & .0864162 & 11.27 & 0.000 & 1.585366 & 1.924642 \\
& & & & & & \\
c.income_median\#c.logdmg_mean & 1.087544 & .0226245 & 4.03 & 0.000 & 1.044093 & 1.132804 \\
\hline /cut1 & .2247438 & .315957 & & & -.3945205 & .8440081 \\
/cut2 & 1.865321 & .3173347 & & & 1.243357 & 2.487286 \\
\hline
\end{tabular}


. reg weather age sex race2 degree2 ownrent2 rules warmop2 newcomer pov10 metro c.party2\#\#c.logeventsum_mean c.income_median\#\#c.logdmg_mea $>\mathrm{n}$

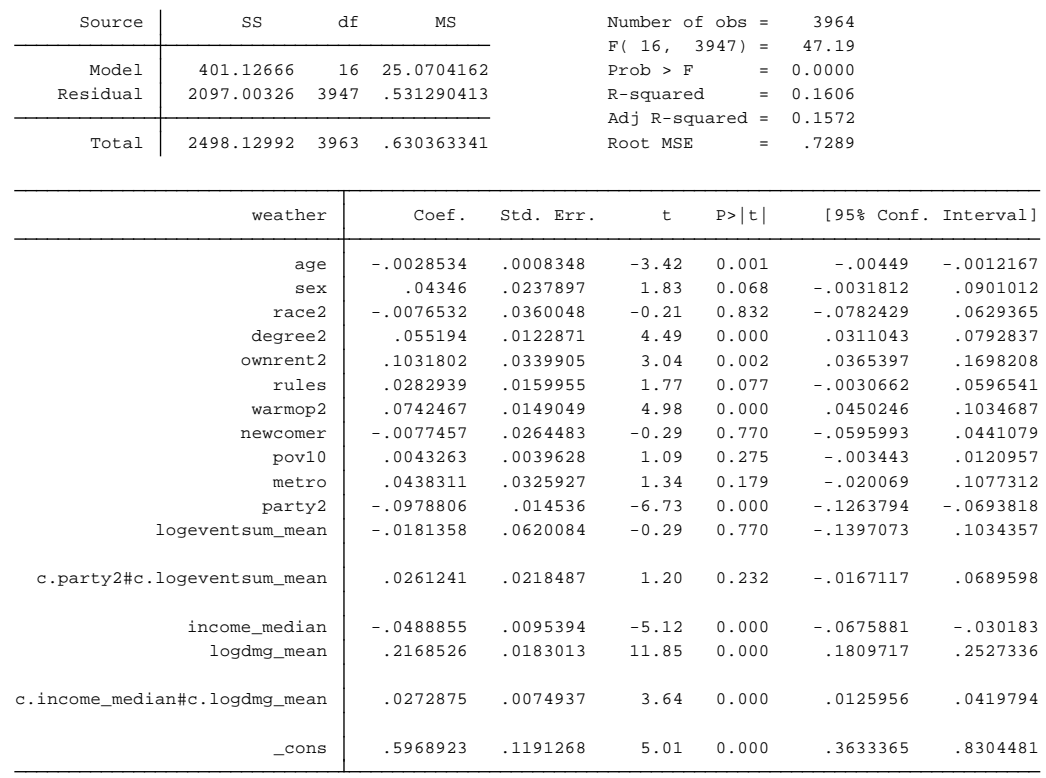


. reg weffects age sex race2 degree2 ownrent2 rules warmop2 newcomer pov10 metro c.party2\#\#c.logeventsum_mean c.income_median\#\#c.logdmg_me $>$ an

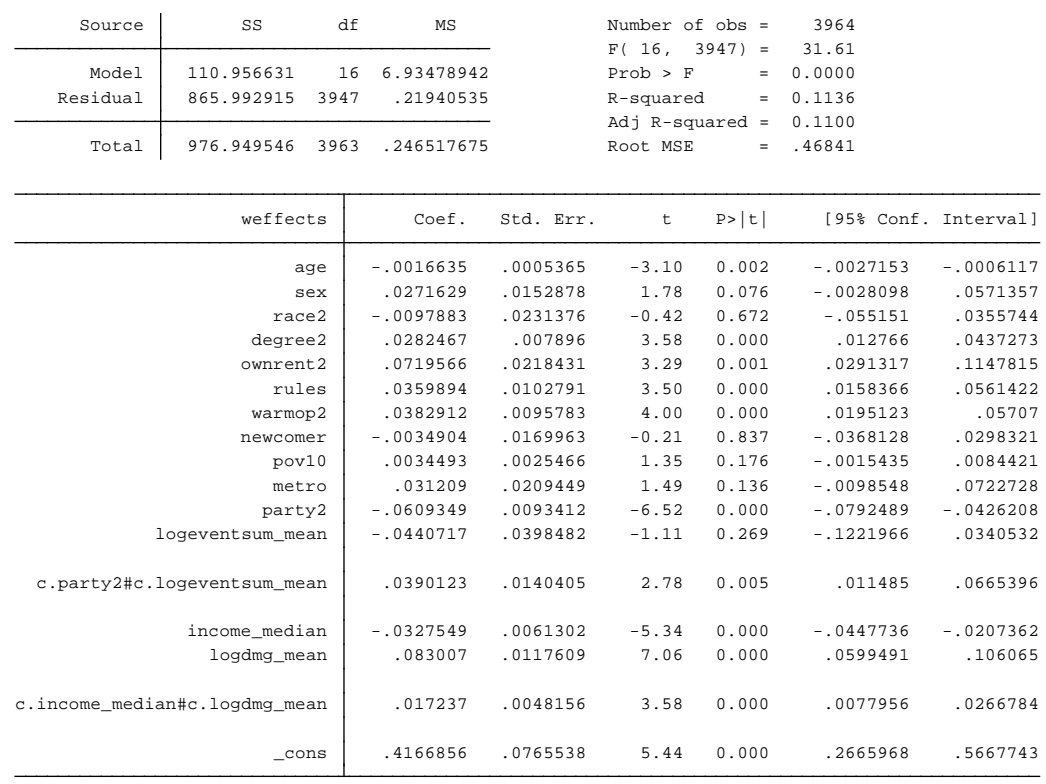


. mlogit weather age sex race2 degree2 ownrent2 rules warmop2 newcomer pov10 metro c.party2\#\#c.logeventsum_mean c.income_median\#\#c.10gdmg_ mean, rrr

Iteration $\odot: \quad \log$ likelihood $=-4225.5246$ Iteration 1: $\quad \log$ likelihood $=-3860.0876$ Iteration 2: $\quad \log$ likelihood $=-3840.291$ Iteration 3: $\log$ likelihood $=-3839.8891$ Iteration 4: $\quad \log$ likelihood $=-3839.8889$

Multinomial logistic regression

$\begin{array}{llr}\text { Number of obs } & = & 3964 \\ \text { LR chi2(32) } & = & 771.27 \\ \text { Prob > chi2 } & = & 0.0000 \\ \text { Pseudo R2 } & = & 0.0913\end{array}$

Log likelihood $=-3839.8889$

\begin{tabular}{|c|c|c|c|c|c|c|}
\hline weather & RRR & Std. Err. & $z$ & $P>|z|$ & {$[95 \%$ Conf. } & Interval] \\
\hline No_effect & \multicolumn{6}{|c|}{ (base outcome) } \\
\hline \multicolumn{7}{|l|}{ Minor_effects } \\
\hline age & .9941313 & .0027057 & -2.16 & 0.031 & .9888424 & .9994484 \\
\hline $\operatorname{sex}$ & 1.114584 & .0858776 & 1.41 & 0.159 & .95835966 & 1.296274 \\
\hline race2 & .9567123 & .1135738 & -0.37 & 0.709 & .7581115 & 1.20734 \\
\hline degree2 & 1.08492 & .0438387 & 2.02 & 0.044 & 1.002312 & 1.174336 \\
\hline ownrent2 & 1.358039 & .1488398 & 2.79 & 0.005 & 1.095523 & 1.683461 \\
\hline rules & 1.24337 & .0644671 & 4.20 & 0.000 & 1.123224 & 1.376366 \\
\hline warmop2 & 1.110897 & .0528796 & 2.21 & 0.027 & 1.011943 & 1.219528 \\
\hline newcomer & .9894923 & .08606608 & -0.12 & 0.903 & .8344098 & 1.173398 \\
\hline pov10 & 1.012762 & .0128586 & 1.00 & 0.318 & .9878703 & 1.03828 \\
\hline metro & 1.125121 & .1157457 & 1.15 & 0.252 & .9196714 & 1.376467 \\
\hline party2 & .7992079 & .0386598 & -4.63 & 0.000 & .726917 & .8786879 \\
\hline logeventsum_mean & .8056564 & .1630791 & -1.07 & 0.286 & .5418158 & 1.197976 \\
\hline c.party2\#c.logevent sum_mean & 1.203151 & .0866069 & 2.57 & 0.010 & 1.044835 & 1.385455 \\
\hline income_median & .8837587 & .0270515 & -4.04 & 0.000 & .8322978 & .9384015 \\
\hline logdmg_mean & 1.096151 & .0722822 & 1.39 & $\odot .164$ & .9632531 & 1.247383 \\
\hline c.income_median\#c.logdmg_mean & 1.07531 & .0292591 & 2.67 & 0.008 & 1.019465 & 1.134214 \\
\hline _cons & .4378691 & .16724 & -2.16 & $\odot .031$ & .2071265 & .9256627 \\
\hline \multicolumn{7}{|l|}{ Major_effects } \\
\hline age & .9899256 & .0032033 & -3.13 & 0.002 & .9836672 & .9962239 \\
\hline sex & 1.164353 & .1072343 & 1.65 & 0.098 & .9720551 & 1.394692 \\
\hline race2 & .9427282 & .1319032 & -0.42 & 0.673 & .7166208 & 1.240177 \\
\hline degree2 & 1.250222 & .0592956 & 4.71 & 0.000 & 1.139243 & 1.372012 \\
\hline ownrent2 & 1.409726 & .1864285 & 2.60 & 0.009 & 1.087847 & 1.826844 \\
\hline rules & 1.059098 & .0656921 & 0.93 & 0.355 & .9378621 & 1.196005 \\
\hline warmop2 & 1.327945 & .0785361 & 4.80 & 0.000 & 1.182604 & 1.491149 \\
\hline newcomer & .988936 & .099561 & -0.11 & 0.912 & .8118458 & 1.204655 \\
\hline pov10 & 1.040704 & .0163501 & 2.54 & 0.011 & 1.009147 & 1.073248 \\
\hline metro & 1.330148 & .1843245 & 2.06 & 0.040 & 1.013784 & 1.745239 \\
\hline party2 & .7039911 & .0391271 & -6.32 & 0.000 & .6313327 & .7850115 \\
\hline logeventsum_mean & .8495995 & .2097816 & -0.66 & $\odot .509$ & .5236451 & 1.378451 \\
\hline c.party2\#c.logevent sum_mean & 1.205025 & .117728 & 1.91 & 0.056 & .9950286 & 1.459339 \\
\hline income_median & .8156687 & .0326472 & -5.09 & 0.000 & .7541269 & .8822327 \\
\hline logdmg_mean & 2.061256 & .1381706 & 10.79 & $\odot . \odot \odot \odot$ & 1.807482 & 2.35066 \\
\hline c.income_median\#c.logdmg_mean & 1.111942 & .0328904 & 3.59 & $\odot . ๑ \odot \odot$ & 1.049311 & 1.178311 \\
\hline _cons & .1527936 & .0724879 & -3.96 & 0.000 & .0602949 & .3871949 \\
\hline
\end{tabular}




\section{APPENDIX C}

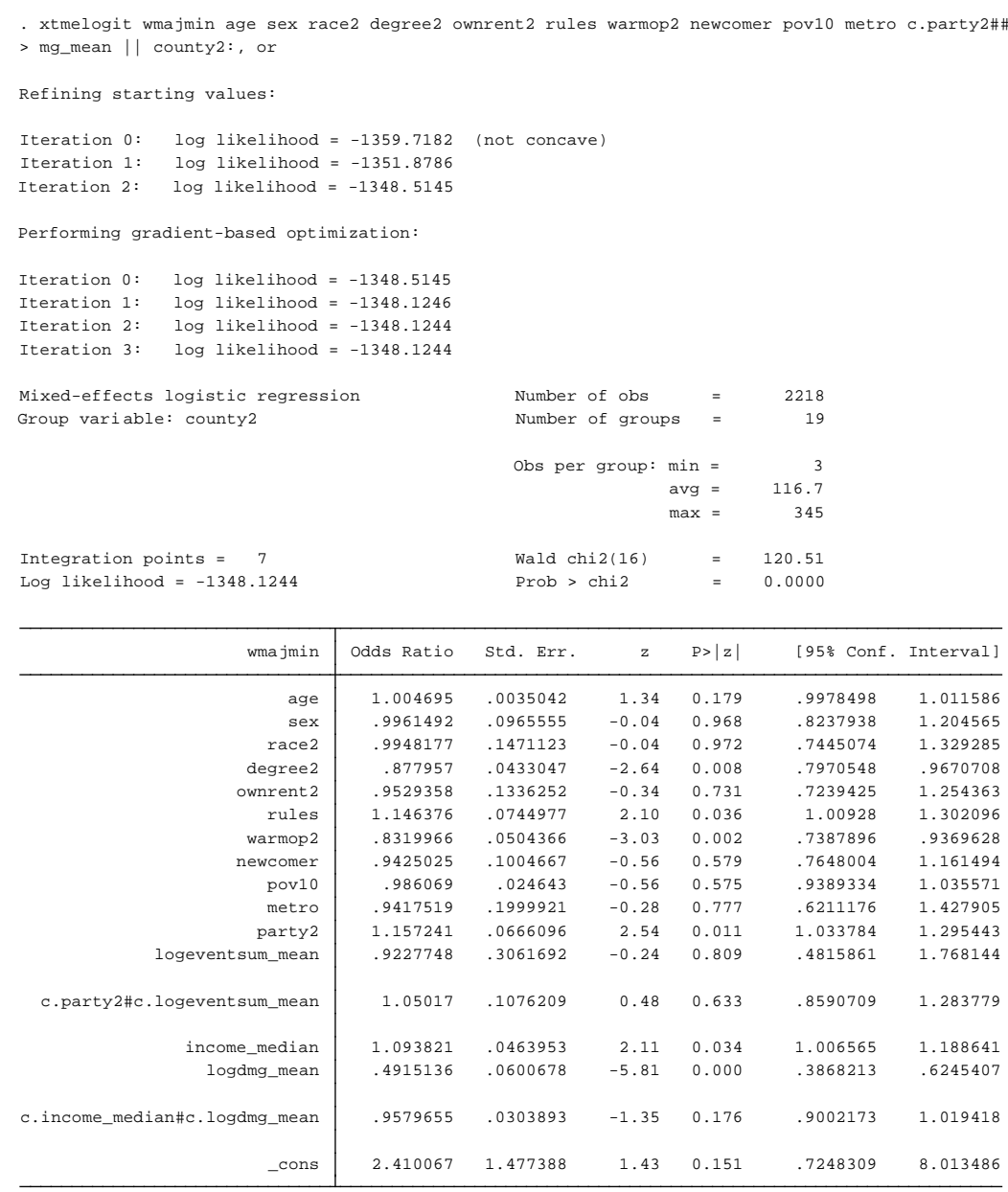

\begin{tabular}{ll|llll}
\hline \multicolumn{2}{c|}{ Random-effects Parameters } & Estimate & Std. Err. & [95\% Conf. Interval] \\
\hline county2: Identity & sd(_cons) & .2185652 & .075095 & .1114613 & .4285862 \\
\hline
\end{tabular}

LR test vs. logistic regression: $\underline{\operatorname{chibar} 2(01)=7.70 \text { Prob }>=\operatorname{chibar} 2=0.0028}$ 
